NBER WORKING PAPER SERIES

\title{
HOLIDAY, JUST ONE DAY OUT OF LIFE: BIRTH TIMING AND POST-NATAL OUTCOMES
}

\author{
Mireille Jacobson \\ Maria Kogelnik \\ Heather Royer \\ Working Paper 27326 \\ http://www.nber.org/papers/w27326 \\ NATIONAL BUREAU OF ECONOMIC RESEARCH \\ 1050 Massachusetts Avenue \\ Cambridge, MA 02138 \\ June 2020
}

We thank Catherine Miao, Molly Schwarz, and Sam Valdez for excellent research assistance, two anonymous referees, the editors, David Card, David Lee, Thomas Lemieux, as well as Rodney Andrews and participants at the Defense against the Dark Arts conference at the University of Michigan for useful comments. Maryte Gylys provided an excellent summary of the medical literature on inductions while she was a medical student at UC-Irvine. John DiNardo inspired and instigated this work by noting the depression of births around major holidays. He thought that one could use holidays to look at the effect of induction on birth outcomes. All mistakes are our own. The views expressed herein are those of the authors and do not necessarily reflect the views of the National Bureau of Economic Research.

NBER working papers are circulated for discussion and comment purposes. They have not been peer-reviewed or been subject to the review by the NBER Board of Directors that accompanies official NBER publications.

(C) 2020 by Mireille Jacobson, Maria Kogelnik, and Heather Royer. All rights reserved. Short sections of text, not to exceed two paragraphs, may be quoted without explicit permission provided that full credit, including $(\odot$ notice, is given to the source. 
Holiday, Just One Day Out of Life: Birth Timing and Post-natal Outcomes

Mireille Jacobson, Maria Kogelnik, and Heather Royer

NBER Working Paper No. 27326

June 2020

JEL No. I11,I12,J13

\begin{abstract}
$\underline{\text { ABSTRACT }}$
Fewer births occur on major US holidays than would otherwise be expected. We use California data to study the nature and health implications of this birth date manipulation. We document $18 \%$ fewer births on the day of and just after a holiday. Cesarean sections account for roughly half of the decline. Using insights from the tax bunching and test score manipulation literature, we show that "missing" holiday births are displaced to a window of time 11 days before the holiday through 16 days after the holiday. Delivery type does not change over this window, consistent with a pure retiming of births rather than an increase in the use of procedures such as cesarean sections. Despite the change in timing, we find little evidence of any adverse health consequences for babies born around a holiday. Even among high-risk pregnancies, which are more likely to be retimed, we find a minimal impact of holiday-related birth timing manipulation on infant health. Finally, while some of the retiming seems to be driven by patients' preferences, provider incentives appear to play a crucial role in holiday-related birth retiming. At Kaiser Permanente hospitals, where systemwide financial incentives discourage providers from electively timing births, the dip in births on holidays is less than for hospitals overall. This suggests that holiday retiming occurs more frequently among providers who face less of a disincentive to electively schedule births.
\end{abstract}

Mireille Jacobson

The Leonard Davis School of Gerontology University of Southern California

3715 McClintock Ave

Los Angeles, CA 90089-0191

and The Paul Merage School of Business

and also NBER

mireillj@usc.edu

Maria Kogelnik

North Hall

University of California at Santa Barbara

Santa Barbara, CA

kogelnik@umail.ucsb.edu
Heather Royer

Department of Economics

University of California, Santa Barbara

2127 North Hall

Santa Barbara, CA 93106

and NBER

royer@econ.ucsb.edu 


\section{Introduction}

The role of medical intervention in childbirth has risen over time. Cesarean section (i.e., the delivery of a baby via a surgical procedure) rates have increased steadily from $21 \%$ in 1996 to $31.9 \%$ in $2016 .{ }^{1}$ Similarly, rates of induction and stimulation of labor (two methods of precipitating a birth) have grown considerably. Labor induction rates among singleton births, for example, increased from 10\% in 1990 to over 23\% in 2012 (Osterman and Martin 2014b). With the growth of these techniques, medical professionals are able to time deliveries quite precisely. In the case of cesarean section, the birth can be timed to a particular day and hour.

The appropriate use of cesarean sections is a matter of considerable interest, with many health care stakeholders and policymakers embarking on quality improvement initiatives to reduce elective use of these procedures. These efforts stem in part from a growing body of evidence demonstrating the harms from cesarean delivery in low-risk pregnancies (e.g., see Card, Fenizia and Silver 2018). The implications of birth timing through labor induction or stimulation are less clearly understood. Likewise, the optimal timing of these interventions remains mostly unclear. The decision of whether or not and when to intervene is all the more important given the association of neonatal health with longer term outcomes such as infant mortality, education, and earnings (Almond et al. 2005; Black et al. 2007; Royer 2009; Figlio et al. 2014). Because of selection - the set of women who undergo cesarean sections, labor induction or labor stimulation is nonrandom - it is challenging to understand how these interventions affect outcomes.

We argue that holidays provide a useful quasi-experiment in this regard. Figure 1 documents the distribution of the number of births across three types of days: major holidays, weekends, and neither major holidays or weekends for two samples - the United States 1968-1988 and California 2000-2016. ${ }^{2}$ The number of births per day is approximately 2 standard deviations lower on major holidays than on non-holiday, non-weekend days. Similar to the holiday drop in births, births decline over the weekend, when fewer medical

\footnotetext{
${ }^{1}$ Source: Centers for Disease Control and Prevention: https://www.cdc.gov/nchs/fastats/delivery.htm

2 The inclusion of the entire United States in this figure is for illustrative purposes as we focus our attention on California for 2000 to 2016. Publicly available data for the United States only include exact date of birth for years prior to 1989 , starting in 1969.
} 
practitioners schedule deliveries. The drop in births as a consequence of holidays is welldocumented elsewhere (Borst and Osley 1975; MacFarlane 1978; Rindfuss et al. 1979; Mangold 1981; Cohen 1983; Hawe et al. 2001; Hong et al. 2006; Goodman, Nelson, Maciosek 2005; Bauer, Bender, Heining, Schmidt 2013; Gelman et al. 2013; Martin et al. 2018). For the most part, however, this literature does not characterize how holiday births are displaced over time or study the consequences of this displacement for delivery or birth outcomes.

To uncover the effects of holidays, we utilize data on the universe of California births between 2000 and 2016. These data, which capture almost 9 million births, allow us to detail the effects of holidays not only on birth timing, but also on delivery methods (e.g., vaginal versus cesarean section) and birth outcomes (e.g., birth weight, Apgar scores, delivery complications). Although unique, California is ethnically and racially diverse and accounts for over $12 \%$ of the US population and of annual births. ${ }^{3}$ For 2016, the use of cesarean section in California matched the national average. ${ }^{4}$

We begin by systematically documenting the depression of births around major US holidays. This requires careful consideration of the appropriate counterfactual, both because births exhibit regular seasonal and within-week patterns and because holidays impact the distribution of births in a broad region of the event. Comparing Monday holidays to births on Wednesday, when births are commonly scheduled, or on Sunday, when they are rarely scheduled, would bias our estimates. Taking into account these day-of-week effects is critical to appropriately quantifying the impact of holidays on births. Furthermore, because holidays cause births to be displaced, comparing birth counts on the holiday versus on the days just before (or just after) the holiday would likely be biased if births are systematically elevated before (or after) the holiday. Accounting for seasonal patterns is also critical because we are interested in the effects of holidays on the timing of delivery and not the timing of conception.

To determine the period over which births around a holiday appear to be retimed, we use insights from the tax bunching and test score manipulation literature (Saez 2010; Chetty et al. 2011; Kleven and Waseem 2013; Diamond and Persson 2017; Dee et al. 2018). Unlike analyses of test score or income tax manipulation, which push observations in one

\footnotetext{
${ }^{3}$ See https://www.kff.org/other/state-indicator/number-of-births/

${ }^{4}$ Source: https://www.cdc.gov/nchs/pressroom/sosmap/cesarean_births/cesareans.htm
} 
direction (e.g., above a test score threshold as in Dee et al. 2018 or before a tax deadline as in Dickert-Conlin and Chandra 1999), holidays can shift births both before and after they would otherwise occur. Thus, we identify a "manipulation window," which in our setting is the days both before and after a holiday during which some births are shifted due to the holiday. As the "missing mass" of births due to the holiday (i.e., fewer births than otherwise would be expected) must be counteracted with an "excess mass" of births (i.e., more births than otherwise would be expected), our manipulation window is the period of time around a holiday for which the sum of the missing mass and the excess mass is closest to zero.

Using this zero net mass heuristic, we identify a manipulation window that spans the period from 11 days prior to 16 days after the holiday. ${ }^{5}$ This implies that the manipulation of births around holidays occurs over 4 weeks. However, three-quarters of the manipulation is contained within $+/-1$ week of the holiday. To create a counterfactual set of births, we match births within this roughly 4-week manipulation window to the closest day just outside the window that falls on the same day of the week. For days prior to the holiday, this means we compare births on day $d$ with births on day $d-14$. For days following the holiday, each day $d$ is contrasted with day $d+21$. These nearest-day, day-of-week matched controls enable us to isolate the holiday effect from strong seasonal and within-week cyclical patterns in births. Relative to this counterfactual, we estimate that about 500 births or $18 \%$ of births on the day of the holiday and the day just after are shifted to other days within the manipulation window. About $50 \%$ of the decline across these two days is due to a reduction in cesarean sections. The remainder is roughly split between spontaneous vaginal births and vaginal births after an induction or stimulation of labor. The relative reduction in births on the holiday is larger for high-risk births, defined as births to a mom with a prior cesarean section, a breeched birth, a multiple birth pregnancy, or with an infection such as HIV. About $65 \%$ of high-risk births that would have otherwise occurred on the holiday are shifted away from the holiday.

Although the births retimed due to holidays are selected, we can use outcomes for all births in the holiday manipulation window to understand the reduced-form impact of holiday birth timing manipulation. Using logic invoked in Diamond and Persson (2017), who

\footnotetext{
5 The total number of births moved to the period before versus after the holiday is roughly equal, although the pre and post periods themselves are unequal such that displacement of a similar number of births occurs over more post than pre-holiday days.
} 
study the effect of test score manipulation on earnings, we compare birth outcomes for days in the manipulation window to counterfactual days just outside the manipulation window. Following this methodology, we find little evidence of adverse effects on outcomes in the holiday manipulation window. Our reduced-form holiday effect on birthweight, for example, is a reduction of 2 grams off of a mean of about 3300 grams. We find no other meaningful changes in a host of other outcomes, including newborn conditions, labor complications, low Apgar scores, admission to the neonatal intensive care unit (NICU) or the use of assisted ventilation. These estimates are small from a health perspective even if we inflate them by reasonable approximations of the fraction of retimed births to generate an implied IV estimate of the effect of retimed births on outcomes. Scaling by the roughly 500 births out of 40,000 that are retimed over the 28-day holiday manipulation period implies a roughly 160 gram or $4.8 \%$ reduction in birth weight due to holidays. Even among high-risk pregnancies, we find little impact of holiday-related birth timing manipulation on infant health. For high-risk births, our implied IV estimates suggest reductions in birth weight on the order of 50 grams. These findings contrast with the adverse effects found in papers on cesarean sections (e.g., Card, Fenizia and Silver 2018), although those papers contrast the starker effect of using the procedure versus not.

A key distinction of our work is that it largely compares the effects of changes in the scheduling of procedures that likely would have happened absent the holiday. We base this assertion on the fact that we find no net changes in delivery type within the manipulation window. While we cannot rule out compositional changes in the use of interventions, with, for example, some births that would have been spontaneous retimed via cesarean section and other births that would have been cesarean section delayed to the point of becoming spontaneous, the fact that we find no changes in interventions on the extensive margin suggests our results speak largely to the effect of the optimal timing of these interventions.

This paper adds to an extensive literature on the effect of holidays on the number of births. Most of this earlier work, which we discuss below, focuses on international settings or uses data from earlier years, when both cesarean sections and inductions were far less frequent. More recently, Gelman et al. (2013) and follow-on analysis at fivethirtyeight.com analyze US births and establish similar patterns of birth counts on holidays as we do in this 
paper. ${ }^{6}$ Martin et al. (2018), in an analysis of UK births, probe deeper into understanding the holiday effect by examining changes in delivery type on holidays. ${ }^{7}$ Like Gelman et al. (2013), Martin et al. (2018) show neither how holiday births are displaced over time, nor what the consequences of this displacement are for delivery or birth outcomes. ${ }^{8}$ Our work fills these gaps by exploring the dynamics of retimed births, i.e., how births are temporally displaced around holidays; the manner of the retiming, i.e., how delivery types change on holidays and across the period of displacement; and the health consequences of these changes.

More broadly, this paper provides insights on how the timing of delivery through medical interventions impacts infant health. Based on scheduling manipulations due to holidays, the re-timing of interventions within plus or minus two weeks has only very small (and likely medically and economically insignificant) effects on infant health outcomes. This finding is noteworthy given that ACOG's consensus recommendations concerning birth generally fall within a few weeks of a due date, depending on the precise condition of the baby or mom (see Spong et al. 2011). In addition to informing general obstetric practices, these results are also instructive for hospitals setting policies about delivery timing and staffing around the holidays.

This paper also adds to the economics literature on the relationship between financial incentives to time deliveries and post-natal health outcomes. Schulkind and Shapiro (2014) find that the annual dependent tax deduction allowance shifts deliveries from January to December, lowering birth weight and Apgar scores. Borra et al. $(2016 ; 2018)$ find that the revocation of a baby bonus in Spain led to reductions in birth weight and increases in hospitalization rates. Our paper is distinct from these two in that our main estimates, which exclude January $1^{\text {st }}$ as a holiday of interest, represent responses to holidays independent of financial incentives. In contrast to tax incentives or baby bonuses, which require specific knowledge to take advantage of them, major holidays likely affect the timing decisions of a larger population. Perhaps most importantly, while the response to these financial incentives

6 Source: https:// fivethirtyeight.com/features/some-people-are-too-superstitious-to-have-a-baby-on-fridaythe-13th/

${ }^{7}$ As Martin et al. (2018) analyze data from England and Wales, where planned cesarean sections account for only $11 \%$ of all births, their work may have more limited insights in the US context.

${ }^{8}$ Previous studies document higher rates of perinatal and/or neonatal mortality on holidays (Macfarlane 1978; Stephansson et al. 2003; Hong et al. 2006). These effects, which do not consider the outcomes of the displaced births, may be due to the selection of births on holidays and/or the experience and level of hospital staffing on holidays. Similar increases in mortality rates have been found on weekends relative to weekdays (Gould et al. 2003; Hendry 1981; Mathers 1983; Hamilton and Restrepo 2006; Pasupathy et al. 2010; Restrepo et al. 2018). 
necessarily means moving a birth earlier, holiday-related retiming provides more flexibility. Births can, in principle, be shifted both before and after the holiday. This greater flexibility in retiming may account for some of the differences in outcomes between our own paper and that of papers studying deadline-based tax incentives and baby bonuses.

Finally, our results are informative for regression discontinuity research designs based on birth dates. Since holidays impact births by as much as 2 weeks away, many birth date-based regression discontinuity designs risk comparing outcomes for births that are affected by holiday-related retiming. Moreover, the typical donut regression discontinuity approach (Barreca, Lindo, and Waddell 2016) to address potential selection near a discontinuity threshold would require a wide period removed from the analysis (i.e., the 28day window). With the exclusion of those dates, the regression discontinuity may be less appealing because the groups on either side may be inherently less comparable. Our work implies that research using a birth-date based regression discontinuity approach should consider, the proximity of the date to any major holiday and remove the data roughly 2 weeks on either side of the holiday, at least as a robustness check.

In the remainder of the paper, we first describe a conceptual model for understanding how holidays may affect birth timing in Section II. We present our empirical approach in Section III and our results in Section IV. We present a set of robustness checks and sensitivity analyses in Section V. In Section VI we discuss analyses focused on interpretation and mechanisms and in Section VII we conclude.

\section{Conceptual Framework: How Holidays affect Birth Timing and Outcomes}

Why might holidays affect the use of medical interventions to time births? The reasons are multifold and include preferences for leisure at the time of the holiday among both patients and health care providers, financial incentives, as well as cultural beliefs.

For many holidays (e.g. $4^{\text {th }}$ of July, Thanksgiving), medical providers and parents may have a strong disutility for a birth during that period. As holidays are often associated with social and family gatherings, working on that day or giving birth on that day may generate large utility costs. Consequently, hospitals often compensate their staff via extra pay or extra time off if they are working on a holiday, and thus have some incentives to reduce their staff on holidays and reschedule procedures that might otherwise have been scheduled for a 
holiday.

In the case of New Year's, parents expecting a new child around January $1^{\text {st }}$ face incentives to expedite the birth of their child to qualify for a tax exemption in the current year. In the US, the timing of births around January $1^{\text {st }}$ is sensitive to the annual child tax benefit, as these benefits are not prorated (Lalumia, Sallee and Turner 2015; Schulkind and Shapiro 2014; Dickert-Conlin and Chandra 1999). ${ }^{9}$ To disentangle the effect of holidays from financial incentives, we focus specifically on holidays that are likely to coincide with time off and social gatherings, but not with financial incentives. For this reason, we exclude New Year's from our main analysis.

Furthermore, being born on a certain day may be associated with good or bad luck. In countries and among ethnic groups that follow the lunar calendar, for example, births are more common on auspicious days and less common on inauspicious days (Lo 2003; Lin, Xirasagar, Tung 2006; Almond et al. 2015). Likewise, in the US, births are more common on Valentine's Day and less common on Halloween (Levy, Chung and Slade 2011). In addition, some parents might prefer that their child's birthday does not coincide with a fixed day holiday, such as Christmas or July $4^{\text {th }}$. Similar to inauspicious dates, some dates, such as September 11 after 2001 and Friday the $13^{\text {th }}$ have "negative" connotations. Because such days are unlikely to enter medical providers' utility function, we use these dates later to isolate demand-side influencers (separate from supply-side shifters) in birth timing.

Irrespective of the motivation, providers can intervene to time a birth through the use of a cesarean section, induction, or stimulation of labor. A cesarean section is the surgical delivery of a child through the mother's abdomen. It can be used to time a birth quite precisely, down to the exact day. Induction and stimulation of labor are less invasive but allow for a less precise timing of births. Induction of labor refers to techniques to stimulate uterine contractions prior to the onset of spontaneous labor (Grobman et al. 2018). Similarly, stimulation of labor, also known as augmentation of labor, refers to techniques that help labor progress after the onset of spontaneous labor. The process of inducing or stimulating labor is usually achieved through administering drugs such as oxytocin. Other methods of precipitating labor include membrane stripping to detach the

\footnotetext{
${ }^{9}$ Two other well-documented policies provide incentives for birth timing manipulation: baby bonuses (Gans and Leigh 2009; Brunner and Kuhn 2014; Borra, Gonzalez and Sevilla 2018)) and family leave (Neugart and Ohlsson 2013; Tamm 2013; Jürges 2017).
} 
fetal membranes from the cervix, nipple stimulation, and acupuncture (Bouvlain, Stan, and Iron 2005; Kavanagh, Kelly, and Thomas 2005; Smith and Crowther 2013; Modlock, Nielsen, and Uldbjerg 2010). Clinical guidelines often use the terms induction and stimulation interchangeably. Inductions enable the timing of a birth within a 1 to 3 -day window. ${ }^{10}$ The decision to use these procedures is not costless and involves important tradeoffs. Indications for a planned or scheduled cesarean section, as distinguished from an emergency cesarean section, include mechanical obstructions like placenta previa, meaning the placenta covers the cervix; breech position, meaning the fetus is not in the head down position; multiple births, such as twins or triplets and maternal infections, such as HIV, which face increased transmission risk during active labor (Berghella et al. 2018). ${ }^{11}$ Since the late 1980s, one of the most important reasons to plan a cesarean section is a prior delivery via cesarean section (Oster 2018). Many hospitals prohibit vaginal births after a previous cesarean section (VBAC births) to reduce the risks of a uterine rupture. In $2017,87 \%$ of pregnant women in the US who had a previous cesarean section subsequently delivered via cesarean section. ${ }^{12}$

The optimal use and timing of cesarean sections is a source of considerable debate. Non-labor deliveries lead to changes in stress operation, immune response, and altered epigenetic functioning based on experiments in non-human species (Black et al. 2015). Individuals born via cesarean section have higher rates of infant hospitalization, obesity, and type 1 diabetes (Black et al. 2015). While this medical literature is correlational, Card, Fenizia and Silver (2018) show - using differential distance to high or low cesarean section rate hospitals - that even low-risk pregnancies face higher risks, particularly acute respiratory conditions, when delivered by cesarean section. Consequently, planned cesarean sections are largely timed weighing the underlying health risks precipitating a cesarean section against worries about insufficient respiratory development. The American College of Obstetricians and Gynecologists (ACOG) recommends that most cesarean sections take place at 39 weeks

\footnotetext{
10 Analysis of nearly 11,000 women undergoing labor induction finds that over 65\% reach active labor, or 5-cm dilation, within 6 hours of induction and over 96\% within 15 hours (Grobman et al. 2018). Median time to delivery after the active phase is 4 hours and the $95^{\text {th }}$ percentile is 13 hours for nulliparous women with epidural analgesia; time to delivery decreases slightly with parity and without epidural analgesia (Zhang et al. 2010b).

${ }^{11}$ Unscheduled or emergency cesarean sections are typically performed when clinicians perceive imminent risk such as fetal distress, a lack of blood and oxygen flow through the umbilical cord, placenta abruption (the disconnecting of the placenta from the uterine wall), stalled labor, or a baby being too large for the birth canal.

12 Source is authors' calculation of the 2017 Detailed Natality Files.
} 
or later, as earlier cesarean sections are associated with adverse respiratory and neonatal outcomes (Tita et al. 2009). ${ }^{13}$ Typical indications for labor induction and stimulation include a post-term pregnancy and premature labor rupture of membranes ("water breaking") along with several of the precursors to cesarean sections, including hypertension, preeclampsia, and maternal diabetes (Grobman et al. 2018). Clinicians generally consider induction/stimulation medically indicated when the risks of continued pregnancy outweigh the maternal and fetal risks of delivery earlier than may have occurred spontaneously. Unless the fetus or mother is at risk, ACOG does not recommend inducing a birth before 39 weeks of gestation. ${ }^{14}$ For late-term pregnancies (pregnancies in the $41^{\text {st }}$ week), induction is to be considered and in the post-term pregnancies (pregnancies in the $42^{\text {nd }}$ week or later), induction is recommended. ${ }^{15}$ The risks associated with induction are minimal, particularly in comparison to those associated with cesarean sections. A recent randomized-controlled evaluation of labor induction among low-risk first-time mothers documents reduced rates of cesarean sections without adverse perinatal outcomes (Grobman et al. 2018). ACOG, however, continues to list infection, uterine rupture, increased risk of cesarean section, and fetal death as potential risks of induction. ${ }^{16}$

An intervention to alter a birth's timing in response to a holiday can have one of two effects on the delivery process: 1) the delivery method is altered, which will most likely also alter the delivery timing, or 2) the delivery timing alone is altered. In the first scenario, a birth may have been intended to be spontaneous in absence of the holiday, but then is delivered via cesarean section, induction or stimulation as a result of the holiday. In the second scenario, a birth may have been planned to happen via cesarean section, induction, or stimulation even in the absence of the holiday, but the timing of that procedure may be

\footnotetext{
13 A classic obstetrics textbook (Edmonds, 2008) recommends planning the delivery of twins at 37 to 38 weeks. Even with multiple acute risks present, consensus recommendations typically suggest cesarean section scheduling after 36 weeks of gestation, although recommendations vary by condition (see Sprong et al. 2011). ACOG guidelines have become more cautious about early planned cesarean sections over time.

${ }^{14}$ Source: https://www.acog.org/Patients/FAQs/Induction-of-Labor-at-39-Weeks?

15 Several observational studies suggest that cesarean section rates are higher among induced births (Bailit et al. 2015; Luthy et al. 2004). The experimental literature finds otherwise. Hannah et al. (1992) find no differences in outcomes, with the exception of lower cesarean section delivery rates in women with uncomplicated pregnancies at 41 weeks or more duration randomized to induction of labor versus watchful waiting (or "expectation management"). Nielsen et al. (2005) found no differences in cesarean section rates among women between 39 and 42 weeks of gestation and favorable pre-labor cervix (or "Bishop scores") randomized to induction versus expectant management. Meta-analyses come to similar conclusions (Saccone et al. 2015; Walker et al. 2015)

16 Source: https://www.acog.org/Patients/FAQs/Labor-Induction
} 
altered as a result of it. We refer to holiday-related changes in delivery type as extensive margin changes and changes in the timing of a delivery type as intensive margin changes.

While our data do not allow us to fully separate these two scenarios, as described later, we can estimate the overall effect of holidays on the prevalence of the different delivery types. This information allows us to answer the question of whether a holiday increases the overall incidence of cesarean sections. A priori, we would expect the second scenario would be more common as it does not conflict with ACOG guidelines discouraging the use of cesarean sections for uncomplicated pregnancies and implies only a rescheduling of procedures among people already intending to use them.

Given the decision to time a birth to avoid a holiday, when are such births likely to be (re)scheduled? Consider a birth with a due date near a holiday. To avoid the holiday, providers can decide to schedule the birth before or after the holiday. Having a birth early increases the health risks to newborns and moms. But scheduling the birth after the holiday, particularly among pregnancies that are nearly full term, raises the risk that a woman goes into spontaneous labor, a process that for some complications (e.g., breech birth, eclampsia), providers want to avoid. Moreover, for births past the due date, risks of delaying birth include high birth weight (a precursor for diabetes) and perinatal mortality (Galal et al. 2012). For births very near term, the probability of imminent birth is high. Among spontaneous vaginal births in the United States in 2017, only $8 \%$ of births occurred before 38 weeks of gestation and $68 \%$ of births were between 38 and 40 weeks of gestation inclusive; $24 \%$ of births occur after 40 weeks. ${ }^{17}$ For births far from term, the risk of labor naturally starting is lower, although high-risk births may have higher probabilities of early delivery. In sum, it is ex-ante plausible that births may be shifted to occur before or after a holiday. As discussed above, both providers and patients can impact the decision to retime a birth. Below, we perform several analyses to test the importance of the supply (i.e., clinician-driven) versus demand (i.e., patient-driven) channels. First, we separately examine births around September $11^{\text {th }}$ (after 2001) and Friday the $13^{\text {th }}$, as these days arguably affect the demand to (re)schedule, while leaving the supply side of medical professionals unaffected. Second, we separately consider the impact of holidays on the pattern of births at Kaiser Foundation Hospitals, a closed HMO system that has a disincentive to schedule elective delivery. Both analyses,

${ }_{17}$ Based on authors' calculation using the 2017 Detailed Natality Files. 
which we discuss in more detail below, suggest that while patients' preferences matter, providers play a considerable role in birth timing.

Ultimately, our interest is in not just the impact of holidays on birth timing, but the consequences, if any, of this behavior on maternal and infant health. Most directly, holidays may impact maternal and infant health through the timing of delivery and choice of delivery method, but also through several other ways: First, holidays may affect birth outcomes through the supply of medical professionals. Staffing may be reduced on holidays. Second, holidays may affect the quality of staffing. If working on a holiday is undesirable, less experienced workers with lower seniority may be requested to work on a holiday. Junior staff may also get a higher marginal utility from enhanced holiday pay (e.g., time and a half), and may therefore self-select to work holiday shifts. Finally, holidays may have indirect or external effects on birth outcomes if the rescheduling of some births causes congestion in hospitals on days proximate to holidays. That is, holiday-related retiming of some births may impact the capacity of hospitals to attend to the needs of other deliveries. Although to the extent these are predictable changes, holidays likely adjust their staffing accordingly.

\section{Empirical Approach}

Data

Our primary data source is the restricted-access 2000-2016 California Birth Statistical Master Files. These data cover the universe of California births during this period and come from birth certificate information that the parents and medical provider fill out at the time of birth. These data include demographic information (e.g., age, education) for the parents, health conditions/outcomes of the mother and infant (e.g., gestational diabetes, birth weight, gestational length), and the use of medical interventions (e.g., cesarean section, induction, and stimulation). Crucial to our approach, these data include the exact date of birth of the infant. With such information, we can document precisely the displacement of births across the holiday period.

Table 1 provides some basic descriptive statistics on the interaction of holidays with births and delivery methods. Births average 1442 per day, but are systematically lower on holidays and weekends (with a mean of about 1100 births per day) than on other days. The data on delivery mode make clear that this is a result of scheduling. The number of cesarean 
section deliveries is nearly $50 \%$ lower on holidays and weekends than on other days. Induced/stimulated births are about $28 \%$ lower. Spontaneous vaginal births are also lower on holidays (by about 15\%), although they account for a much higher share of births on holidays $(52 \%)$ than on other non-weekend days (44\%).

\section{Selection of Holidays}

Not all holidays are likely to impact the timing of births. Moreover, it is not a priori obvious which holidays should matter most for patients or providers. As a uniform selection rule aimed at isolating holidays that patients or medical providers may want to avoid because of the joint utility of leisure (i.e., I enjoy the holiday because my friends and families also have that day off), we first consider federal holidays for which salaried workers typically get paid time off. This set contains New Year's Day, Presidents' Day, Memorial Day, Independence Day, Labor Day, Thanksgiving, and Christmas. We exclude Martin Luther King Day and Veterans Day from the analysis because many private sector workers do not get paid time off on these days. We further exclude Christmas and New Year's Day in our main analysis for two reasons: First, they coincide with changes in tax incentives to time births. Our interest is in holiday-related birth timing, not in holiday + incentive-related timing. Second, the pattern of birth timing manipulation around these holidays looks quite different from that of other holidays, spanning a much wider interval. This unusual pattern is likely due to the fact that many individuals take time off during the week between Christmas and New Year's. We provide supplementary estimates that include Christmas and New Year's as holidays to show that our qualitative findings are not materially affected by their exclusion.

\section{Determining the Holiday Manipulation Window}

To determine the effect of a holiday, we first need to establish which days around a holiday are impacted by it, what we refer to as the "manipulation window." To do this, we borrow the insight from the public finance bunching and test score manipulation literatures (e.g., Kleven 2016; Diamond and Persson 2017; Dee et al. 2018) that within a manipulation region, the missing mass - in our case, the drop in births around the holiday - must equal the excess mass - in our case, the rise in births away from the holiday. To identify our manipulation region, we perform a grid search around all holidays collectively to determine 
the region over which the net change in births including the holidays themselves is closest to zero. Specifically, we calculate the net change in births (i.e., the excess mass minus the missing mass) for a combination of start and end dates for the manipulation region. We begin with a 3-day minimum period on each side of the holiday working towards a 21-day maximum period on each side of the holiday. In practice, excess mass is defined as occurring when (births - expected births) $>0$. Similarly, missing mass is defined as (births - expected births $<0$. Ex ante, there are 19*19=361 possible manipulation periods.

Calculation of the "optimal" window necessitates an appropriate counterfactual. That is, it is necessary to know how many births would have happened on each day around a holiday in absence of the holiday. We use births in the weeks in close proximity of the holiday but outside of the manipulation region as a counterfactual. ${ }^{18}$ The construction of this counterfactual involves matching each date in the manipulation window with a day outside of the manipulation window that falls on the same day of the week. We match on day of the week because it is an important predictor of the number of births, as seen in Figure 1. Days preceding a holiday (inclusive of the holiday) are matched with days that precede the manipulation window and days following a holiday are matched with days that follow the manipulation window. For each day in the manipulation window, it has a paired day for each day outside of the window.

Panel A of Figure 2 provides a hypothetical example for ease of illustration of this approach. In this figure, the manipulation region is -3 to 3 , i.e., holidays lead to a displacement of births 3 days before and up through 3 days after the holiday. To create our counterfactual, each day in the manipulation window is matched to the closest day outside that window that occurs on the same day of the week. In this hypothetical example, the day before the holiday (-1) is a Wednesday and is thus matched with the previous Wednesday in

\footnotetext{
18 This counterfactual selection is a departure from the bunching literature, which estimates the counterfactual distribution via the inclusion of high order polynomials in the "running" variable (i.e., the variable determining treatment, which is date of birth in our setting). For example, the literature on income manipulation due to taxes specifies a polynomial function in pre-tax income to predict what the distribution of pre-tax income would look like in the absence of tax incentives. We argue that our departure is reasonable because the counterfactual distribution is easier to estimate in our case for two reasons. Births in the weeks surrounding the holiday window are births that are quasi-uniformly distributed. In contrast, the income distribution exhibits considerable curvature, so higher order polynomials are needed to properly characterize the counterfactual distribution. Second, while discrete changes in marginal tax rates may cause some individuals to not report income, resulting in a non-equivalence of the missing and excess masses, holiday-related birth retiming is ultimately constrained by biology and medicine. For completeness, in results not reported, we have followed the previous bunching literature's approach without substantive changes in our conclusions.
} 
the counterfactual region (-8). The date of the holiday is matched with a day 7 days before the holiday. The day 2 days after the holiday is matched with a day 9 days after the holiday, and so on. Note that when the manipulation region spans a partial week, our estimation procedure excludes some dates near the holiday. For example, in the -3 to 3 manipulation region example, we do not include dates $[4,7]$ and $[-4,-6]$ in our estimation of the holiday effect. We do this at a cost of having counterfactual dates further from the holiday (e.g., 0 is matched to -7 rather than -4$)$, but at the benefit of making comparisons across the same day of the week.

In the end, our empirical procedure amounts to estimating regressions of this form:

$$
\text { (1) } Y_{i t}=\alpha_{0}+\sum_{j=1}^{l} \beta_{j} 1\left(\text { holiday }_{i}\right) * D_{i j}+\sum_{j=1}^{l} \gamma_{j} D_{i j}+\eta_{j t}+\sum_{k=1}^{6} \delta_{k} D O W_{i}+\epsilon_{i t}
$$

$Y_{i t}$ is the count of the number of births on calendar day $i$ and year $t$ (e.g., September $3^{\text {rd }}$, 2000). $l$ denotes the total number of days in the manipulation window. $D_{i j}$ are indicator variables for each of the matched pairs (i.e., I matched pairs). For the example laid out in Panel A of Figure 2, $l$ would equal 7 as there are 7 days in the manipulation region. $1\left(\right.$ holiday $\left._{i}\right) * D_{i j}$ is the interaction between the pair dummies and an indicator for whether a specific day is contained within holiday interval (e.g., in our hypothetical example, 1 (holiday ${ }_{i}$ ) equals 1 for days -3 to +3 , and 0 otherwise). $\eta_{j t}$ are holiday-by-year fixed effects (e.g., Labor Day Period 2005) and $D O W_{i}$ are day-of-the week dummies. The $\beta_{j}$ s are the parameters of interest. They are interpreted as the excess births (if positive) or missing births (if negative) occurring on that day as a result of the holiday.

The possibility of overlap in the manipulation windows across holidays further complicates this regression. For example, in regressions that include Christmas and New Year's as holidays, the post-Christmas period will coincide with the pre-New Year's period. We address this by allowing each date to contribute to the estimate of multiple $\beta_{j}$ s. Additionally, we control for other holidays that do not fall into our "paid time off"-heuristic but that may also affect birth timing, specifically Halloween and Valentine's Day. We refer to these as "nuisance holidays" and control for these in all specifications. To control for these nuisance holidays, we include a separate set of dummy variables, separately for each holiday, that span the full optimal window. 
Appendix Figure 1 shows the excess mass minus the missing mass for each combination of start and end dates in our grid search. Our chosen manipulation window is such that the absolute value of this difference is closest to 0 . Across all combinations of start dates 3 to 21 days before the holiday and end dates 3 to 21 days after the holiday, the net birth mass is lowest at -11 to +16 days around the holiday. Specifically, the algorithm yields an "optimal" window where the excess mass - missing mass (i.e., the sum of the estimated $\beta_{j}$ s from (1) throughout the manipulation region) is equal to 2.2 births. Given over 40,000 births in a typical 28-day period, 2.2 births is small and meaningfully close to 0 .

In contrast to Panel A of Figure 2, which shows a hypothetical manipulation window that is symmetric or balanced around the holiday, our optimal manipulation window is unbalanced. To control for day of the week properly in this unbalanced window, we do not constrain the control period to be the same distance from the holiday on either side of the holiday. As shown in Panel B of Figure 2, with our manipulation window of $[-11,+16]$, we compare days before the holiday to days between 3.5 weeks and 2 weeks before the holiday; days after the holiday are compared to days just over three weeks later. As the optimal window is relatively wide, the counterfactual dates are as far as 37 days away from the holiday.

To address potential comparability concerns, we perform supplementary analyses that (i) widen or narrow the manipulation region (shown below), (ii) consider the windows with the second-smallest sum of the excess and missing mass (shown below), and (iii) use higher order polynomial functions in date of birth (available upon request). All of these analyses generate similar qualitative conclusions.

\section{Analysis of the Holiday Effect}

With our chosen manipulation window and control days, we now fix $l$ to 28 , the total number of days manipulated, in equation (1) and estimate:

$$
\text { (2) } Y_{i t}=\alpha_{0}+\sum_{j=1}^{28} \beta_{j} 1\left(\text { holiday }_{i}\right) * D_{i j}+\sum_{j=1}^{28} \gamma_{j} D_{i j}+\eta_{j t}+\sum_{k=1}^{6} \delta_{k} D O W_{i}+\epsilon_{i t} \text {. }
$$

Our main set of analyses documenting the displacement of births across the holiday period provides estimates of the $\beta_{j}$ s (i.e., how births in the holiday period compare to those outside the holiday period). 
In addition to births overall, we analyze the number of births by delivery mode cesarean section, induced/stimulated vaginal birth, spontaneous vaginal birth - to understand how the birth timing manipulation occurs. This is done via estimating regressions of the form of equation (2) but replacing the dependent variable $Y_{i t}$ with counts of the number of births delivered by one of those modes (e.g., cesarean section). We also perform the same type of analysis but with counts of births by term length category (e.g., pre-term vs. full term) and separately consider average gestational age by day to characterize the relationship between holiday birth timing manipulation and gestational length.

Using the same analytic sample and basic specification, we also consider the nature of the selection across the holiday period by analyzing the count of births by age, race and education of moms as well as delivery payment sources. Finally, we consider outcomes such as birth weight and the share of births with low birthweight or low Apgar scores. Again, this is done considering each of these outcomes as separate dependent variables.

Regression equations (1) and (2) describe the nature of the displacement of births due to the holiday by day. To understand the overall impact of the holiday on outcomes, we run a more aggregated regression that considers the average effect across the manipulation window rather than the day-by-day effects. Specifically, we contrast births in the manipulation window with the counterfactual births outside the manipulation window to derive a reduced-form effect of the holiday. This approach is robust to selection within the manipulation period (e.g., births on holidays are selected such that comparisons of the outcomes of births within the window would lead to biased estimates of the effect of holidays) but assumes no selection into the optimal holiday manipulation window from the counterfactual window. We can partially test the no-selection-assumption by comparing the observable background characteristics of mothers within the manipulation window to those from counterfactual days. Diamond and Persson (2017) in their study of the long-run effects of test score manipulation adopt a similar logic by comparing outcomes of students in the manipulated region with the outcomes of students just outside of the manipulated region.

To estimate the total reduced-form impact of holidays, we adopt an estimating equation analogous to equations (1) and (2) but aggregate the per-day holiday effect into one holiday effect. That is, we estimate the following equation: 
(3) $Y_{i t}=\alpha_{0}+\beta_{1}$ (holidayinterval $\left._{i t}\right)+\sum_{j=1}^{28} \gamma_{j} D_{i j}+\eta_{j t}+\sum_{k=1}^{6} \delta_{k} D O W_{i}+\epsilon_{i t}$

where $Y_{i t}$ is a dependent variable of interest for a calendar date $\mathrm{i}$ in a particular year $t$ (e.g., number of births, number of cesarean section births, mean gestation, mean birth weight). The key variable of interest is 1 (holidayinterval $i t$ ), an indicator for the 28-day period around a holiday (i.e., a birth occurring between -11 and 16 days around a holiday). The coefficient on this indicator, $\beta_{1}$, captures the reduced form effect of birth timing manipulation on mean daily outcomes over the holiday period.

Holidays will not impact all births in the manipulation window. Thus, to get a sense of the effect of a birth timing manipulation, we want to scale our reduced-form effects by the fraction of births in the manipulation window whose timing is manipulated. To do this, we divide the estimates from (3) by an estimate of the fraction of births in the manipulation region that are retimed due to the holiday. We provide such implied IV estimates mainly as a benchmark to gauge the size of our effects, as it is challenging to credibly identify the exact fraction of manipulated births. These implied IV estimates are intended to capture the size of the effect of a birth being manipulated as opposed to the reduced-form effects, which capture the effect of a birth being in the holiday manipulation window.

One reasonable estimate of the fraction manipulated is the ratio of the dip in births very proximate to the holiday (the day of the holiday + the day after) to the number of total births occurring in the manipulation window. This scaling factor implicitly assumes that the manipulation is local to the holiday and that it is the manipulated births alone that are impacted by the rescheduling. If, for example, a holiday shifts a birth from 1 day before the holiday to occurring 2 days after, such a manipulation would not be captured in our calculation of the manipulated fraction. Holiday-related rescheduling could, in principle, have a domino effect, whereby other scheduled births around the holiday are shifted due to resource constraints. Such reshuffling of scheduled births would also not be captured by our measure of manipulated births. As we will discuss later in more detail, this possibility would imply that the fraction of manipulated births by which we inflate our estimates is a lower bound of the effect of a birth manipulation. Thus, any scaled up estimates of the effect of birth timing manipulation on the outcomes studied here are upper bounds. 
As discussed above, holiday-related shifting may also impose externalities on births that are not retimed due to the holidays. For example, a disproportionate shifting of births to the few days before or a few days after the holiday could cause congestion at some hospitals. To the extent that any such externality affects measured outcomes for births that are not directly manipulated, this would be captured in our aggregate outcome analysis.

Across all outcomes, we estimate equations (1), (2), and (3) using linear regression models. Because we analyze counts of births and deliveries by type, however, we also perform sensitivity checks using Poisson regression models for these outcomes. Qualitatively, our results are insensitive to model choice.

\section{Results}

Our results follow in several steps. First, we document the effect of the holidays on the timing of births using the exact date of birth from the California birth files. Second, we examine how those patterns vary by delivery type. Third, we study how the manipulation affects gestational length, which is directly impacted by birth timing manipulation. Fourth, we characterize the type of births affected by holiday timing. Fifth, we analyze the effects on birth outcomes. Finally, given that negative birth outcomes are relatively rare, we repeat the analysis for the sample of "high-risk" births (defined below). This sample has both a high probability of being scheduled and, independent of scheduling, of experiencing adverse outcomes.

\section{Change in Births Around Holidays}

Figure 3 plots the estimated $\beta_{j} s$ from equation (2) or the change in daily births across the holiday period, the 11 days before to 16 days after the holiday as determined by our "optimal" window, relative to the counterfactual days either before or after the holiday period. Time zero is the holiday. As expected, the number of births is lower on the holiday itself than would otherwise be expected. The same is true of the day after the holiday, i.e., $t=+1$. We estimate a combined decline of roughly 512 births on the day of and just after a holiday. Given a mean of 1447 births per day in the analytic sample, this represents an almost $18 \%$ reduction in births over the 2 -day period than would be otherwise expected.

Figure 3 makes evident that the holiday period is marked by a hollowing out of the 
birth distribution across days. The missing mass from the holiday and the day after are pushed both earlier and later than would have occurred in absence of the holiday. Although the shift in births is largest within the first week before and after the holiday, there are sizeable relative increases in births even as much as 14 days away. That is, holidays lead to a shift of births within an interval of roughly 2 weeks before and 2 weeks after the holiday.

The general pattern of displacement, i.e., the hollowing out of the birth distribution around a holiday, is quite similar when we include Christmas and New Year's in the analysis (see Appendix Figure 2). One modest difference is that births decline the day before as well as the day after the holiday relative to counterfactual days. This is mostly driven by a reduction in births on Christmas Eve. The drop in births is also slightly larger when Christmas and New Year's are included, consistent with heterogeneous effects of different holidays. Appendix Figure 3 shows, for each holiday separately, the average number of births on that holiday minus the average number of births on all days in the sample. The holiday drop in births is largest for Christmas Day, followed by New Year's and Memorial Day.

Figure 4 documents the holiday effect for California births for 4 different time periods. ${ }^{19}$ As the mean number of births varies considerably over time, we present Poisson estimates of equation (2) in this figure. In the early 1970s, the number of births on holidays was roughly 15\% lower than expected. As medical delivery interventions became more common, this drop increased. Interestingly, however, the holiday effect is larger for the 2000-2002 period than for the 2014-2016 period. The fall in the holiday effect may be attributable to ACOG's 2013 guidance on what constitutes an early-term birth and in what instances such deliveries are warranted (ACOG 2013; Oster 2018). ${ }^{20}$

Table 2 provides estimates of the net or aggregate impact of holidays on births per day across the entire manipulation window based on equation (3). The table supports our optimal holiday manipulation window choice. Specifically, the first column of Panel A reveals that there are only an estimated 4 fewer births per day across the holiday interval, which corresponds to a decrease of about $0.3 \%$ over the holiday period. Recall that the

\footnotetext{
19 The California data prior to 2000 are taken from the National Vital Statistics data.

${ }^{20}$ In 2013 ACOG redefined full term birth as deliveries between 37 and 42 weeks to deliveries between 39 and 40 weeks and reclassified deliveries from 37 to 38 weeks as "early term" births (Oster 2018). ACOG also made specific recommendations on the risk factors that warrant early term delivery, with the implication that early (timed) deliveries should be avoided when specific risks are not involved (ACOG 2013; Oster 2018).
} 
objective of the optimal window is to have this figure as close to 0 as possible. ${ }^{21}$ When including Christmas and New Year's in the set of holidays, this figure is similarly small with one more birth per day or a $0.09 \%$ increase in total births over the holiday period (Panel B).

\section{Change in Delivery Type Around Holidays}

Figure 5 breaks out the change in the number of births by delivery type. We create three mutually exclusive categories: (1) births by cesarean section, (2) vaginal births after the induction/stimulation of labor and (3) vaginal births after spontaneous labor. ${ }^{22}$ Note that the last two categories, by definition, exclude cases that end in a cesarean section. Cesarean sections decline by about 251, primarily the day of and the day after the holiday. This represents a 2-day decline in cesarean sections of over $25 \%$ relative to a daily average of 443 cesarean sections. These cesarean sections are shifted to both before and after the holiday. The same basic patterns are found for spontaneous vaginal births and vaginal births after induction/stimulation of labor. Specifically, on the day of and just after the holiday, spontaneous vaginal births decline by about 146, representing a decline of about $10 \%$ over the 2-day period given an average day with 709 spontaneous vaginal births. Induced/stimulated vaginal births decline by about 115 over the 2 -day period, representing a drop of almost $20 \%$. The reduction in cesarean sections on the holiday and the day after accounts for roughly $50 \%$ of the total decline in births. The remaining decline is split between spontaneous vaginal births $(27 \%)$ and stimulated/induced vaginal births $(27 \%){ }^{23}$ These findings are consistent with Martin et al. (2018), which finds that the decline in births due to UK bank holidays is driven primarily by a reduction in scheduled cesarean sections followed by declines in induced vaginal births. ${ }^{24}$ Measured across the whole 28 -day holiday interval, we find no meaningful changes in delivery types (see Table 2, Panel A). Both cesarean section births and induced/stimulated vaginal births decline by 2.4 to 2.7 per day.

\footnotetext{
21 This -4 births per day (or $28^{*}(-4)=-112$ ) is different from 2.2 births from our manipulation window selection algorithm because of different regression specifications (equation (2) versus equation (3)).

22 We classify births that are reported as both spontaneous and induced as induced births, and those reported as both vaginal and cesarean as cesarean sections.

${ }^{23}$ Note the sum of C-section, spontaneous vaginal, and induced/stimulated vaginal does not equal the total birth effect. That is because there is a small missing category (unclassified births). The holiday effect (i.e., the day of the holiday and the day after) for the unclassified birth category is a reduction of 8 births.

${ }^{24}$ Unlike our work, Martin et al. (2018) do not look at the complete displacement of births around the holiday period, but instead focus on the impacts on the holiday day, the last week day before the holiday, and the first week day after the holiday.
} 
Although the estimated decline is statistically distinguishable from 0 for inductions, it amounts to a less than $1 \%$ decline. Thus, while births and delivery types are rescheduled across holiday intervals, the likelihood of a given delivery type (e.g., cesarean section delivery) changes only very modestly.

While we do not find evidence that holidays change delivery methods, we cannot rule this possibility out either. For instance, it could be that births shift from spontaneous vaginal births to induced vaginal births before a holiday, and from induced vaginal births to spontaneous vaginal births after the holiday. These two effects would wash each other out and appear as though there was no impact on delivery type. However, as best we can gather, holidays appear to affect the timing of delivery and not the type of delivery (i.e., consistent with the second scenario in our conceptual framework).

The general pattern of findings is quite similar when we include Christmas and New Year's in the analysis (Table 2, Panel B). The only notable difference is a statistically significant, albeit very small, increase in spontaneous vaginal births. Interestingly, the cesarean effects are negative, not positive. The point estimate implies that spontaneous vaginal births increase by about $0.6 \%$ as a result of holidays. In other words, the rescheduling of cesarean sections and inductions as a result of the holiday means that a few more births are delivered without medical intervention, a clear but very small change along the extensive margin of delivery type.

\section{Change in Gestational Length}

A separate but related question to understanding the delivery processes underlying the retiming of holiday births is when these births get re-timed. We analyze the number of deliveries by ACOG's definitions of "term pregnancy." Specifically, we classify deliveries according to the following ACOG categories: (1) pre-term, which is prior to 37 weeks gestation; (2) early term, which is $370 / 7$ weeks through 38 6/7 weeks of gestation; (3) full term, which is $390 / 7$ weeks through 40 6/7 weeks of gestation; (4) late term, which is 41 0/7 weeks through $416 / 7$ weeks of gestation; and (5) post-term, which is 42 weeks of gestation and beyond. We also consider the average length of gestation.

Figure 6 shows the change in mean gestational age by day (Panel A) and the change in the number of daily births according to the 5 ACOG term length categories: pre-, early, full, late and post-term (Panels B-F, respectively). Mean gestational age is about $1 / 2$ day lower 
on the day after a holiday, with much of the change on the holiday itself. Although statistically significant, this decline is neither medically nor economically meaningful relative to a mean gestational age of about 275 days.

While mean gestational age is largely unchanged across the holiday interval, the composition of births by term length does change across the window. If holidays only affected the timing of "elective" intervention births, we would only expect impacts on births nearer to full-term. But births of all term lengths, with the exception of late term births, decline on the holiday itself relative to the counterfactual. Thus, the decline in total holiday births observed in Figure 1 is composed of births across the gestational age spectrum.

The rise in births before the holidays is mostly attributable to an increase in the number of full term births, whereas the increase after the holiday is largely due to a rise in the number of early term births. Because we cannot pinpoint exactly when these births would have happened in absence of the holidays, it is difficult to disentangle the exact mechanisms leading to these patterns. But these results are consistent with full-term births that would have been due on or near the holiday being moved earlier on average, and with earlier term births that would have occurred proximate to the holiday being moved later on average. The asymmetry of this shifting may be because medical professionals worry less about pushing the timing of full term births to an earlier date.

Measured across the whole 28-day holiday interval, we find no meaningful change in gestational length (see Table 3, Panel A). Mean gestational age is about 0.03 days longer in the holiday period, and this estimate is not statistically significant. Furthermore, the number of full term births appears unchanged when comparing the holiday period with the control region. In contrast, we find about $1.5(1 \%)$ more pre-term births per day and nearly $6(1.6 \%)$ fewer early term births per day on average, corresponding to about 43 more pre-term and 157 fewer early term births in the holiday interval relative to the control region. On the other hand, late term births increase by about 3.6 (2.6\%) per day, and post-term births decline by $3.3(4.2 \%)$ per day on average in the holiday interval. This implies that roughly 100 more late term births and 93 fewer post-term births occur in the holiday interval, relative to the control region. Taken together, the net timing of births is changed only modestly relative to what would occur absent a holiday. When Christmas and New Year's Day are included, all the term length results are small in magnitude and, with the exception of full term births, consistently smaller in magnitude than the Panel A estimates. None of the estimates that 
include Christmas and New Year's is statistically different from zero.

\section{Nature of Selection}

Crucial to our interpretation of the impact of holiday-related birth retiming on outcomes is an understanding of who is affected by holidays. A priori, medical providers may be most willing to move births in cases where they already plan to schedule the delivery but where any rescheduling may be expected to have little impact on birth outcomes. To assess this possibility, we study how the characteristics of moms and babies differ across days within the holiday interval.

We first consider two measures of health risk: 1) whether the pregnancy is "low risk" and 2) whether the mom is over age 35, the cut-off traditionally used to define "advanced maternal age." Low risk pregnancies are defined similar to Card et al. (2018) such that all of the following criteria apply to the birth: (i) singleton, (ii) not breech, (iii) gestation lasted at least 259 days, (iv) mother was at least 18 and no more than 35 years old, (iv) mother did not have preeclampsia or eclampsia, (v) mother had no more than 20 prenatal visits, (vi) baby had no intrauterine growth restriction, and (vii) mother had no previous cesarean section. ${ }^{25}$

However, the shift of high-risk (or non-low risk) births away from the holiday is only apparent for the holiday itself and not, for example, the day after the holiday. This pattern is corroborated by Panel B of Figure 7, which shows that moms of babies born on a holiday are less likely to be of "advanced maternal age," a strong predictor of pregnancy complications (Fretts 2018). On the other hand, as shown in Panels C and D of Figure 7, women giving birth on a holiday are slightly less likely to be white and more likely to be teenagers. These patterns may indicate, aside from selection according to health risk, that socioeconomic status is a predictor of holiday birth timing, with the more advantaged births more likely to be moved.

While the timing of births within the holiday manipulation window is clearly endogenous, in aggregate, births in the manipulation region versus those outside of the manipulation period should not be subject to selection. That is, if we have chosen a valid counterfactual, the births inside the holiday manipulation window should be ex-ante

\footnotetext{
${ }^{25}$ Card et al. (2018) also exclude current cesarean sections. Since delivery type is one of our outcomes of interest, we do not make this restriction. In addition, as Card et al. focus on first births, we report our results on low risk first births as well.
} 
otherwise similar to our "control" births, i.e., the counterfactual births outside of the holiday manipulation window. This assumption, which is crucial to generating valid estimates of the effect of holidays on birth outcomes, can be partially tested by estimating equation (3) using births categorized by the characteristics of mothers as dependent variables.

Across the holiday manipulation window, births based on most characteristics are balanced (i.e., being within the manipulation window is not correlated with pre-determined characteristics), with the exception of maternal age and delivery payment type (see Table 4). On average, 2 fewer babies per day are born to mothers older than 35 (a 1\% effect), 5 more deliveries per day are paid using public funds (a $0.8 \%$ effect), and 8.5 fewer deliveries per day are paid using private funds (a 1.2\% effect) in the holiday manipulation window. Aggregated across the holiday interval, this amounts to 56 fewer births from older mothers, 238 fewer deliveries using insurance and 146 more using public insurance than in the control region. Note, however, that these characteristics are not independent. For example, two-thirds of deliveries by older moms are private pay. None of the other coefficients are statistically significant and, more importantly, all are small in magnitude. For example, we estimate that about $0.2 \%$ fewer babies are born to mothers with a high school degree or less in the holiday interval. This pattern holds in both our main holiday analysis (Panel A of Table 4), and when we add Christmas and New Year's to the analysis (Panel B of Table 4).

Overall, the selection effects point to no clear direction of bias. But since a comparison of births within the manipulation window to those outside of the manipulation window could still be clouded with selection effects, we analyze birth outcomes in the next section both with and without controls for the background variables for which we find statistically-significant holiday effects (i.e., maternal age and payment type).

\section{Birth Outcomes}

Holidays shift births both before the holiday and after the holiday. Shifts in either of these directions may have heterogeneous effects. One plausible hypothesis, supported by the medical literature, is that moving a birth earlier may lead to an increase in adverse outcomes, whereas moving a birth later may not. The net effect on birth outcomes would be a weighted average of the effects on the births pushed earlier and those pushed later. In this case, the estimated effect on outcomes would not be very informative with regard to the effect of scheduling a birth early. 
Another feature worth pointing out is the degree to which births are manipulated. To a best approximation, manipulated births are shifted by a couple of days (not a couple of weeks). Ex-ante, one may presume that extending a pregnancy by a few days is likely to have minimal effects on outcomes. However, given the discussions amongst ACOG and the frequency with which birth timing is manipulated (e.g., weekends in addition to holidays), our estimates on birth outcomes are informative as to whether these common timing manipulations have deleterious effects. Moreover, ex ante, it is unclear whether the holiday drop occurs exclusively because of a change in timing as opposed to a change in both the timing of births and the mode of delivery. An alteration in the delivery mode might increase the likelihood of adverse outcomes more than a change in the timing of delivery by a few days.

Figure 8 shows how mean birth weight, the fraction of births with a newborn condition, and the fraction of births with a labor complication vary within the holiday period. $^{26}$ The fraction of births with newborn conditions or with labor complications increases on a holiday by about 0.5 percentage points. These estimates imply increases of about $4 \%$ and $2.5 \%$ respectively, although neither estimate is statistically distinguishable from zero. Babies born on the day of or the day just before or after the holiday have slightly lower birth weight (between 20 and 30 grams lower off a mean of about 3300 grams) than would be predicted absent the holiday. The patterns we see here, particularly on holidays, are consistent with some of the selection effects we observed earlier (i.e., disadvantaged women are more likely to give birth on the holiday). But for outcomes other than birth weight, which may be sensitive to staffing levels and quality, the estimates are also congruous with adverse impacts of reductions in the quantity or quality of staffing.

Next, we examine the net impact of birth timing on birth outcomes over the entire 28-day holiday interval relative to the control region. As above, we use equation (3) but consider outcomes such as mean birth weight, or the share of babies that had any newborn conditions. These estimates are reduced-form impacts, as they average across all births in the sample. Since only a relatively small number of births are clearly manipulated by the holiday,

\footnotetext{
${ }^{26}$ Newborn conditions include conditions related to the central nervous system, respiratory system, digestive system, and chromosomal anomalies. There are a total of 75 possible conditions. Labor complications (which include delivery complications) include premature rupture of membrane ( $>12$ hours), cord prolapse, fetal distress, anesthetic complications, unsuccessful attempt at vaginal birth after cesarean section, and maternal blood transfusion. There are about 30 possible labor and delivery complications.
} 
we also scale the reduced-form effects by an estimate of the fraction of manipulated births to derive a "LATE." Our best estimate of the manipulated fraction is $0.013 ; 512$ fewer births on the holiday and day after, divided by a total of about 40,500 births in the manipulation window. This scaling gives us a sort of IV estimate - the effect of manipulating the timing of a birth, provided that the usual IV assumptions are met, including that the occurrence of holidays only shifts births away from occurring on the holiday. We are cautious in interpreting scaled estimates as IV estimates since we cannot measure the manipulated fraction directly. For example, a cesarean section that would have been scheduled for 2 days after Thanksgiving but is moved to the Tuesday before Thanksgiving would not be counted as a manipulated birth according to our back-of-the-envelope calculation. To the extent that we miss manipulations like this, we will be underestimating the fraction manipulated and thus, our scaling will deliver upward-biased estimates. Nonetheless, we discuss these scaled estimates to provide a sort of benchmark of the potential effects on manipulated births.

As shown in Panel A of Table 5, across the full 28-day holiday interval, we find a 2gram lower mean birth weight relative to the counterfactual days (a $0.06 \%$ effect). Although statistically distinguishable from zero, this difference is small. ${ }^{27}$ The "IV effect" for mean birth weight implies reductions of roughly 160 grams. When New Year's and Christmas are included in the analysis, the implied IV estimate is less than one-third that size, and not statistically significant (see Panel B of Table 5). If we further control for potential selection in the manipulation window, specifically by including the share of moms over age 35 , the share of private insurance delivery payments and the share of public insurance delivery payments in Equation (3), the implied IV estimate is about 105 grams (see Appendix Table 1). ${ }^{28}$ For comparison, the effect of smoking on birth weight is approximately 250 grams (Almond, Chay, and Lee, 2005) and in twin comparisons, a 150-gram difference in birth weight would imply a 0.0045 difference in high school completion and a $0.6 \%$ difference in earnings (Black et al., 2007).

Since changes in birth weight at the mean may not be as meaningful as those in the tails, we also analyze the share of births that are low birth weight (i.e., below 2,500 grams), or very low birth weight (i.e., below 1,500 grams). We find that the share of babies with low or

27 The 2-gram decrease from holiday retiming is about the same as the lower bound of the $95^{\text {th }}$ percentile confidence interval of the estimated impact of a $\$ 1000$ increase in tax benefits in Schulkind and Shapiro (2014).

28 These controls are motivated by the results in Table 4 (Panel A), as maternal age and payment types are the only statistically significant selection categories. 
very low birth weight is slightly higher in the holiday interval, however these effects are small and not statistically significant (see Table 5 and Appendix Table 2). This finding is consistent with prior work on financial-related birth timing (Schulkind and Shapiro 2014; Borra et al. 2016; Borra et al. 2018). ${ }^{29}$

In contrast, other results imply that holidays modestly reduce the likelihood of adverse outcomes. For example, we find that the share of births with any newborn conditions, as well as the share of births with any labor complications, slightly decreases in the holiday interval - by about $1 \%$ and $0.4 \%$, respectively. The latter is not statistically significant. These changes correspond to reductions of about $1.5(1.2 \%)$ fewer births with any newborn conditions, and $4(0.6 \%)$ fewer births with any labor complications per day in the holiday window. We also find slight reductions in the mean number of newborn conditions and labor complications of about $1 \%$ and $0.3 \%$, respectively (see Appendix Table 2). We also find declines in the share of newborns that had a low Apgar score ${ }^{30}$ (see Table 5), that were in a neo-natal intensive care unit, or that had assisted ventilation (see Appendix Table 2), although none of these estimates is either statistically significant or economically meaningful.

Taken together, these results point to no consistent negative or positive effect of holiday birth timing on outcomes. Aside from slight reductions in average birth weight, we find very limited evidence of adverse consequences of the re-timing of births to accommodate major holidays. We urge some caution in overstating this finding, however: While the reduction in births in proximity to the holiday is large, it is challenging to precisely estimate the effect of the holiday displacement on outcomes, since births get retimed over a relatively wide window (28 days). As John DiNardo was famous for reminding us, dividing a reduced-form estimate by a small number will likely lead to imprecise estimates.

\section{Sub-sample of High-Risk Pregnancies}

A potentially important caveat to our conclusions about the limited consequences of holiday-related birth timing is that most pregnancies tend to be low risk. The low risk nature of most births may make it difficult to pick up any real effects of birth timing. To assess this

\footnotetext{
${ }^{29}$ We urge some caution in this interpretation. Although small and insignificant, the scaled impact implies an increase of about 18 low birthweight births per day, or about $18 \%$ off a base of 98 births.

${ }^{30}$ A newborn is defined to have a low Apgar score if either their 1-minute or their 5-minute Apgar score is below 7 .
} 
issue, we redo the main analysis on the sample of births to women with high-risk pregnancies, where high-risk is defined as meeting at least one of the following criteria: mom had a prior cesarean section, baby is in the breeched position, mom has a multiple birth pregnancy, or mom has an infection such as HIV. In our sample, about 230 or $16 \%$ of births per day are from high-risk pregnancies. Almost all of these pregnancies result in a cesarean section birth $(94.4 \%)$.

As in the overall sample, births from high-risk pregnancies drop on holidays (see Figure 9 Panel A). The drop is considerable - 150 births off a base of 259 births from highrisk pregnancies. As expected, given that the high rate of (planned) cesarean section delivery among this group, the decline is almost entirely driven by cesarean sections (see Figure 9 Panel B). Across the full holiday interval, we find a very small decline in the total number of births for the high-risk group of about 1.6 high-risk births per day. While ideally this estimate would be as close to 0 as possible (i.e., within the holiday window, the net number of births is 0 ), recall that the optimal window is derived using the full sample of births. ${ }^{31}$ Importantly, this effect is not sizable.

As in the full sample, early term high-risk births that would have occurred on the holiday appear to be pushed later, and late term high-risk births are pushed earlier (see Figure 10). However, we find no meaningful effect of birth retiming on the mean gestational age of high-risk births across the holiday window (see Table 7 and Figure 10). Mean gestational age increases by only about 0.1 days off a base of 269 days. In the holiday region, there is a statistically significant and very small reduction of about 2 births with private insurance payments (see Table 8). The estimates of other selection criteria are even smaller in magnitude, and not statistically significant. Nonetheless, to address any concern about selection, we control for delivery payment variables in our birth outcome regressions as a robustness check (see Appendix Table 3).

In Table 9, we consider the impact of the holiday on birth outcomes for the high-risk sample (see Figure 11 for the day-by-day patterns in outcomes). The results point to no clear health-improving or health-worsening effect of holidays. Mean birth weight decreases by just over 1 gram, although this estimate is quite imprecise. Scaling by the roughly 159

\footnotetext{
31 To be consistent with the overall sample, we used the optimal manipulation window determined by the overall sample. If instead, the optimal manipulation window is calculated using only the sample of high-risk births, the window is $[-18,13]$.
} 
manipulated high-risk births out of a total of 7252 high-risk births over the holiday window - or the $2.2 \%$ of high-risk births that are manipulated - implies a decrease in birth weight on the order of 60 grams. ${ }^{32}$ Furthermore, we estimate a small decrease in the share of newborns with low birth weight, and the share of births with any newborn conditions. The share of high-risk births with any labor complications, or with a low Apgar score, on the other hand, is marginally higher in the holiday interval. However, none of these effects are statistically significant.

Overall, in accordance with the results from the main sample, the mounting evidence does not point to sizable adverse effects of birth timing manipulation. But since the fraction of births displaced as a result of the holiday is relatively small, precise conclusions about the size of the effects are not possible.

\section{Robustness and Sensitivity Analysis}

We perform numerous robustness and sensitivity checks. All are consistent with our main findings that while holidays affect the timing of birth and, in some cases, mode of delivery, they have limited negative impacts on infant health.

\section{Poisson Regression Models}

To begin, we redo our analysis of daily births, overall and by delivery type, using Poisson Regression Models (PRM). The PRM is better suited to the count nature of these daily data. As shown in Appendix Figure 4, estimates from the PRM also show a hollowing out of the birth distribution over the 28-day holiday period. Declines are observed on the holiday itself as well as the day after, with small daily increases offsetting the declines spread out across the rest of the holiday period.

The PRM estimates of the decline on the holiday and the day after are quite similar to what we find using a linear regression model of birth counts. Specifically, the PRM implies a drop in daily births of about $23 \%$ on the day of the holiday and $10 \%$ the day after, which is remarkably close to the 346 and 165 birth declines off a daily mean of 1447 births

\footnotetext{
32 Specifically, the manipulated fraction of $2.2 \%$ is the 159 birth decline in high-risk births on the holiday off a base of 259 high-risk births per day over 28 days or 7252 high-risk births overall.
} 
from the linear regression models (i.e., reductions of $24 \%$ and $11 \%$, respectively). ${ }^{33}$ Thus, the use of the linear regression model appears to have limited impact on our conclusions concerning the daily birth displacements.

Likewise, our estimates of the aggregate or net effect of holidays on births and delivery types across the full 28-day holiday period are remarkably similar across the two models. The estimates in Appendix Table 4, using PRMs, imply a $-0.21 \%$ decline in daily births, a $-0.4 \%$ decline in cesarean sections, a $0.08 \%$ increase in spontaneous vaginal births and a $-0.9 \%$ decline in induced/stimulated vaginal births. The analogous calculations from Table 2 , imply a $-0.28 \%$ decline in daily births, $-0.5 \%$ decline in cesarean sections, $0.07 \%$ increase in spontaneous vaginal births and a $-0.9 \%$ decline in induced/stimulated vaginal births relative to their means.

\section{Separating Holiday Effects from Day of Week Effects}

As another specification check, we restrict our analysis to those holidays that fall on fixed dates and thus varying days of the week across years. The restricted holiday set includes New Year's, July $4^{\text {th }}$ and Christmas across 17 years. As day-of-the-week effects are strong, this restriction allows us to better separate out the effect of holidays from any day of the week effect. The pattern of displacement (see Appendix Figure 5 and Appendix Table 5), however, follows the same hollowing-out pattern of the earlier figures. This suggests that our findings are unlikely to be driven by day of the week effects.

\section{Sensitivity to the Holiday Manipulation Window}

We next consider the sensitivity of our analysis to the manipulation window. The optimal manipulation window was chosen such that the reduction in births right around the holiday is fully offset with increases in births on either side of the holiday. As discussed above, however, the length of this manipulation window and the days captured by it have implications for the control period. Specifically, as the manipulation region becomes wider, the matched dates are further from the holiday. To address this issue, we test the robustness of our results to either narrowing or widening the holiday period by 3 days on either side. Thus, we consider as the treatment period either 8 days before and 13 days after (narrower

\footnotetext{
${ }^{33}$ To interpret the PRM coefficients as percent change, we transform them as follows: $e^{b}-1$. Thus, a coefficient
} of -0.26 corresponds to a decline of $23 \%$. 
window) or 13 days before and 19 days after (wider window) the holiday. In addition, we consider our "second-best" windows, that is, the windows which according to our grid search led to the second-lowest absolute value of the sum of excess and missing mass. As can be seen in Appendix Figure 1, the windows $[-10,+18]$ and $[-14,+10]$ both result in a net mass of 2.4 births, rather than the 2.2 of our optimal window.

Appendix Figure 6 shows the evolution of the displacement of births using alternative window sizes. The broad pattern of birth displacement is not materially affected by the window choice, which is expected given that the sharp decline in births occurs over only 2 days and the corresponding increase is spread out over many days on either side of the holiday.

When we consider the net change in births overall and by delivery type, the analysis makes clear why the optimal $[-11,16]$ day window is preferred. Specifically, as shown in Appendix Table 6, a smaller window (Panel B) implies a net drop in births of nearly 10 per day and a wider window a net increase in births of more than 8 per day. Both of these effects are statistically significant. It is a window in between the two that comes closer to capturing the region over which holidays displace births. Similarly, we consider our "second-best" windows in Panels D and E. The net drop in births for these windows is close to the optimal window, yet slightly bigger. Thus, all these alternative windows move us further from the zero net mass heuristic used for identification.

The findings for selection are quite similar across all windows (see Appendix Table 7). Across all windows, we find some evidence of selection in terms of the share of deliveries paid for via private insurance, and for three of the five windows considered, there are significant changes in the number of deliveries paid via public programs. Overall, the degree of selection appears to be dampened for the non-optimal windows.

Appendix Table 8 shows our estimates of birth outcome effects as we vary the window size. Holiday effect estimates for birth weight and numbers of births by outcomes are sensitive to window size - both flip sign with the wider window and decrease in magnitude as we change window size. However, effect sizes are very modest in magnitude across all windows. On balance, these results support the conclusion that holiday birth retiming does not have overwhelming negative impacts on newborn health. 


\section{Interpretation and Mechanisms}

\section{Who are the Compliers?}

To better interpret our findings, we characterize the groups that are most likely to shift their births as a result of the holiday. To do this, we estimate separately by observable characteristics the percent of births across the manipulation period that are shifted away from the holiday and the day after. As shown in Appendix Table 9, we estimate this scaling factor for younger moms versus older moms, defined as age 35 and over; high-risk versus low-risk births (first births and any parity); non-Hispanic white versus non-Hispanic black, non-Hispanic Asian and Hispanic moms; moms with a high school education or less versus college or more; and public versus private pay or self-pay deliveries. As we explain below, we also consider births at Kaiser Foundation Hospitals. We find that the magnitude of the first stage is largest for high-risk births. Based on 2.2\% manipulated, the fraction of manipulated births is about 75\% higher for the high-risk group than for the sample as a whole. As the group of high-risk births is especially likely to have a scheduled cesarean section, this is consistent with our hypothesis that holiday effects are disproportionately driven by re-timed rather than newly timed births.

\section{Isolating the Role of Patient Demand versus Provider Convenience}

The conceptual framework outlined three mechanisms by which holidays could affect infant health: the timing of delivery, the mode of delivery, and the quality and/or quantity of staffing on holidays. It is conceivable, for instance, that some hospitals are understaffed on holidays, or that the staff in service are less experienced on average on those days. This might negatively affect neonatal health outcomes, and thus lead to an upward bias of the effect of birth timing on outcomes. A separate but related question is whether any change in delivery timing and/or mode is driven by the demand-side (patients) or the supply-side (providers).

Unfortunately, our data do not capture the quality or quantity of medical staff present at birth in our data. To the extent holiday-related changes in demand are predictable, hospitals may adjust staffing accordingly. We can, however, make some progress on the issue of provider versus patient demand as a driver of holiday-related birth retiming. To remove supply side factors from consideration, we focus on certain days that could plausibly affect a 
woman's scheduling decision but seem unlikely to impact provider work schedules.

Specifically, we look at September $11^{\text {th }}$ after 2001 , and Friday the $13^{\text {th }}$, as parents may want to avoid births on these days. ${ }^{34}$ Mothers might avoid giving birth on September $11^{\text {th }}$ so that their child's birthday is not associated with the terrorist attacks of $9 / 11$. Furthermore, Friday the $13^{\text {th }}$ is considered unlucky in Western culture. Provided that neither of these days has a direct impact on the staffing of hospitals, analyzing outcomes around these days can help us to better understand the effects of (re-)scheduled deliveries separately from supply side effects. However, to the extent that there is heterogeneity in the effects of holidays, it may be difficult to extrapolate from these two dates.

When estimating how September $11^{\text {th }}$ and Friday $13^{\text {th }}$ affect our outcomes of interest, we largely build on our main empirical strategy. That is, we consider the time window spanned by 11 days prior and 16 days after these days as the manipulation region and control for all holidays. Put differently, September $11^{\text {th }}$ and Friday $13^{\text {th }}$ are our "holidays" of interest in this context and actual holidays as well as Halloween and Valentine's Day are treated as possible confounders and "nuisance holidays."

Appendix Figure 7 suggests that approximately 115 fewer births occur on September $11^{\text {th }}$ and Friday $13^{\text {th }}$ on average. The change is driven largely by a decline in about 65 cesarean sections. Furthermore, there about 25 fewer inductions and spontaneous vaginal births are happening on these days. That births get (re-)scheduled around events such as September $11^{\text {th }}$ and Friday $13^{\text {th }}$ - which presumably leave the quality and quantity of the supply side unaffected - suggests that demand side factors might account for some of the holiday birth timing manipulations. In other words, these results suggest that holiday birth timing manipulation might in part be driven by patients' preferences. On the other hand, the magnitude of the change in births is only about $20 \%$ of what we find for major holidays, suggesting that provider preferences likely play an important role in the rescheduling of births around holidays.

As another test of the role of providers, we consider births at Kaiser Foundation

\footnotetext{
34 To induce supply side variation, we also investigated how the annual ACOG meetings affect birth timing. Past work (Gans, Leigh, Varganova 2007) shows evidence that births fall in United States during the meetings by $1 \%$ but use national data and an earlier time period (1990-2003) along with a less-controlled regression specification. However, we did not find that the meetings affected birth timing even though many of the meetings occurred in California.
} 
Hospitals, which are primarily births by Kaiser Permanente members. ${ }^{35}$ The Kaiser system, which owns its hospitals in California, has a strong disincentive to perform elective cesarean sections over vaginal births since they are paid per member per month rather than fee-forservice and cesarean sections are more resource-intensive. Consistent with the idea that provider decisions matter for retimed deliveries, our analysis finds that less than $0.65 \%$ of Kaiser deliveries in the holiday window are retimed in contrast to about $1.26 \%$ for the sample as a whole (see the last row of Appendix Table 9). Thus, while patient preferences matter, the analysis here suggests that provider incentives play a crucial role in holidayrelated birth retiming. That is, one sees more holiday-related retiming where providers face less of a disincentive to electively schedule births.

\section{Conclusions}

Consistent with previous studies, we find that births are less common on holidays. Births that would have otherwise occurred on holidays are shifted to both the two weeks before and after the holiday, with most of the retiming occurring within $+/-1$ week. This large window of birth timing adjustment suggests caution should be used in birth-date based regression discontinuity research designs when the regression discontinuity relies on birthdates near a holiday.

We find clear evidence that holidays shift the timing of births on the intensive margin. That is, among births scheduled via cesarean section or induction, holidays affect the precise timing of these procedures. We find little support for the idea that holidays affect birth timing on the extensive margin, i.e., that more births are scheduled via cesarean section or induction as a result of holidays, given that there is no net change in delivery types. Consistent with the conclusion that changes are largely on the intensive margin, we find that high-risk pregnancies are more likely to be shifted as a result of holidays. That said, extensive margin changes cannot be ruled out without knowing the intended delivery plan of mothers in our sample.

We also find suggestive evidence that the supply-channel (i.e., provider choice) dominates holiday-related birth retiming. Our evidence is twofold. First, we find that in

35 The exception would be for emergency deliveries. 
Kaiser Foundation Hospitals, where financial incentives work against elective delivery scheduling, holiday related birth timing is a much smaller share of births around holidays than in hospitals that lack such incentives. Second, we find modest birth retiming on Friday the $13^{\text {th }}$ and September 11 after 2001, two days that should be more salient to patients than providers. This suggests that the demand-side channel (i.e., patient choice) plays a perhaps more limited role in holiday-related birth timing.

Across our sample, we find little consistent evidence of unfavorable health consequences as a result of holiday-related birth timing. This is true for the overall sample and the sample of high-risk births. This finding contrasts somewhat with the conclusions from studies of deadline-based financial incentives to retime births such as Schulkind and Shapiro (2014) and Borra et al $(2016 ; 2018)$. This difference may reflect the fact that holidays provide flexibility to retime births to either before or after the reference date whereas financial incentives act in one direction (i.e., either move births earlier or later), or that the set of parents who choose to time their child's birth in response to financial incentives is selected. That said, some caution is warranted in extrapolating our findings given the relatively small share of births ( 0.013 as a lower bound) that get moved across the holiday period.

As the rate of medical interventions in the delivery process is much higher than it was decades ago, worries about the possible adverse effects of intervening linger. Our quasiexperimental results, using holidays as a natural experiment, can be informative in that regard. As the delivery mode is not impacted in aggregate, these results are most useful for guiding decisions on when to intervene (and not on whether to intervene). Even absent our extrapolation to understanding the effects of timing delivery interventions, this work is beneficial for hospitals deciding on holiday policies regarding staffing and the use of medical interventions such as cesarean sections, inductions, and stimulations. Our results suggest that the current shifting of births to accommodate the holiday plans of both providers and patients does not have large adverse health consequences for either newborns or their moms at delivery. 


\section{References}

ACOG. "Clinical Management Guidelines for Obstetrician-Gynecologist. Induction of Labor." Practice Bulletin 10 (2009).

ACOG. "Committee Opinion.” No. 560, April 2013, www.acog.org/-/media/CommitteeOpinions/Committee-on-Obstetric-

Practice $/$ co560.pdf?dmc=1\&ts=20151219T0215099943. Accessed January 10, 2019.

ACOG. "Guidelines for Perinatal Care." 2012, www.circulomedicodezarate.org/ebooks/Guidelines_for_Perinatal_Care.pdf. Accessed January 4, 2019.

ACOG. "Labor Induction.” 2017, www.acog.org/Patients/FAQs/Labor-Induction. Accessed January 4, 2019.

Almond, Douglas, Christine Pal Chee, Maria Micaela Sviatschi, and Nan Zhong. "Auspicious Birth Dates among Chinese in California.” Economics \& Human Biology No. 18 (2015): 153-159.

Almond, Douglas, Kenneth Y. Chay, and David S. Lee. "The Costs of Low Birth Weight.” The Quarterly Journal of Economics 120, No. 3 (2005): 1031-1083.

Bailit, Jennifer L., William Grobman, Yuan Zhao, Ronald J. Wapner, Uma M. Reddy, Michael W. Varner, Kenneth J. Leveno et al. "Nonmedically Indicated Induction vs. Expectant Treatment in Term Nulliparous Women." American Journal of Obstetrics and Gynecology 212, No. 1 (2015): 103-e1.

Barreca, Alan I., Jason M. Lindo, and Glen R. Waddell. "Heaping-Induced Bias in Regression-Discontinuity Designs.” Economic Inquiry 54, No. 1 (2016): 268-293.

Bauer, Thomas K., Stefan Bender, Jörg Heining, and Christoph M. Schmidt. "The Lunar Cycle, Sunspots and the Frequency of Births in Germany, 1920-1989." Economics \& Human Biology 11, No. 4 (2013): 545-550.

Berghella, Vincenzo. "cesarean Delivery: Preoperative Planning and Patient Preparation." UptoDate, Lockwood, C (Ed), UptoDate, Waltham, MA. (2018).

Bialik, Carl. "Some People Are Too Superstitious To Have A Baby on Friday The 13th." FiveThirtyEight, 13 May 2018, fivethirtyeight.com/features/some-people-are-toosuperstitious-to-have-a-baby-on-friday-the-13th. Accessed January 3, 2019.

Black, Mairead, Siladitya Bhattacharya, Sam Philip, Jane E. Norman, and David J. McLernon. "Planned cesarean Delivery at Term and Adverse Outcomes in Childhood Health.” Jama 314, No. 21 (2015): 2271-2279. 
Black, Sandra E., Paul J. Devereux, and Kjell G. Salvanes. "From the Cradle to the Labor Market? The Effect of Birth Weight on Adult Outcomes." The Quarterly Journal of Economics 122, No. 1 (2007): 409-439.

Borra, Cristina, Libertad González, and Almudena Sevilla. "Birth Timing and Neonatal Health.” American Economic Review Papers and Proceedings 106, No. 5 (2016): 329-32.

Borra, C., L. Gonzalez, and A. Sevilla Sanz. "The Impact of Scheduling Birth Early on Infant Health." Journal of the European Economic Association (2018).

Borst, Lyle B., and M. Osley. "Holiday Effects upon Natality." American Journal of Obstetrics \& Gynecology 122, No. 7 (1975): 902-903.

Boulvain, Michel, Catalin M. Stan, and Olivier Irion. "Membrane Sweeping for Induction of Labour." Cochrane Database of Systematic Reviews 1 (2005).

Brunner, Beatrice, and Andreas Kuhn. "Announcement Effects of Health Policy Reforms: Evidence from the Abolition of Austria's Baby Bonus." The European Journal of Health Economics 15, No. 4 (2014): 373-388.

Card, David, Alessandra Fenizia, and David Silver. "The Health Effects of cesarean Delivery for Low-Risk First Births.” No. w24493. NBER working paper, 2018.

Chetty, Raj, John N. Friedman, Tore Olsen, and Luigi Pistaferri. “Adjustment Costs, Firm Responses, and Micro vs. Macro Labor Supply Elasticities: Evidence from Danish Tax Records." The Quarterly Journal of Economics 126, No. 2 (2011): 749-804.

Cohen, Jacob. "Applied Multiple Regression/Correlation Analysis for the Behavioral Sciences.” Hillsdale, NJ: Erlbaum No. 81 (1983).

Dee, Thomas S., Will Dobbie, Brian A. Jacob, and Jonah Rockoff. "The Causes and Consequences of Test Score Manipulation: Evidence from the New York Regents Examinations." No. w22165. NBER working paper, 2016.

Diamond, Rebecca, and Petra Persson. "The long-term consequences of teacher discretion in grading of high-stakes tests.” No. w22207. NBER working paper, 2017.

Dickert-Conlin, Stacy, and Amitabh Chandra. "Taxes and the Timing of Births." Journal of Political Economy 107, No. 1 (1999): 161-177.

Edmonds, Keith. Dewhurst's Textbook on Obstetrics and Gynaecology. Wiley-Blackwell, 2008.

Figlio, David, Jonathan Guryan, Krzysztof Karbownik, and Jeffrey Roth. "The Effects of Poor Neonatal Health on Children's Cognitive Development." American Economic Review 104, No. 12 (2014): 3921-55. 
Fretts, Ruth C. "Effects of Advanced Maternal Age on Pregnancy" Updated on September 4, 2018. https://www.uptodate.com/contents/effects-of-advanced-maternal-age-onpregnancy. Accessed January 18, 2019.

Galal, M., I. Symonds, H. Murray, F. Petraglia, and R. Smith. "Postterm pregnancy." Facts, Views \& Vision in ObGyn 4, No. 3 (2012): 175.

Gans, Joshua S., and Andrew Leigh. "Born on the First of July: An (Un)Natural Experiment in Birth Timing." Journal of Public Economics No. 93.1-2 (2009): 246-263.

Gans, Joshua S., Andrew Leigh, and Elena Varganova. "Minding the Shop: The Case of Obstetrics Conferences.” Social Science \& Medicine 65, No. 7 (2007): 1458-1465.

Gelman, A., John Carlin, Hal Stern, David Dunson, Aki Vehtari, and Donald Rubin: Bayesian Data Analysis. Chapman \& Hall/CRC Texts in Statistical Science, No. 3 (2013).

Goodman, Michael J., Winnie W. Nelson, and Michael V. Maciosek. "Births by Day of Week: A Historical Perspective." Journal of Midwifery \& Women's Health 50, No. 1 (2005): 39-43.

Gould, Jeffrey B., Cheng Qin, Amy R. Marks, and Gilberto Chavez. "Neonatal Mortality in Weekend vs. Weekday Births." Jama 289, No. 22 (2003): 2958-2962.

Grobman, W.A., Rice, M.M., Reddy, U.M., Tita, A.T., Silver, R.M., Mallett, G., Hill, K., Thom, E.A., El-Sayed, Y.Y., Perez-Delboy, A. and Rouse, D.J., "Labor Induction versus Expectant Management in Low-Risk Nulliparous Women.” New England Journal of Medicine 379, No. 6 (2018): 513-523.

Hamilton, Patti, and Elizabeth Restrepo. "Sociodemographic Factors Associated with Weekend Birth and Increased Risk of Neonatal Mortality." Journal of Obstetric, Gynecologic \& Neonatal Nursing 35, No. 2 (2006): 208-214.

Hannah, Mary E., Walter J. Hannah, Jonathan Hellmann, Sheila Hewson, Ruth Milner, Andrew Willan, and Canadian Multicenter Post-term Pregnancy Trial Group*. "Induction of Labor as Compared with Serial Antenatal Monitoring in Post-Term Pregnancy: A Randomized Controlled Trial." New England Journal of Medicine 326, No. 24 (1992): 1587-1592.

Hawe, E., A. MacFarlane, and J. Bithell. "Daily and Seasonal Variation in Live Births, Stillbirths and Infant Mortality in England and Wales, 1979-96." Health Statistics Quarterly 9 (2001): 5-15.

Hendry, Robert A. “The Weekend-A Dangerous Time to Be Born?” BJOG: An International Journal of Obstetrics \& Gynaecology 88, No. 12 (1981): 1200-1203. 
Hong, J. S., H. C. Kang, S-W. Yi, Y. J. Han, C. M. Nam, B. Gombojav, and H. Ohrr. "A Comparison of Perinatal Mortality in Korea on Holidays and Working Days." BJOG: An International Journal of Obstetrics \& Gynaecology 113, No. 11 (2006): 1235-1238.

Jürges, Hendrik. "Financial Incentives, Timing of Births, and Infant Health: A Closer Look into the Delivery Room." The European Journal of Health Economics 18, No. 2 (2017): 195-208.

Kavanagh, Josephine, A. J. Kell, and Jane Thomas. 2005. "Breast Stimulation for Cervical Ripening and Induction of Labour," Cochrane Database of Systematic Reviews 3, Article No. CD003392.

Kleven, Henrik Jacobsen. "Bunching.” 2016. Annual Review of Economics 8: 435-464.

Kleven, Henrik J., and Mazhar Waseem. 2013. "Using Notches to Uncover Optimization Frictions and Structural Elasticities: Theory and Evidence from Pakistan." The Quarterly Journal of Economics 128, No. 2: 669-723.

LaLumia, Sara, James M. Sallee, and Nicholas Turner. "New Evidence on Taxes and the Timing of Birth.” American Economic Journal: Economic Policy 7, No. 2 (2015): 258-93.

Levy, Becca R., Pil H. Chung, and Martin D. Slade. "Influence of Valentine's Day and Halloween on Birth Timing." Social Science \& Medicine 73, No. 8 (2011): 1246-1248.

Lin, Herng-Ching, Sudha Xirasagar, and Yu-Chi Tung. "Impact of a Cultural Belief about Ghost Month on Delivery Mode in Taiwan." Journal of Epidemiology \& Community Health 60, No. 6 (2006): 522-526.

Lo, J. C. "Auspicious Time and Caesarean Section." Taiwan J Public Health 22 (2003): 134140.

Luthy, David A., Judith A. Malmgren, and Rosalee W. Zingheim. "cesarean Delivery after Elective Induction in Nulliparous Women: The Physician Effect." American Journal of Obstetrics and Gynecology 191, No. 5 (2004): 1511-1515.

Macfarlane, Alison. "Variations in Number of Births and Perinatal Mortality by Day of Week in England and Wales." Br Med J 2, No. 6153 (1978): 1670-1673.

Mangold, William D. "Neonatal Mortality by the Day of the Week in the 1974-75 Arkansas Live Birth Cohort." American Journal of Public Health 71, No. 6 (1981): 601-605.

Martin, Peter, Mario Cortina-Borja, Mary Newburn, Gill Harper, Rod Gibson, Miranda Dodwell, Nirupa Dattani, and Alison Macfarlane. "Timing of Singleton Births by Onset of Labour and Mode of Birth in NHS Maternity Units in England, 20052014: A Study of Linked Birth Registration, Birth Notification, and Hospital Episode Data." PloS one 13, No. 6 (2018): e0198183. 
Mathers, C. D. "Births and Perinatal Deaths in Australia: Variations by Day of Week.” Journal of Epidemiology \& Community Health 37, No. 1 (1983): 57-62.

Modlock, J., Birgitte Bruun Nielsen, and N. Uldbjerg. "Acupuncture for the Induction of Labour: A Double-Blind Randomised Controlled Study." BJOG: An International Journal of Obstetrics \& Gynaecology 117, No. 10 (2010): 1255-1261.

Neugart, Michael, and Henry Ohlsson. "Economic Incentives and the Timing of Births: Evidence from the German Parental Benefit Reform of 2007." Journal of Population Economics 26, No. 1 (2013): 87-108.

Nielsen, Peter E., Bobby C. Howard, Christina C. Hill, Penny L. Larson, Robert HB Holland, and Paul N. Smith. "Comparison of Elective Induction of Labor with Favorable Bishop Scores versus Expectant Management: A Randomized Clinical Trial." The Journal of Maternal-Fetal \& Neonatal Medicine 18, No. 1 (2005): 59-64.

Oster, Emily. "Expert Behavior Change in Response to Best Practice Changes: Evidence from Obstetrics." working paper (2018), www.brown.edu/research/projects/oster/sites/brown.edu.research.projects.oster/fi les/uploads/DoctorResponse.pdf. Accessed January 4, 2019.

Osterman MJK and JA Martin. "Recent Declines in Induction of Labor by Gestational Age." 2019. NCHS Data Brief 155, 2014b, www.cdc.gov/nchs/data/databriefs/db155.pdf. Accessed January 4, 2019.

Pasupathy, Dharmintra, Angela M. Wood, Jill P. Pell, Michael Fleming, and Gordon CS Smith. "Time of Birth and Risk of Neonatal Death at Term: Retrospective Cohort Study.” Bmj 341 (2010): c3498.

Pillod, Rachel A., Mekhala Dissanayake, Yvonne W. Cheng, and Aaron B. Caughey. 2019. Association of widespread adoption of the 39-week rule with overall mortality due to stillbirth and infant death. JAMA Pediatrics 173, no. 2: 1180-1185.

Restrepo, Elizabeth, Patricia Hamilton, Fuqin Liu, and Peggy Mancuso. "Relationships among Neonatal Mortality, Hospital Volume, Weekday Demand, and Weekend Birth." Canadian Journal of Nursing Research 50, No. 2 (2018): 64-71.

Rindfuss, Ronald R., Judith L. Ladinsky, Elizabeth Coppock, Victor W. Marshall, and A. S. Macpherson. "Convenience and the Occurrence of Births Induction of Labor in the United States and Canada." International Journal of Health Services 9, No. 3 (1979): 439460.

Royer, H., 2009. "Separated at Girth: US twin Estimates of the Effects of Birth Weight." American Economic Journal: Applied Economics, 1(1), 49-85.

Saccone, Gabriele, and Vincenzo Berghella. "Omega-3 Supplementation to Prevent Recurrent Preterm Birth: A Systematic Review and Metaanalysis of Randomized 
Controlled Trials." American Journal of Obstetrics and Gynecology 213, No. 2 (2015): 135140.

Saez, Emmanuel. "Do Taxpayers Bunch at Kink Points?” American Economic Journal: Economic Policy 2.3 (2010): 180-212.

Schulkind, Lisa, and Teny Maghakian Shapiro. "What a Difference a Day Makes: Quantifying the Effects of Birth Timing Manipulation on Infant Health.” Journal of Health Economics 33 (2014): 139-158.

Smith, Caroline, Caroline A. Crowther, and Suzanne J. Grant. "Acupuncture for Induction of Labour." Cochrane Database of Systematic Reviews 8 (2013).

Spong, Catherine Y., Brian M. Mercer, Mary D'Alton, Sarah Kilpatrick, Sean Blackwell, and George Saade. "Timing of Indicated Late-Preterm and Early-Term Birth." Obstetrics and Gynecology 118, No. 2 Pt 1 (2011): 323.

Stephansson, Olof, Paul W. Dickman, Anna LV Johansson, Helle Kieler, and Sven Cnattingius. "Time of Birth and Risk of Intrapartum and Early Neonatal Death.” Epidemiology (2003): 218-222.

Tamm, Marcus. "The impact of a large parental leave benefit reform on the timing of birth around the day of implementation." Oxford Bulletin of Economics and Statistics 75, No. 4 (2013): 585-601.

Tita, A.T., Landon, M.B., Spong, C.Y., Lai, Y., Leveno, K.J., Varner, M.W., Moawad, A.H., Caritis, S.N., Meis, P.J., Wapner, R.J. and Sorokin, Y., "Timing of Elective Repeat cesarean Delivery at Term and Neonatal Outcomes." New England Journal of Medicine 360, No. 2 (2009): 111-120.

Walker, Kate F., Philippa Wilson, George J. Bugg, Anna Dencker, and Jim G. Thornton. "Childbirth Experience Questionnaire: Validating its Use in the United Kingdom.” BMC Pregnancy and Childbirth 15, No. 1 (2015): 86.

Zhang, Jun, James Troendle, Uma M. Reddy, S. Katherine Laughon, D. Ware Branch, Ronald Burkman, Helain J. Landy et al. "Contemporary cesarean Delivery Practice in the United States." American Journal of Obstetrics and Gynecology 203, No. 4 (2010): 326e1.

Zhang, J., Landy, H.J., Branch, D.W., Burkman, R., Haberman, S., Gregory, K.D., Hatjis, C.G., Ramirez, M.M., Bailit, J.L., Gonzalez-Quintero, V.H. and Hibbard, J.U., "Contemporary Patterns of Spontaneous Labor with Normal Neonatal Outcomes." Obstetrics and Gynecology 116, No. 6 (2010): 1281. 


\section{Figure 1. Distribution of the Number of Births Across Different Days}

A. California, 2000-2016

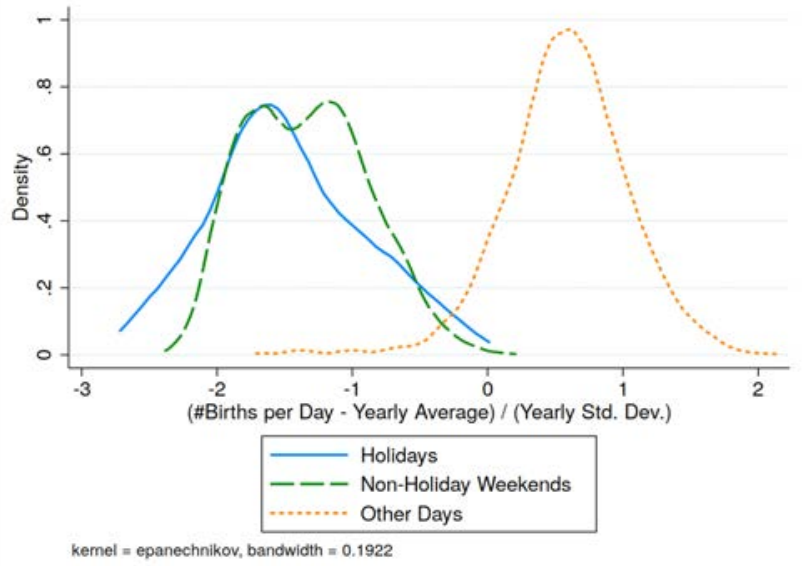

B. United States, 1968-1988

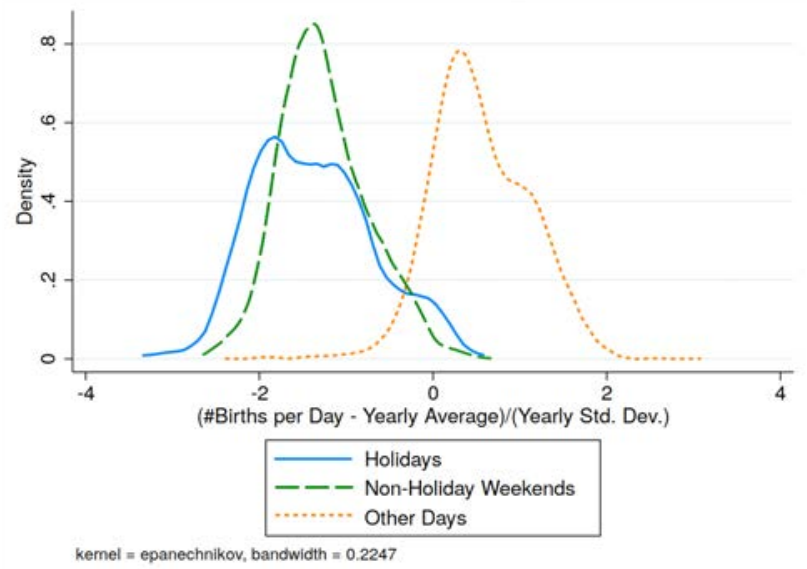

Notes: These figures show the distribution of daily births (as represented in Z-scores) for three types of days: holidays, nonholiday weekends, and other days. The top panel is for California and the bottom panel is for the entire United States. The set of holidays contains New Year's Day, Presidents' Day, Memorial Day, Independence Day, Labor Day, Thanksgiving, and Christmas Day. 
Figure 2: Graphical Representation of Estimation Strategy

A. Illustrative Example with a Hypothetical Manipulation Window

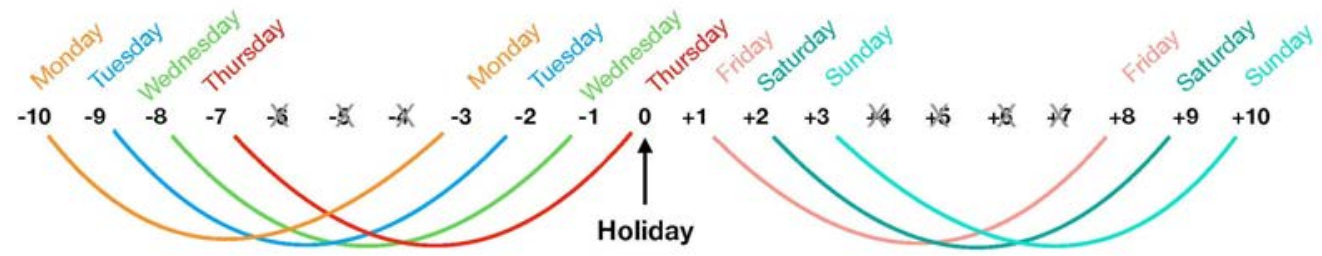

B. Estimated Manipulation Window

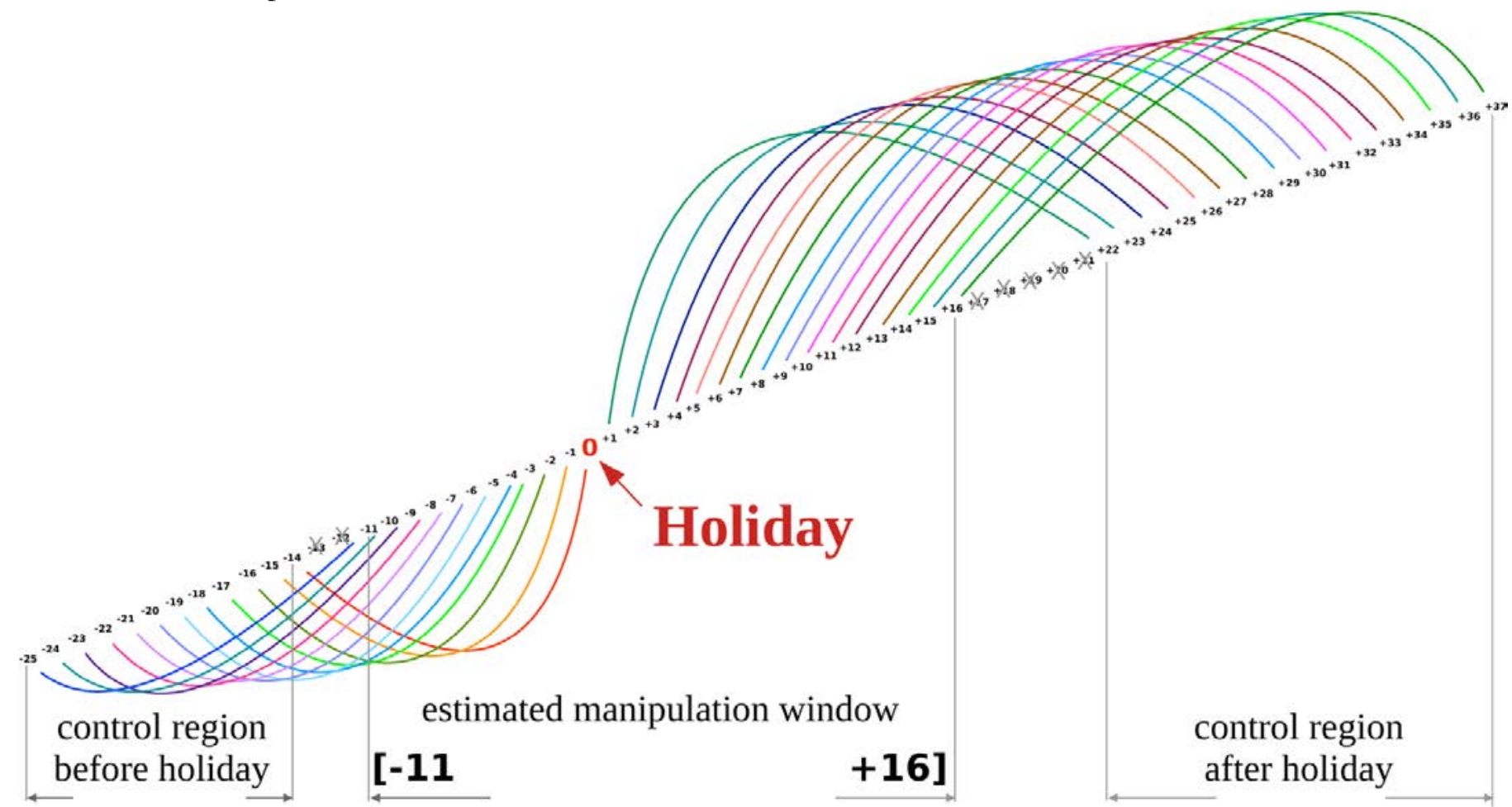

Notes: This figure illustrates how days in the manipulation window are matched with days of the same day of the week in the control region. Panel (A) illustrates this for a hypothetical example for which the estimated window is $[-3,+3]$ and all holidays fall on a Thursday. Since the control region before and after the holiday must include days that fall on the same day of the week, the control region for this hypothetical example contains davs 7-10 before and days 8-10 after a holiday. Panel (B) illustrates the matching prodecure for the actual estimated manipulation window, i.e., $[-11,+16]$. As all days are matched with the closest days that fall on the same day of the week in the control region, the control group therefore spans 14-25 days before a holiday and 22-37 days after a holiday. 
Figure 3. The Effect of a Holiday on the Daily Number of Births in California: 20002016

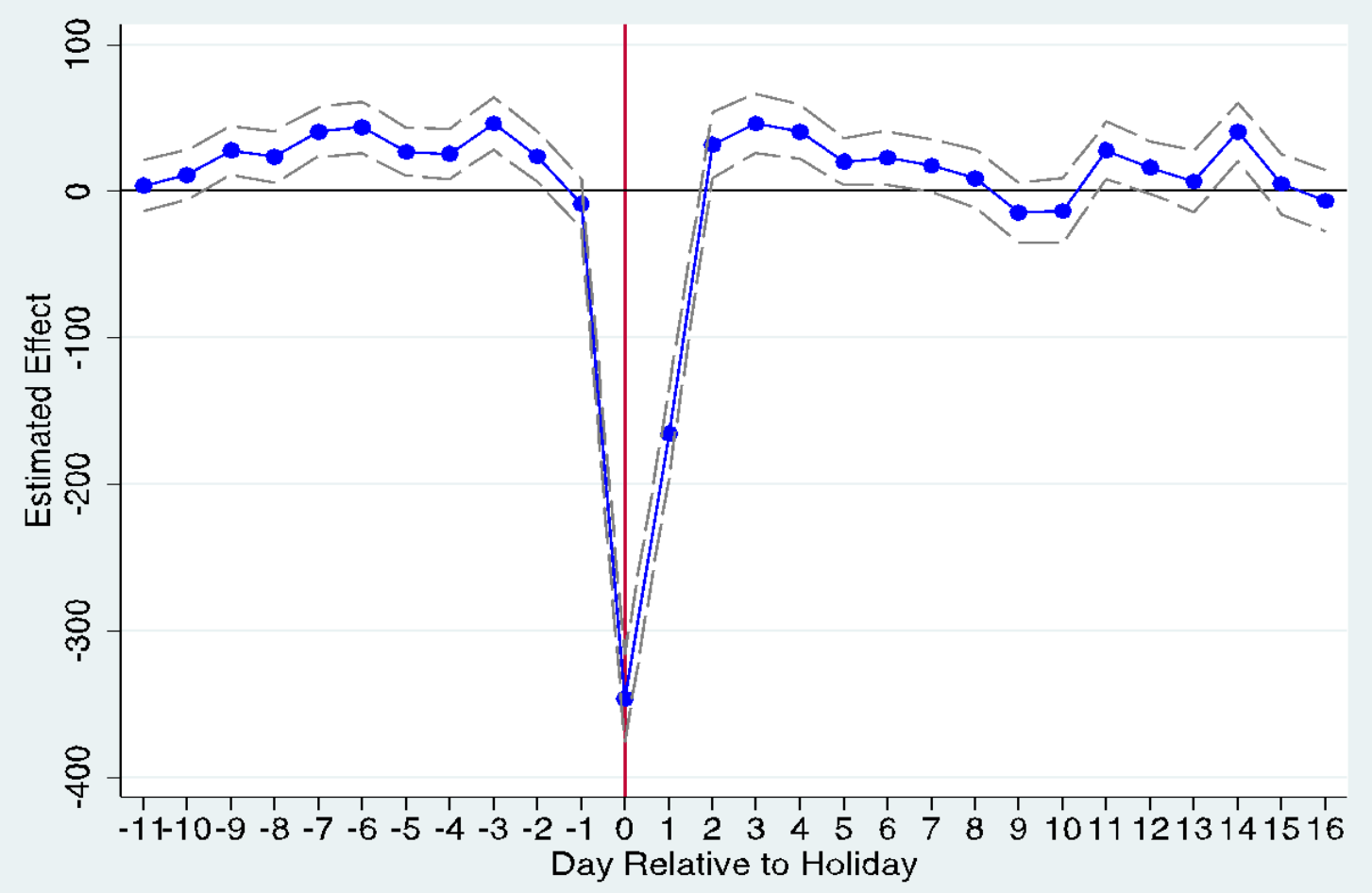

Notes: This figure shows the effect of a holiday on the daily number of births. Plotted are regression estimates from equation (2) with daily births as the dependent variable. On the $\mathrm{x}$-axis is the day relative to the holiday $(-1$ $=$ day before holiday, $1=$ day after holiday, etc.). On the $\mathrm{y}$-axis are estimates of the day relative to holiday dummy coefficients from equation (2) along with the $95 \%$ confidence interval. 
Figure 4. The Effect of a Holiday on the Daily Number of Births in California over Time

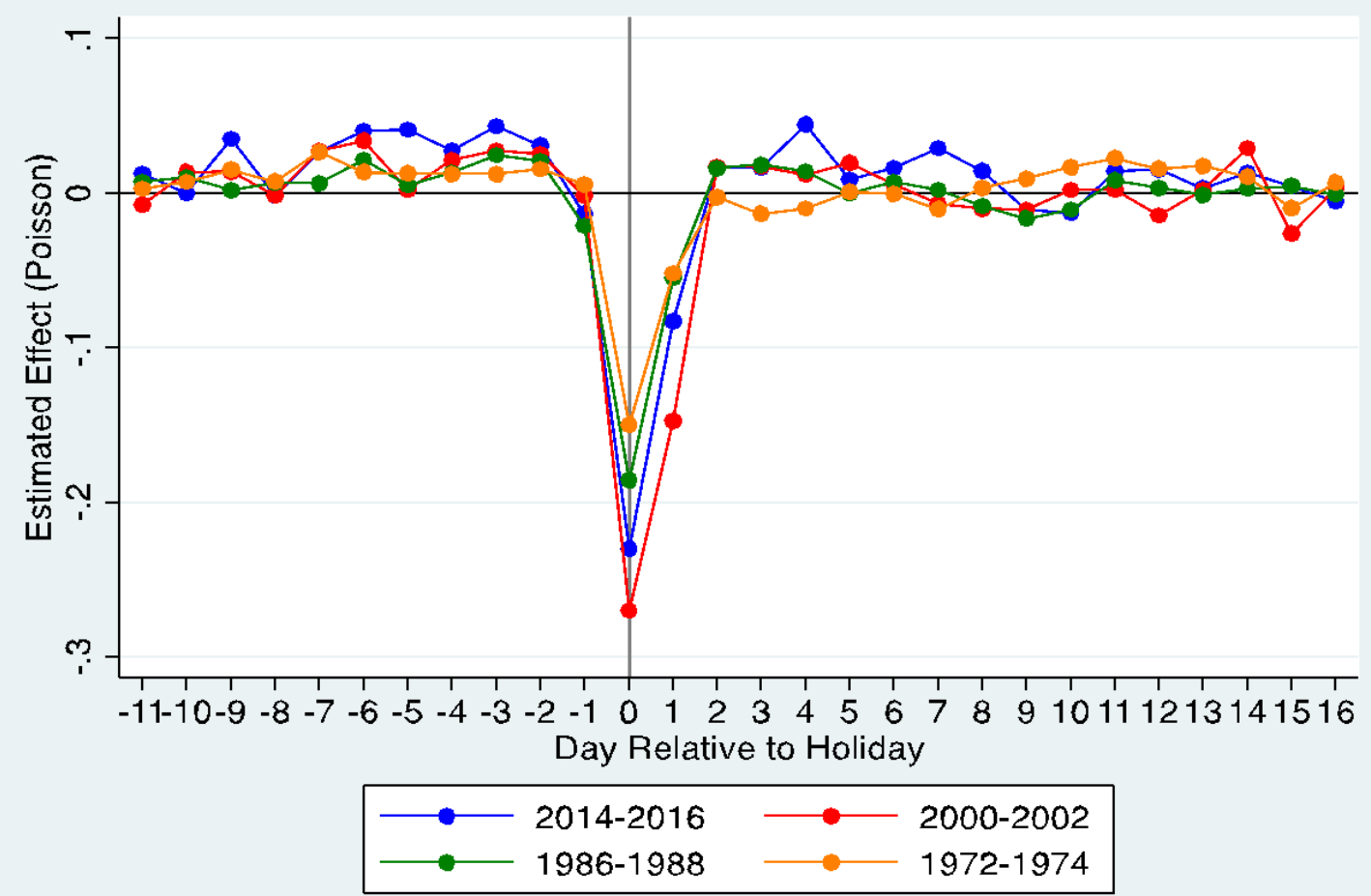

Notes: This figure shows the effect of a holiday on the daily number of births for different time periods (1972-1974, 1986-1988, 2000-2002, 2014-2016). Plotted are Poisson estimates of equation (2). On the x-axis is the day relative to the holiday $(-1=$ day before holiday, $1=$ day after holiday, etc.). On the $y$-axis are estimates of the day relative to holiday dummy coefficients from equation (2). 
Figure 5. Shift in the Number of Births due to a Holiday by Delivery Type in California: 2000-2016

A. Cesarean Section Births

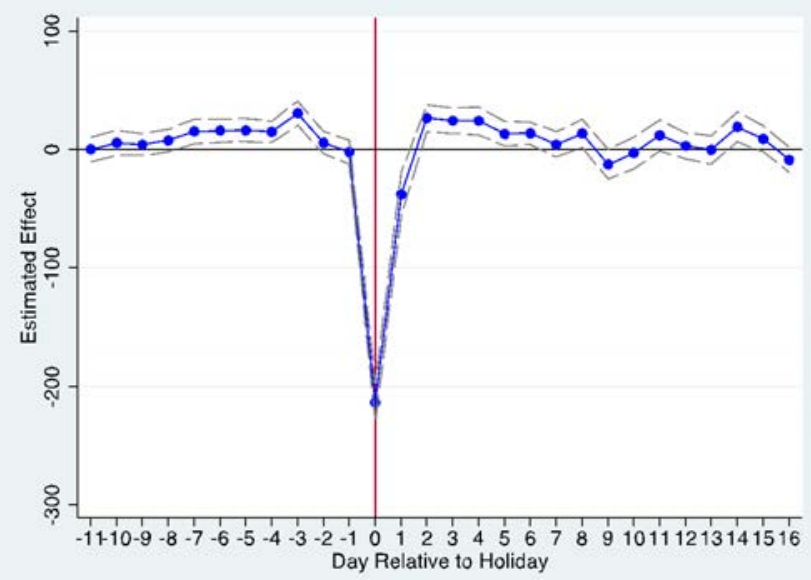

C. Spontaneous Vaginal Births

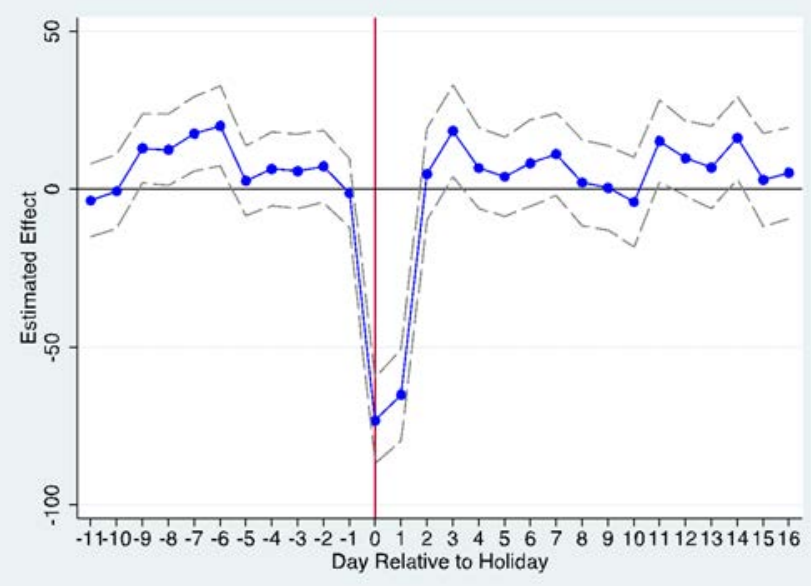

B. Induced/Stimulated Vaginal Births

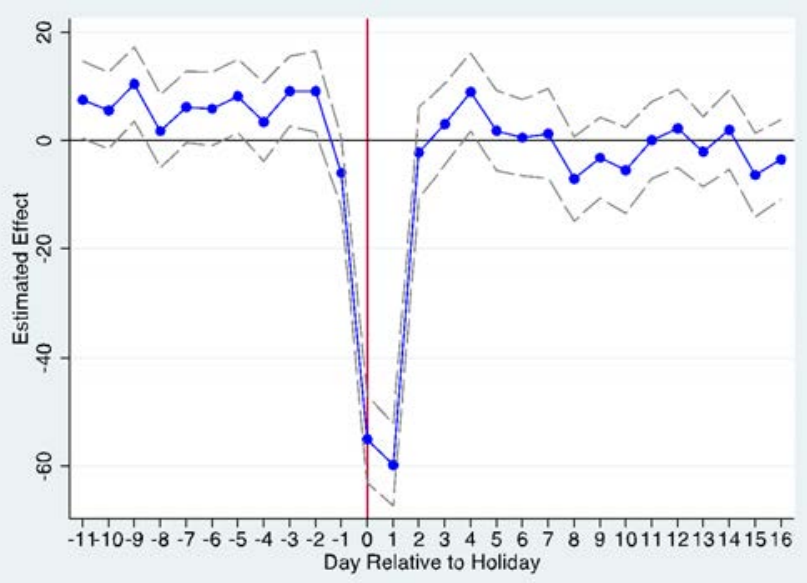

Notes: This figure shows the effect of a holiday on the daily number of cesarean section births (Panel A), induced/stimulated vaginal births (Panel B), and spontaneous vaginal births (Panel C). Plotted are regression estimates from equation (2). On the $\mathrm{x}-$ axis is the day relative to the holiday $(-1=$ day before holiday, $1=$ day after holiday, etc.). On the $y$-axis are estimates of the day relative to holiday dummy coefficients from equation (2) along with the $95 \%$ confidence interval. 
Figure 6. Shift in Births due to a Holiday by Gestational Length in California: 2000-2016

A. Mean Gestational Length in Days

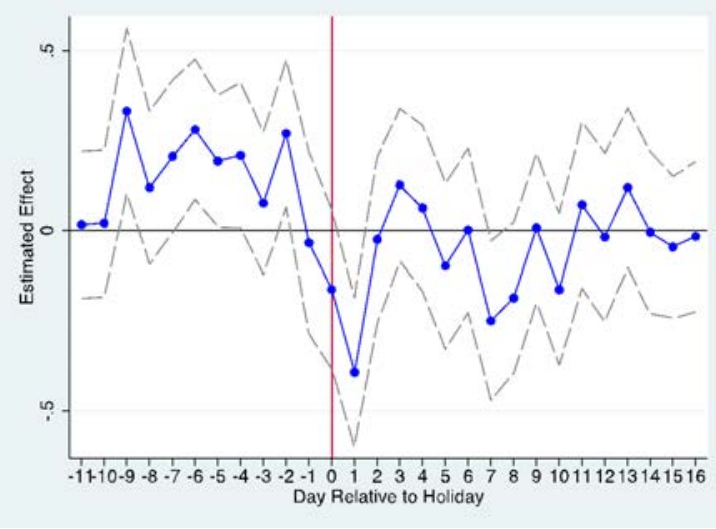

D. Number of Full Term Births

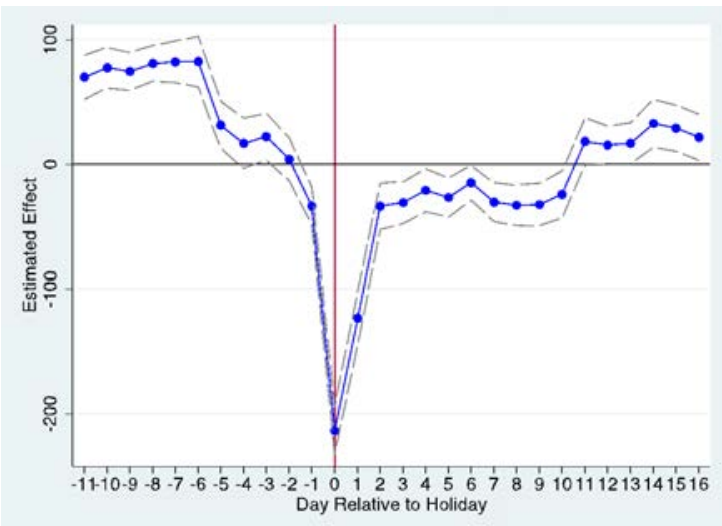

B. Number of Pre-Term Births

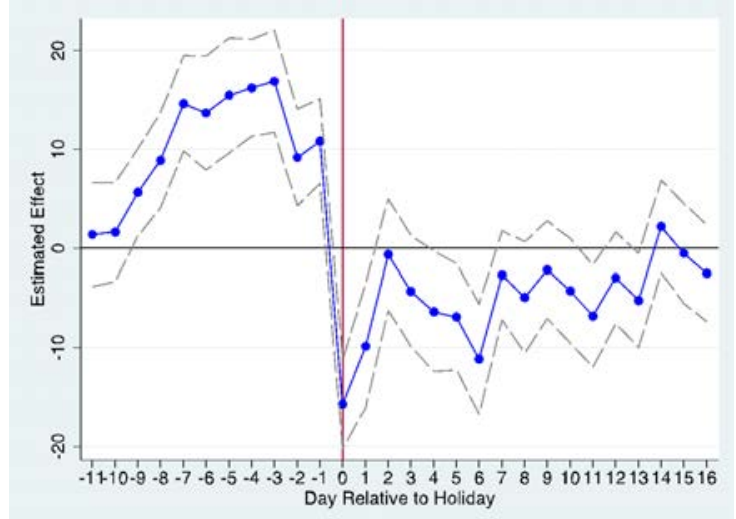

E. Number of Late Term Births

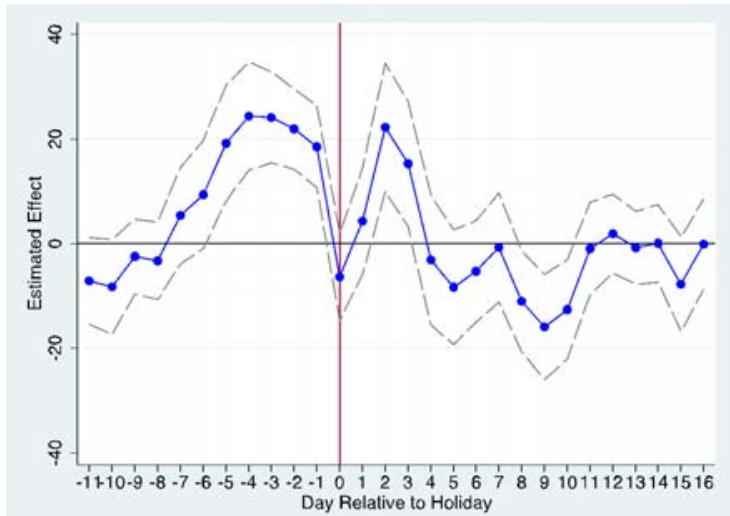

C. Number of Early Term Births

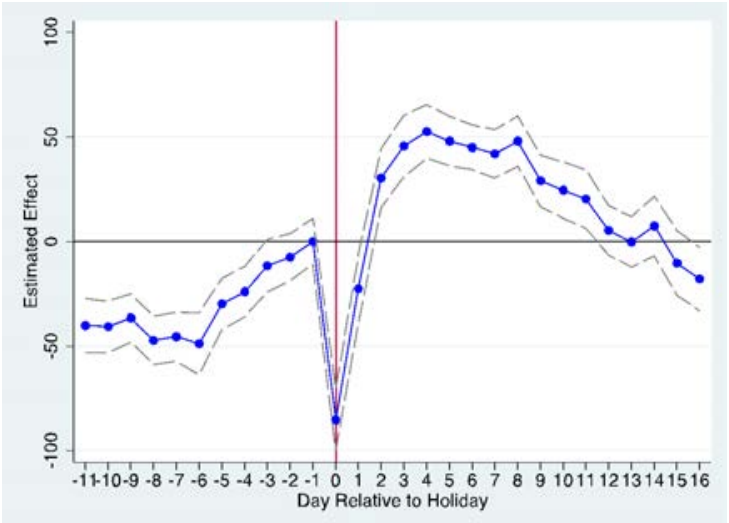

F. Number of Post-Term Births

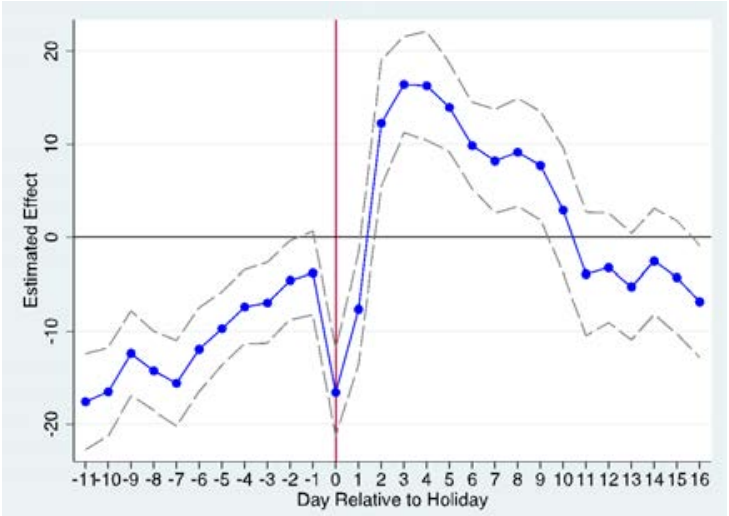

Notes: This figure shows the effect of a holiday on the mean gestation length (Panel A) as well as the number of daily births by term length category: pre-term meaning before 37 weeks (Panel B); early term or 37 0/7 weeks to 38 6/7 weeks (Panel C); full term or 39 0/7 weeks to 40 6/7 weeks (Panel D), late term or 41 0/7 weeks to 41 6/7 weeks (Panel E); and post-term or 42 weeks and later (Panel F). Plotted are regression estimates from equation (2). On the $\mathrm{x}$-axis is the day relative to the holiday $(-1=$ day before holiday, $1=$ day after holiday, etc.). On the $y$-axis are estimates of the day relative to holiday dummy coefficients from equation (2) along with the $95 \%$ confidence interval. 
Figure 7. Shift in the Number of Births due to a Holiday by Maternal Characteristics in California: 2000-2016

A. Low-Risk Pregnancy

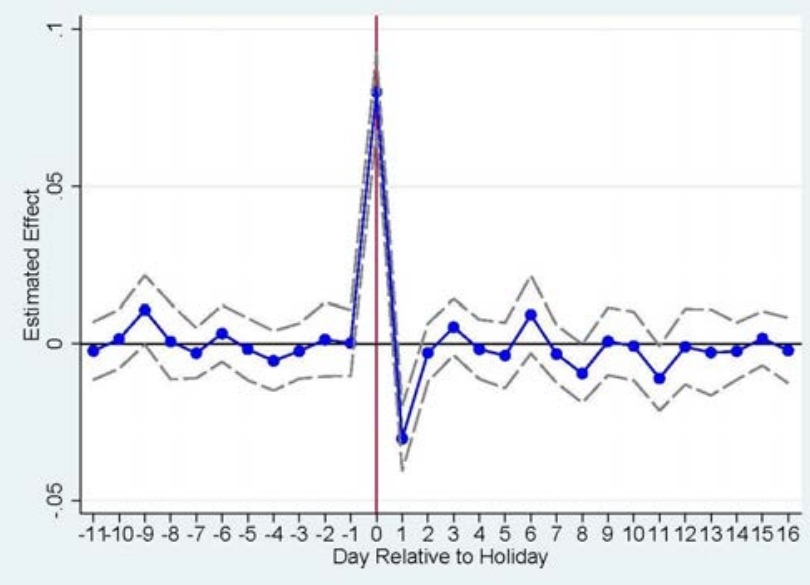

C. White Mother

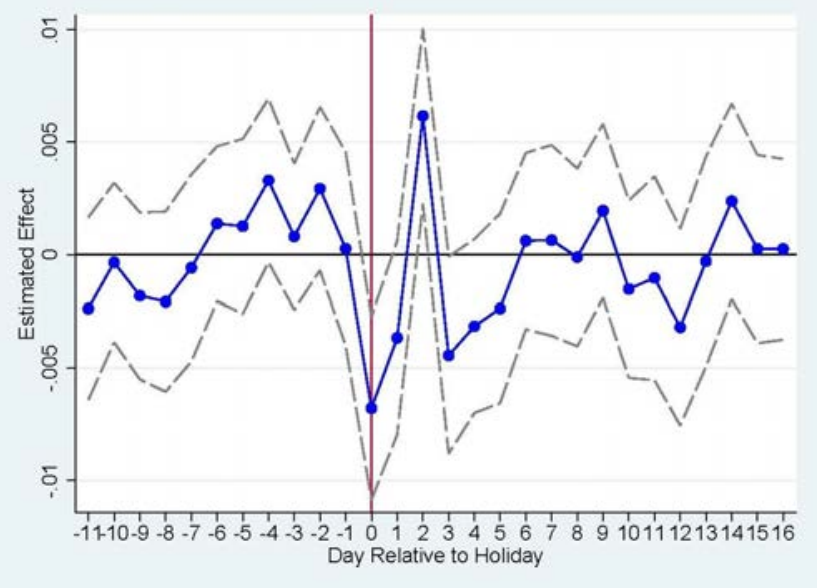

B. Age of Mother over 35

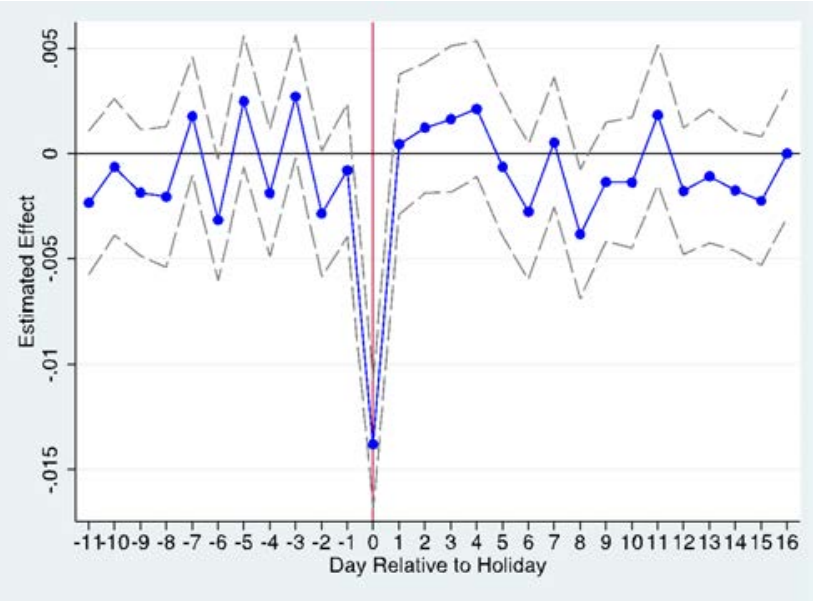

D. Teenage Mother

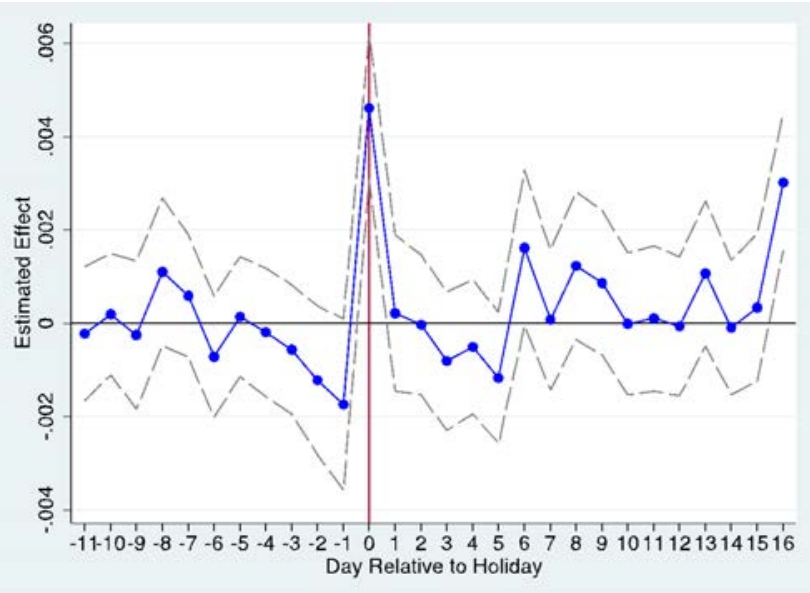

Notes: This figure shows the effect of a holiday on the fraction of births that are low risk (Panel A), fraction of births born to a mother over 35 (Panel B), fraction of births to a white mother (Panel C), and fraction of births to a teenage mom (Panel D).

Plotted are regression estimates from equation (2). On the $\mathrm{x}$-axis is the day relative to the holiday $(-1=$ day before holiday, $1=$ day after holiday, etc.). On the y-axis are estimates of the day relative to holiday dummy coefficients from equation (2) along with the $95 \%$ confidence interval. 
Figure 8. Birth Outcomes Contrasted with Counterfactual by Day Relative to Holiday in California: 2000-2016

A. Mean Birth Weight in Grams

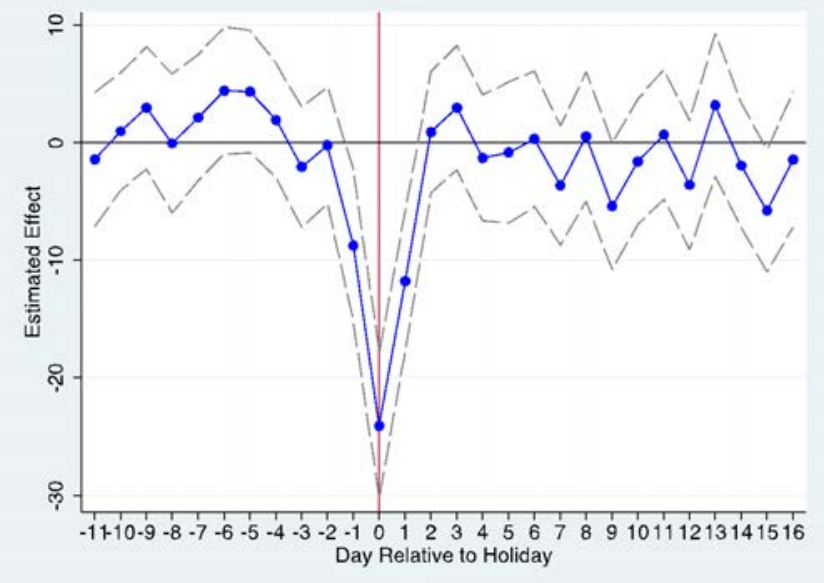

C. Any Labor Complications

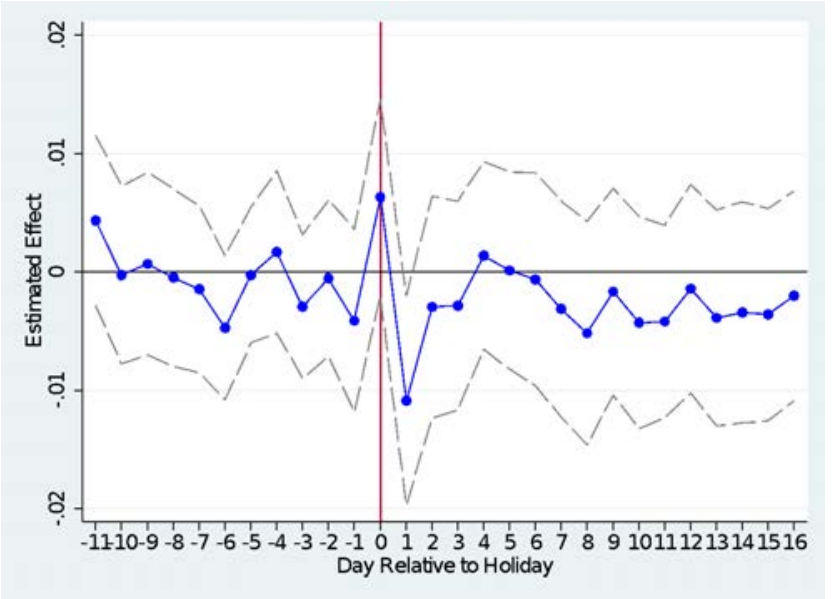

B. Any Newborn Conditions

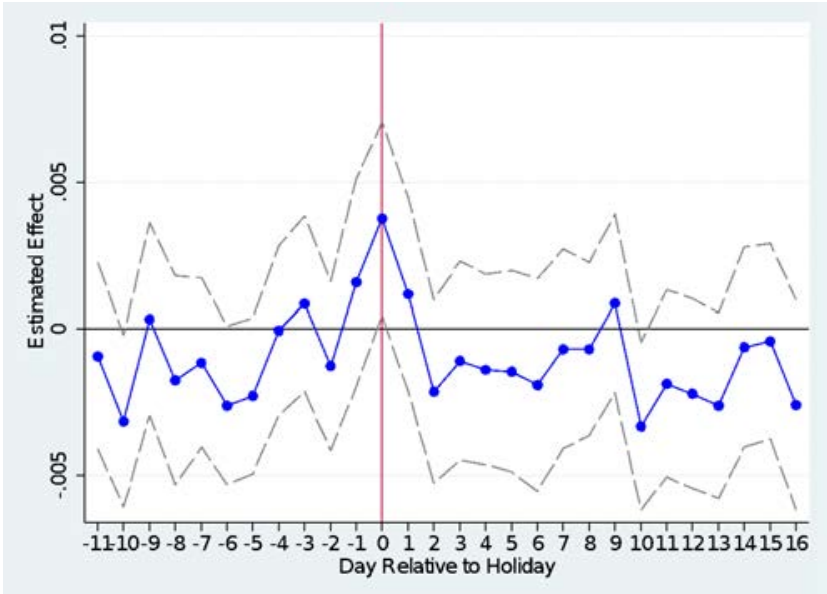

Notes: This figure shows the effect of a holiday on mean birth weight (Panel A), fraction of births with a noted newborn condition (Panel B) and the fraction of births with a noted labor complication (Panel C). Plotted are regression estimates from equation (2). On the $\mathrm{x}$-axis is the day relative to the holiday ( $-1=$ day before holiday, $1=$ day after holiday, etc.). On the $\mathrm{y}$-axis are estimates of the day relative to holiday dummy coefficients from equation (2) along with the $95 \%$ confidence interval. 
Figure 9. Shift in the Number of Births due to a Holiday for High-Risk Pregnancies in California: 2000-2016

A. Births

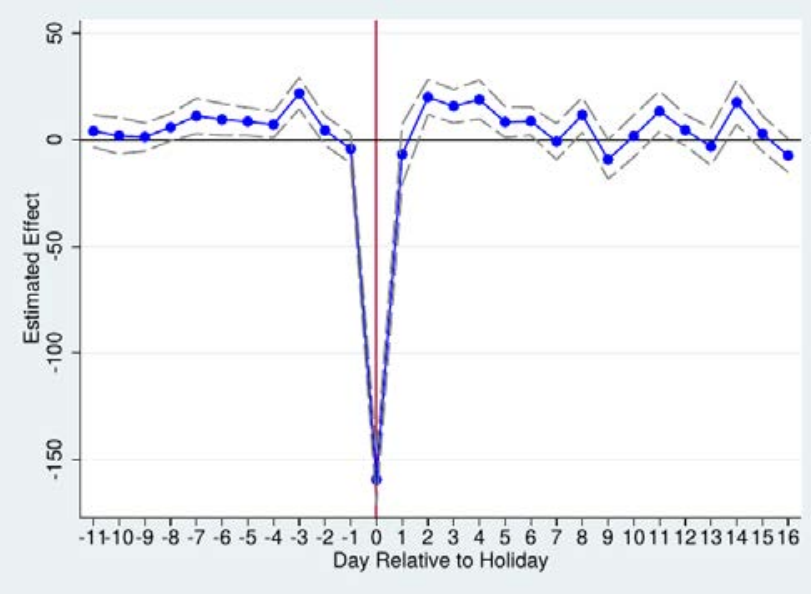

B. Cesarean Section Deliveries

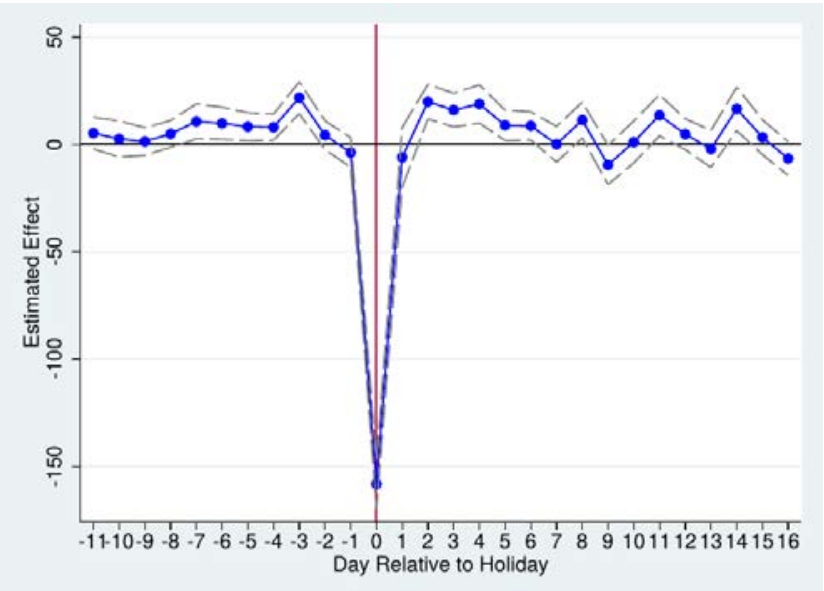

Notes: This figure shows the effect of a holiday for high-risk pregnancies on the daily number of births (Panel A) and the number of cesarean section deliveries (Panel B). Plotted are regression estimates from equation (2). On the $\mathrm{x}$-axis is the day relative to the holiday $(-1=$ day before holiday, $1=$ day after holiday, etc.). On the $y$-axis are estimates of the day relative to holiday dummies from equation (2) along with the $95 \%$ confidence interval. 
Figure 10. Shift in the Number of Births due to a Holiday by Gestational Length for High-Risk Pregancies in California: 2000-2016

A. Mean Gestational Length in Days

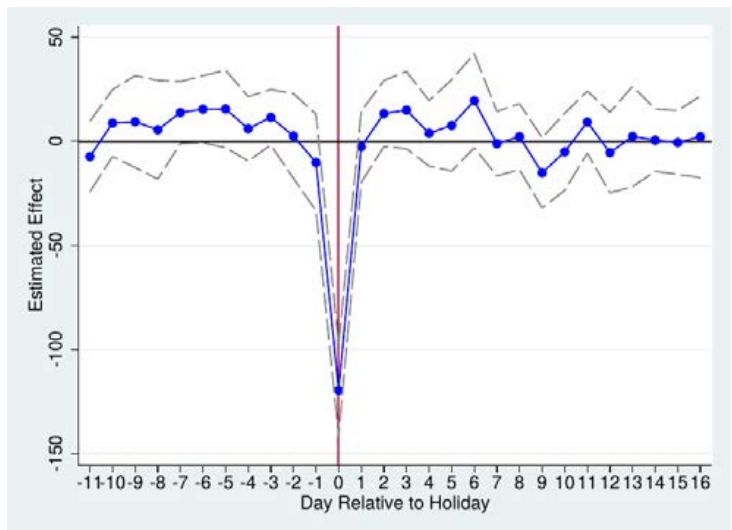

D. Number of Full Term Births

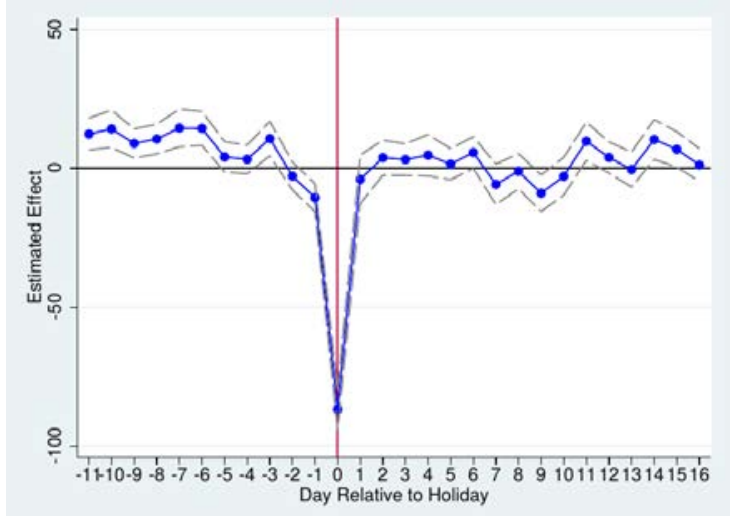

B. Number of Pre-Term Births

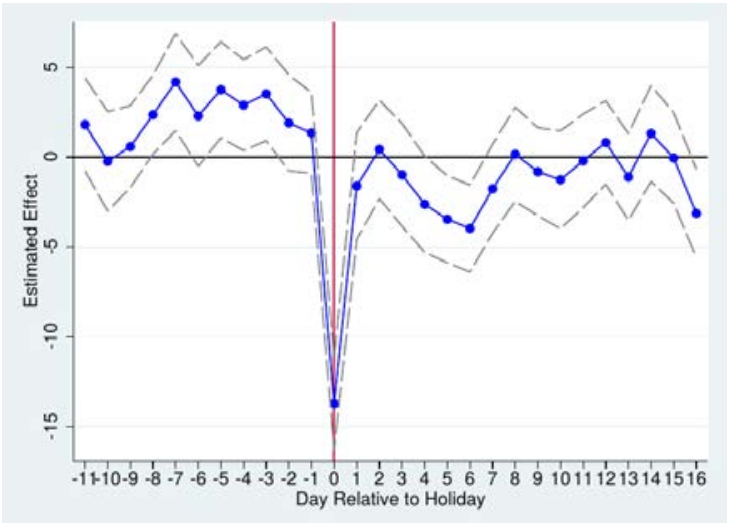

E. Number of Late Term Births

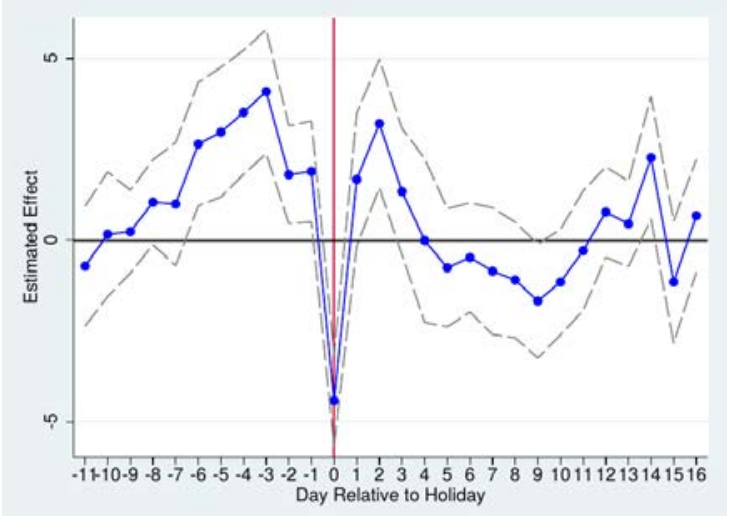

C. Number of Early Term Births

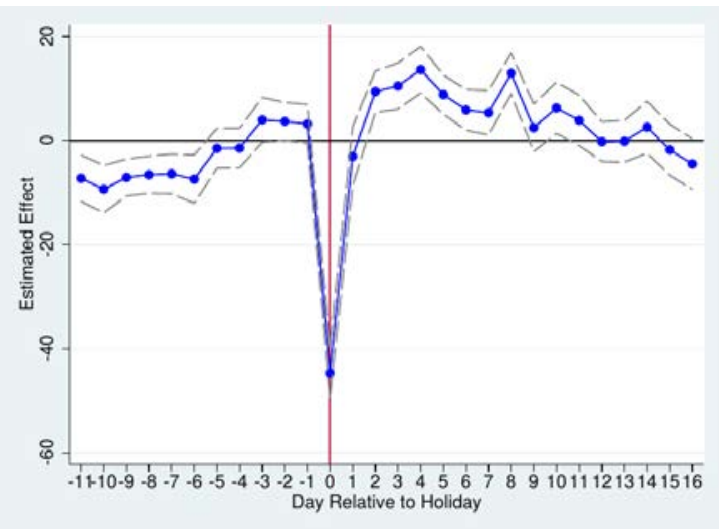

F. Number of Post-Term Births

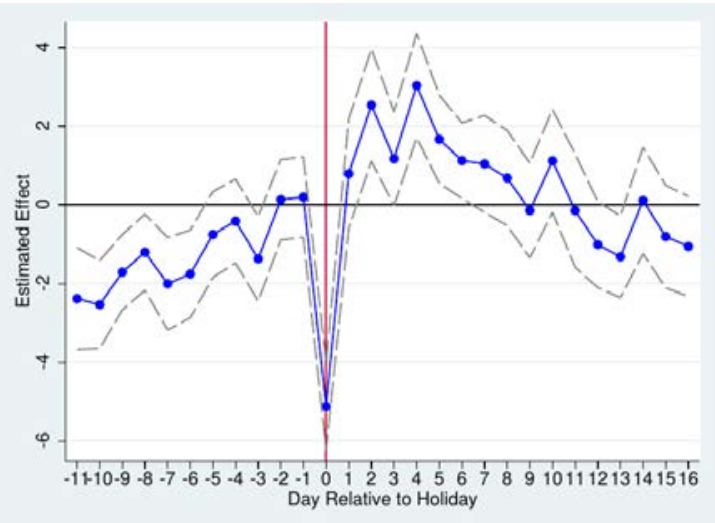

Notes: This figure shows the effect of a holiday on the mean gestation length (Panel A) as well as the number of daily births by term length category: pre-term meaning before 37 weeks (Panel B); early term or 37 0/7 weeks to 38 6/7 weeks (Panel C); full term or 39 0/7 weeks to 40 6/7 weeks (Panel D), late term or 41 0/7 weeks to 41 6/7 weeks (Panel E); and post-term or 42 weeks and later (Panel F) for high-risk pregnancies. Plotted are regression estimates from equation (2). On the x-axis is the day relative to the holiday $(-1=$ day before holiday, $1=$ day after holiday, etc.). On the $y$-axis are estimates of the day relative to holiday dummy coefficients from equation (2) along with the $95 \%$ confidence interval. 
Figure 11. Birth Outcomes Contrasted with Counterfactual by Day Relative to Holiday for HighRisk Births in California: 2000-2016

A. Mean Birth Weight in Grams

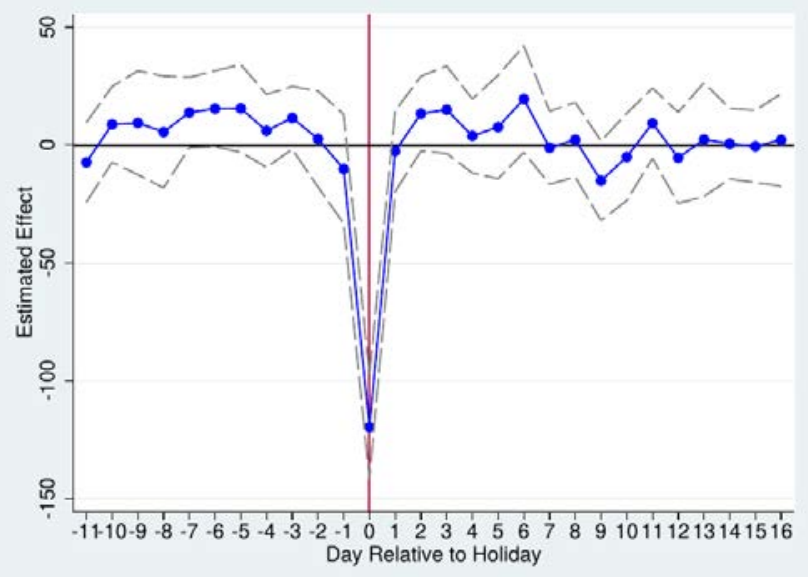

B. Any Newborn Conditions

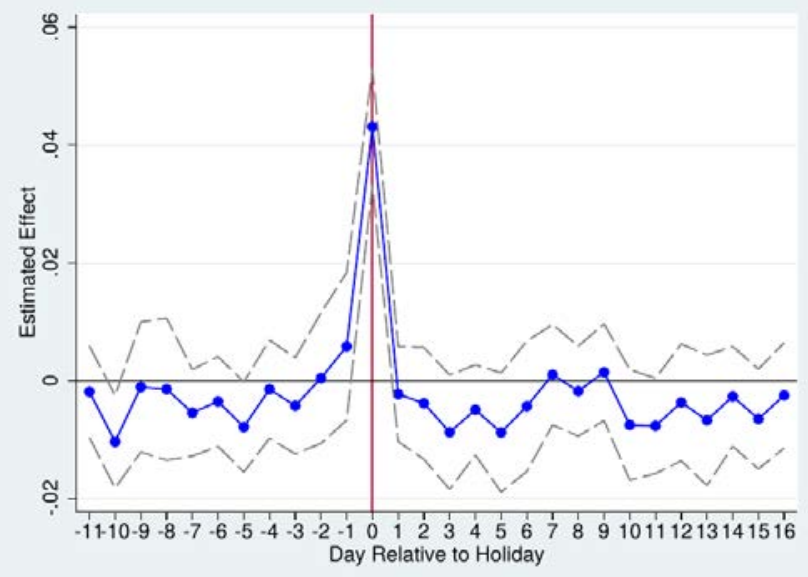

C. Any Labor Complications

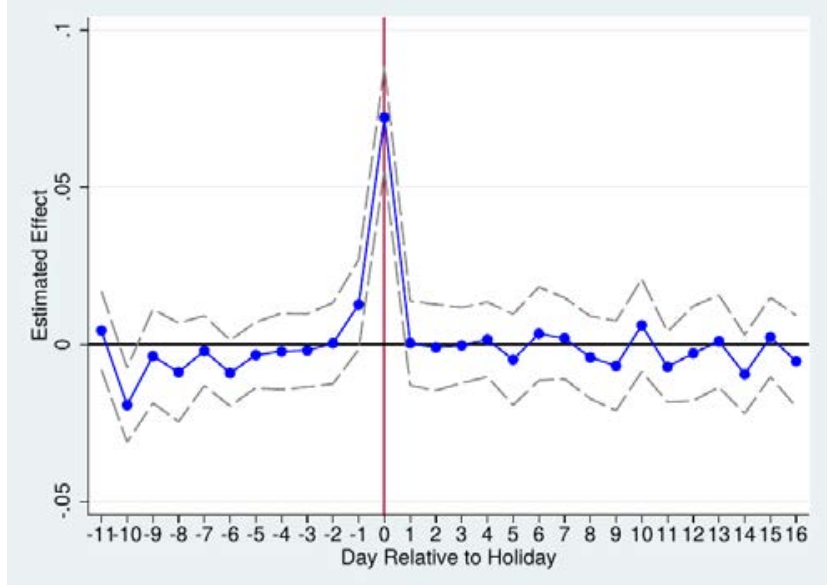

Notes: This figure shows the effect of a holiday on mean birth weight (Panel A), fraction of births with a noted newborn condition (Panel B), and the fraction of births with noted labor complication (Panel C) for high-risk pregnancies. Plotted are regression estimates from equation (2). On the $\mathrm{x}$-axis is the day relative to the holiday $(-1=$ day before holiday, $1=$ day after holiday, etc.). On the y-axis are estimates of the day relative to holiday dummy coefficients from equation (2) along with the $95 \%$ confidence interval. 


\section{Appendix Figure 1. Excess Births - Missing Births for Varying Windows around a Holiday}

Days after holiday

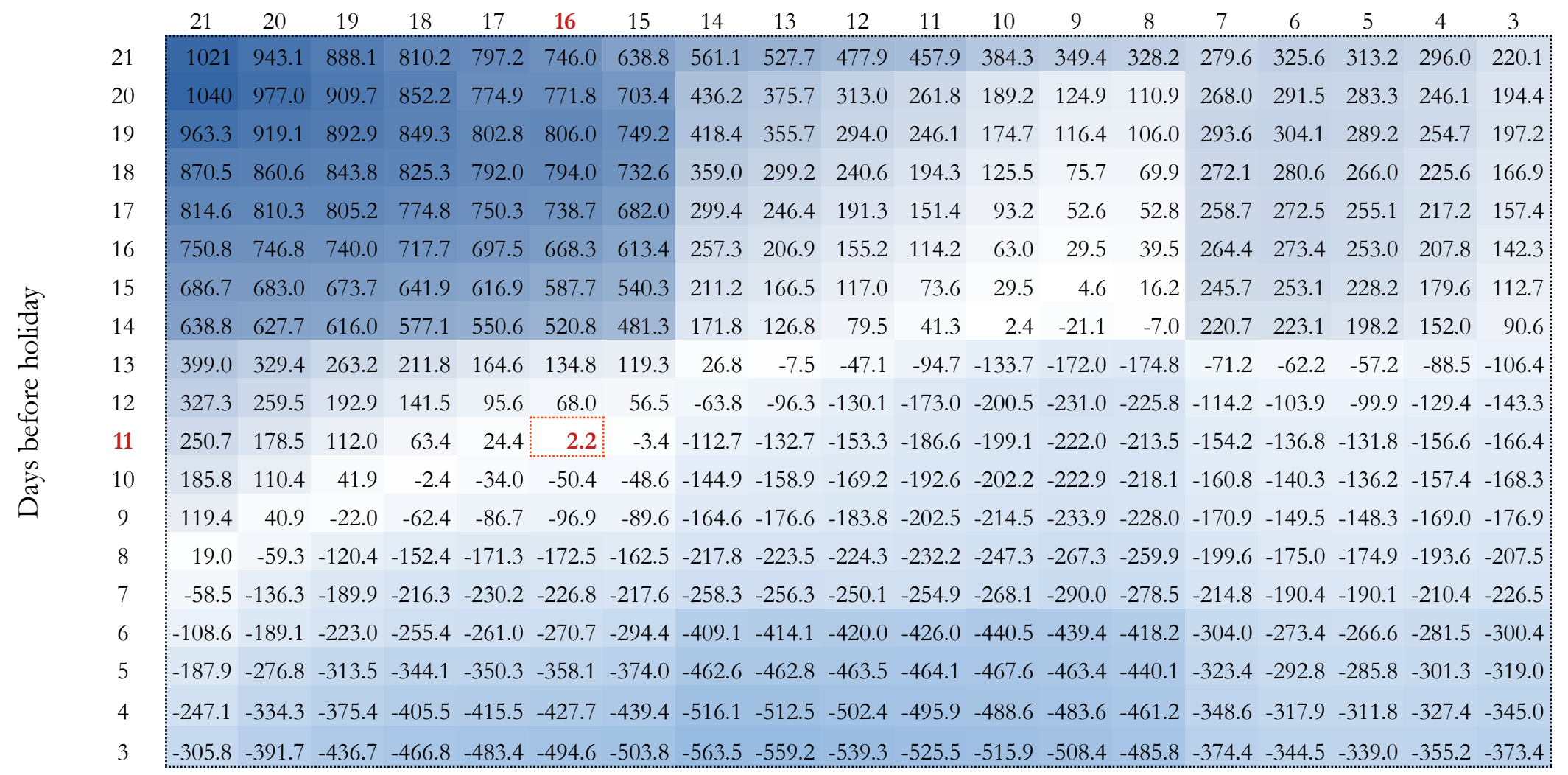

Notes: This figure shows the excess minus the missing number of births for varying windows around a holiday. We choose as the optimal window the one that minimizes the absolute value of this criterion. For our case, the optimal window is the range of days from 11 days before a holiday through 16 days after a holiday. 
Appendix Figure 2. Shift in the Number of Births due to a Holiday including Christmas and New Years in California: 2000-2016

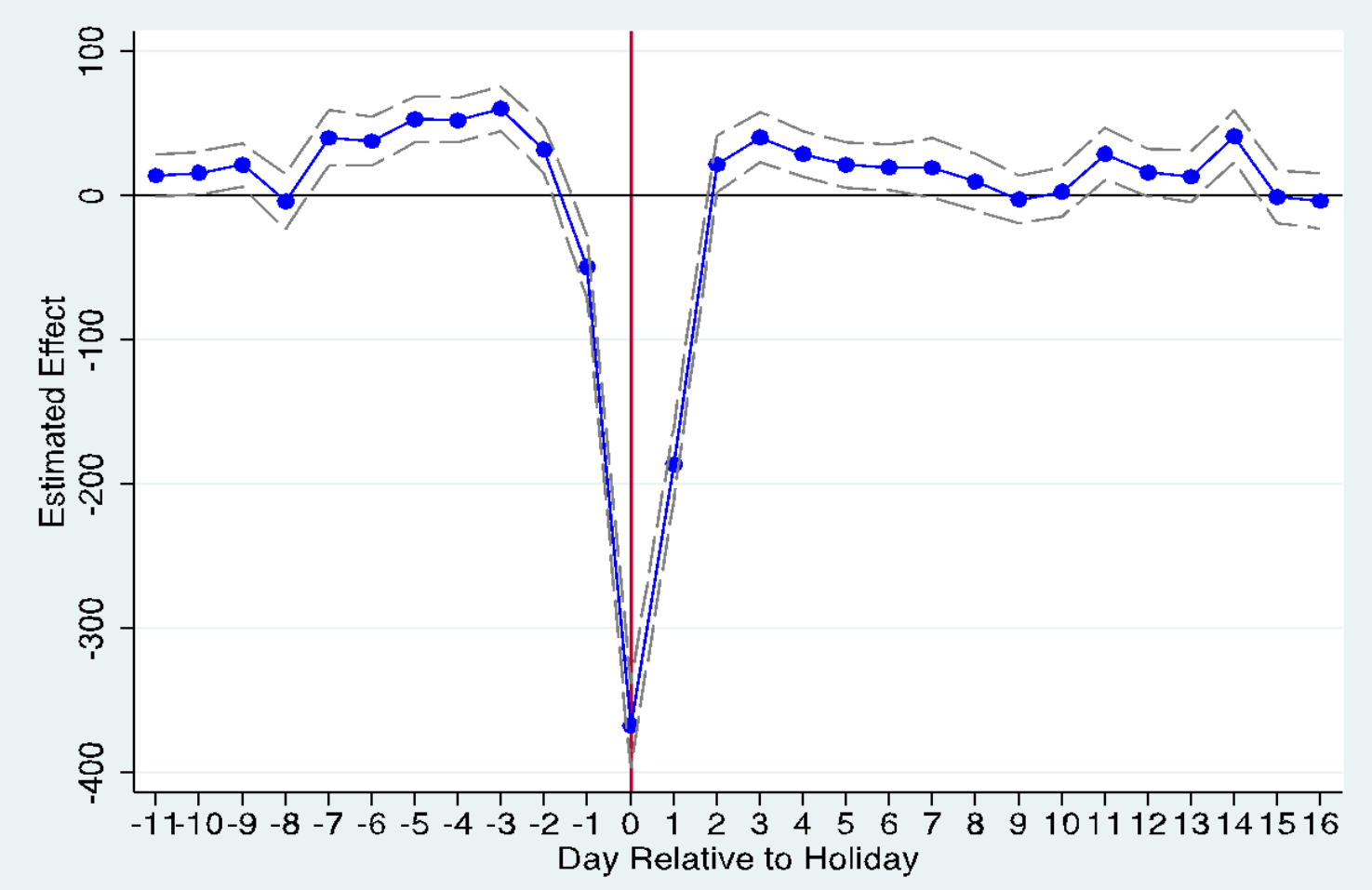

Notes: This figure shows the effect of a holiday on births. In this graph, the set of holidays considered is New Year's Day, Presidents' Day, Memorial Day, Independence Day, Labor Day, Thanksgiving, and Christmas. Plotted are regression estimates from equation (2). On the $\mathrm{x}$-axis is the day relative to the holiday $(-1=$ day before holiday, $1=$ day after holiday, etc.). On the y-axis are estimates of the day relative to holiday dummy coefficients from equation (2) along with the $95 \%$ confidence interval. 
Appendix Figure 3. The Holiday Decline by Specific Holiday

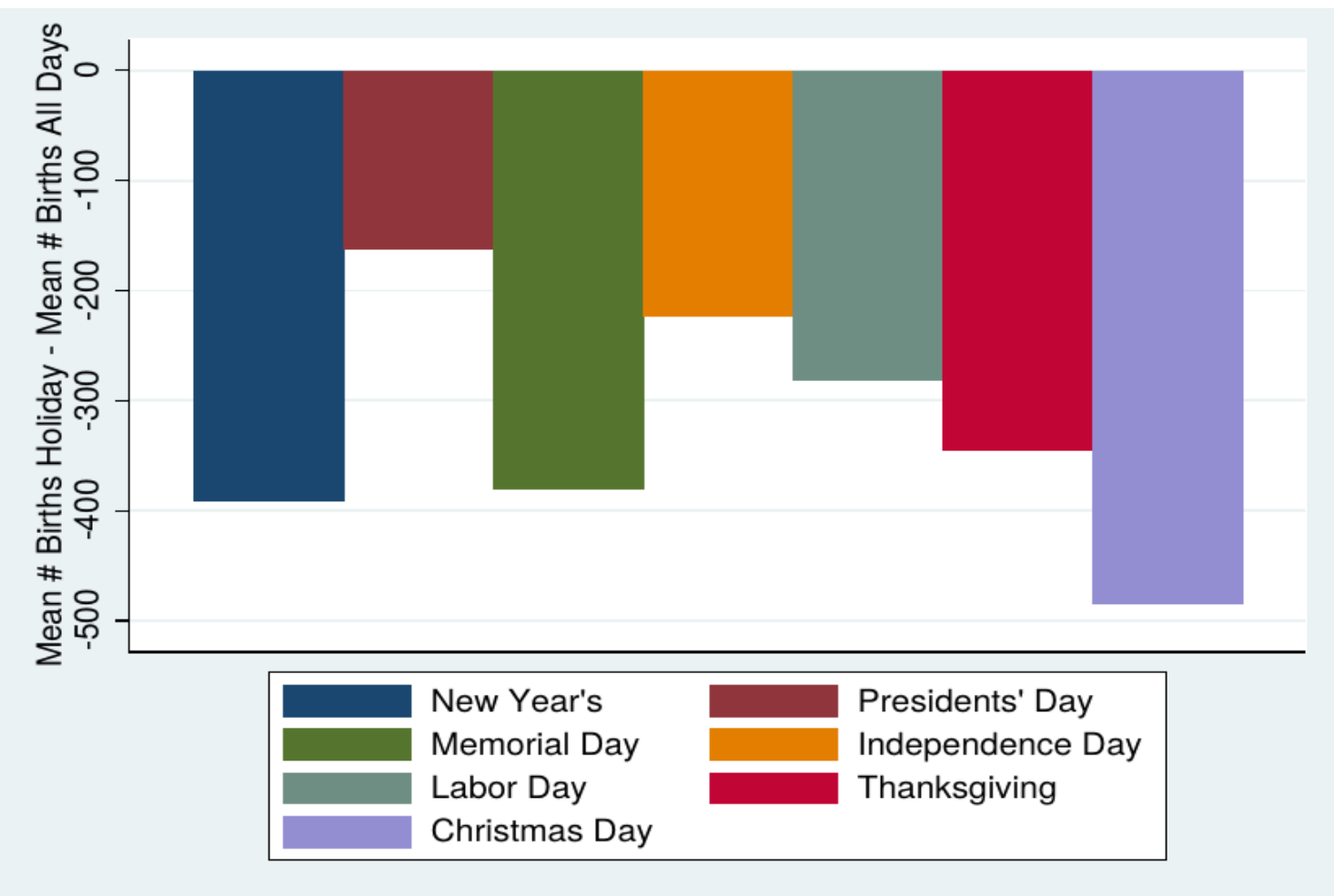

Notes: This figure shows, for each holiday, the mean number of births on that holiday minus the mean of the daily number of births for California from 2000-2016. 
Appendix Figure 4. Poisson Model Estimates of the Shift in the Number of Births due to a Holiday in California: 2000-2016

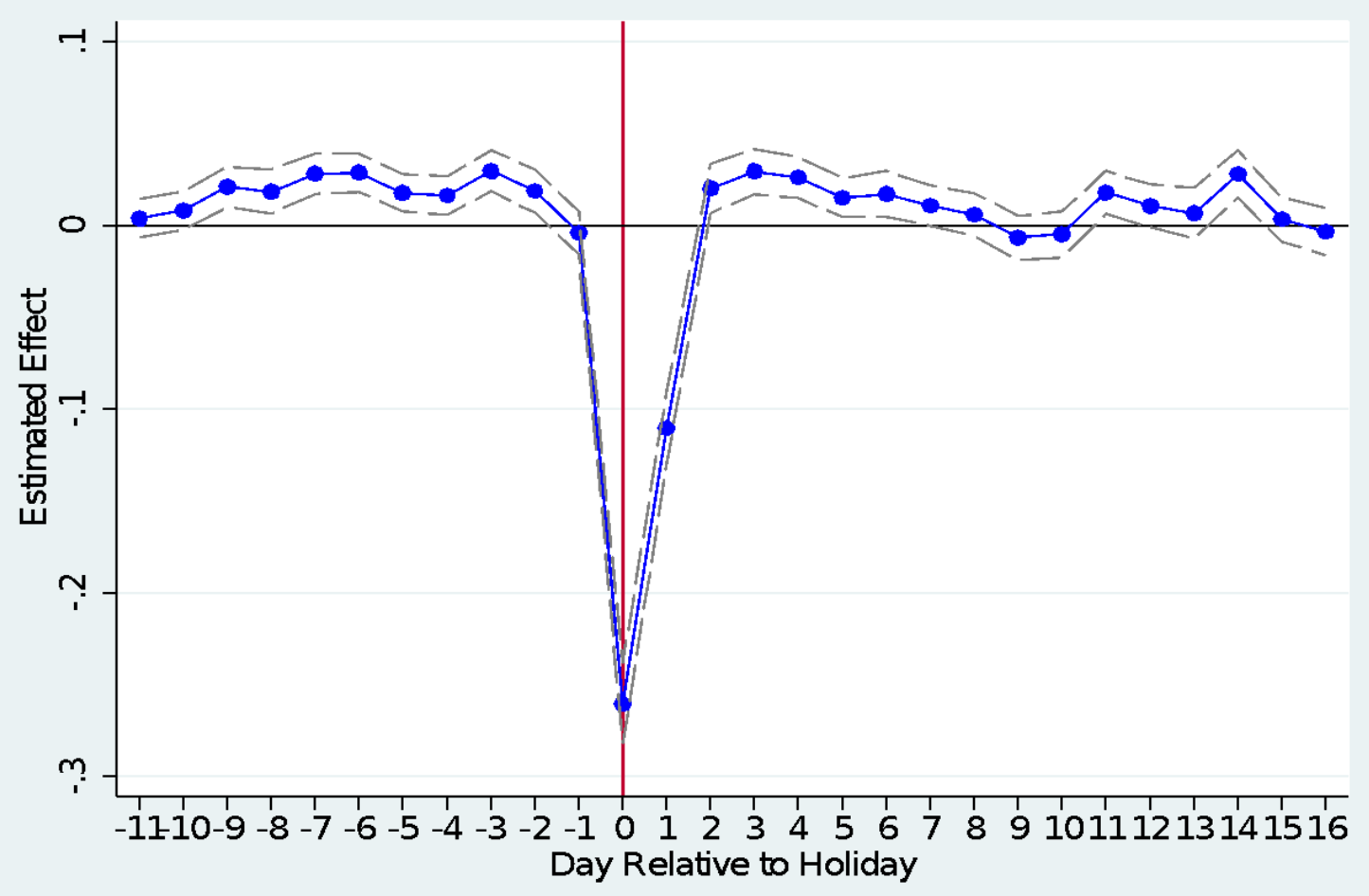

Notes: This figure shows the effect of a holiday on the daily number of births. Estimates are derived from a Poisson model. On the $\mathrm{x}$-axis is the day relative to the holiday $(-1=$ day before holiday, $1=$ day after holiday, etc.). On the y-axis are estimates of the day relative to holiday dummy coefficients from equation (2) along with the $95 \%$ confidence interval. 
Appendix Figure 5. Shift in the Number of Births due to a Holiday using Holidays that Rotate Days of the Week in California: 2000-2016

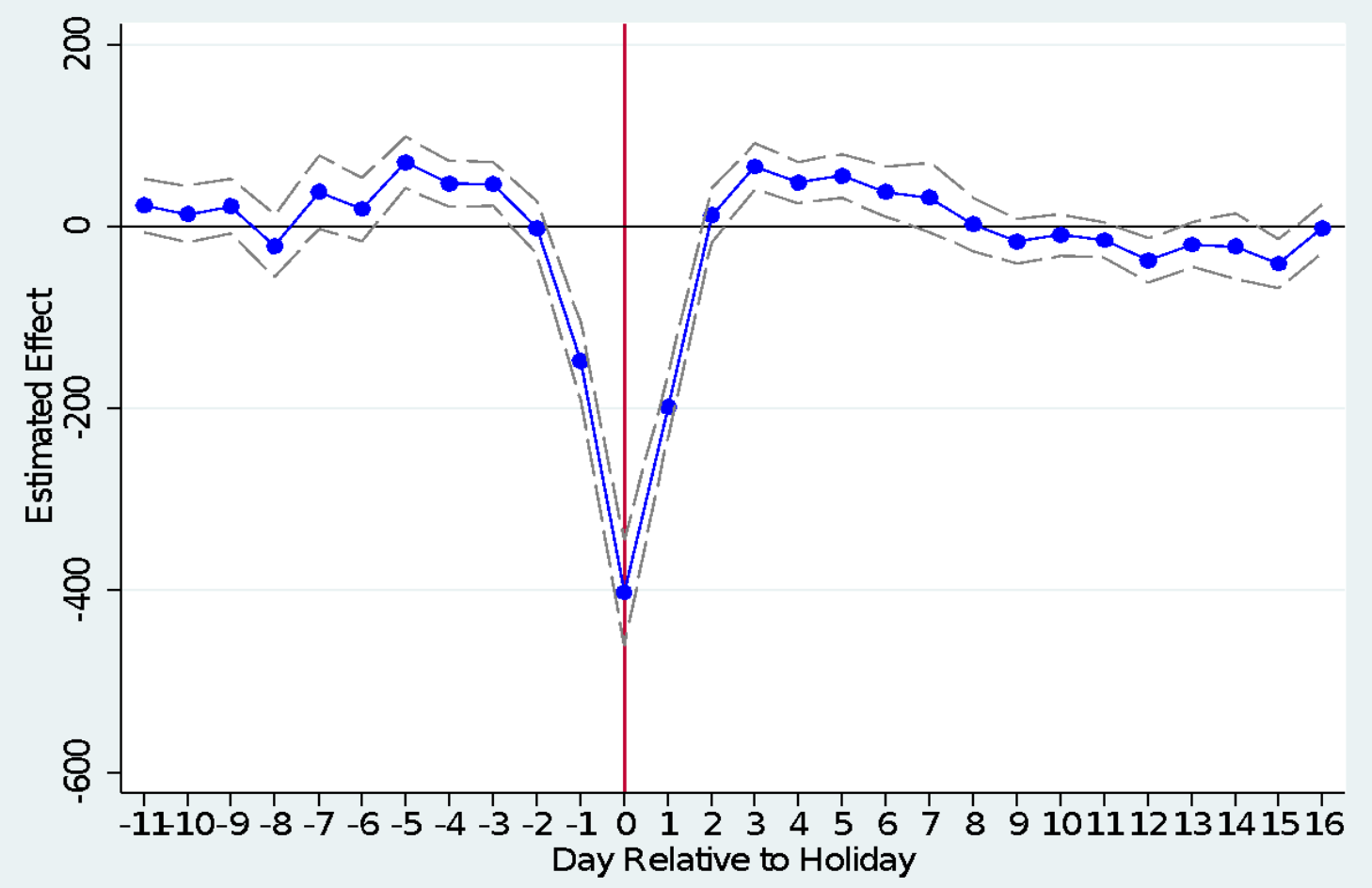

Notes: This figure shows the effect of a holiday on births. The holidays considered as those that do not occur on the same day of the week each year - New Year's Day, Independence Day, and Christmas. Plotted are regression estimates from equation (2). On the $\mathrm{x}$-axis is the day relative to the holiday $(-1=$ day before holiday, $1=$ day after holiday, etc.). On the y-axis are estimates of the day relative to holiday dummy coefficients from equation (2) along with the $95 \%$ confidence interval. 


\section{Appendix Figure 6: Shift in the Number of Births due to a Holiday in California Varying the Holiday Window: 2000-2016}

A. Windows that are 3 Days Wider / Narrower Than Optimal Window

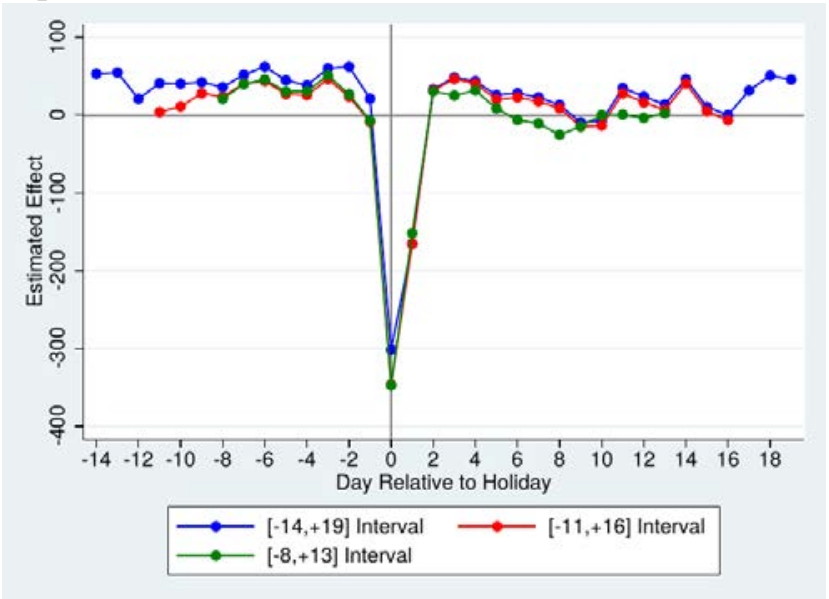

B. "Second-best" Optimal Windows, According to Grid Search

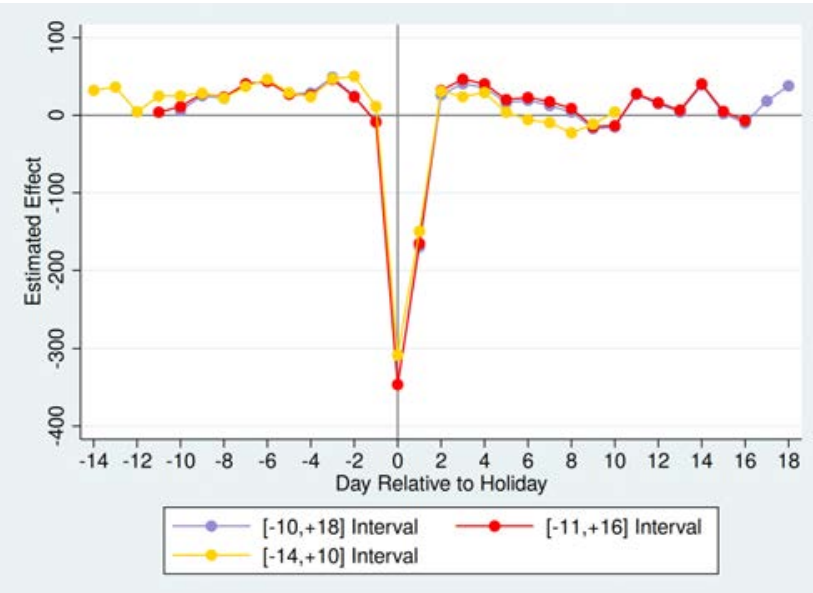

Notes: This figure shows the effect of a holiday on the daily number of births using different window sizes. Plotted are regression estimates from equation (2) with daily births as the dependent variable. On the $\mathrm{x}$-axis is the day relative to the holiday $(-1=$ day before holiday, $1=$ day after holiday, etc.). On the $\mathrm{y}$-axis are estimates of the day relative to holiday dummy coefficients from equation (2). Panel A displays both a narrower and a wider window around each holiday. The $[-8,+13]$ interval uses the days between 8 days before each holiday to 13 days after each holiday. The $[-14,+19]$ interval uses the days between 14 days before each holiday to 19 days after each holiday. The $[-11,+16]$ interval (our "optimal" window) uses the days between 11 days before and 16 days after. Panel B displays two windows that are "second-best" according to our grid search, as the absolute sum of the excess and missing numbers of births, as estimated in equation (1), are second-closest to zero. 


\section{Appendix Figure 7. Shift in the Number of Births due to September 11th (2001-2016) and Friday the 13th (2000-2016) in California}

A. Births

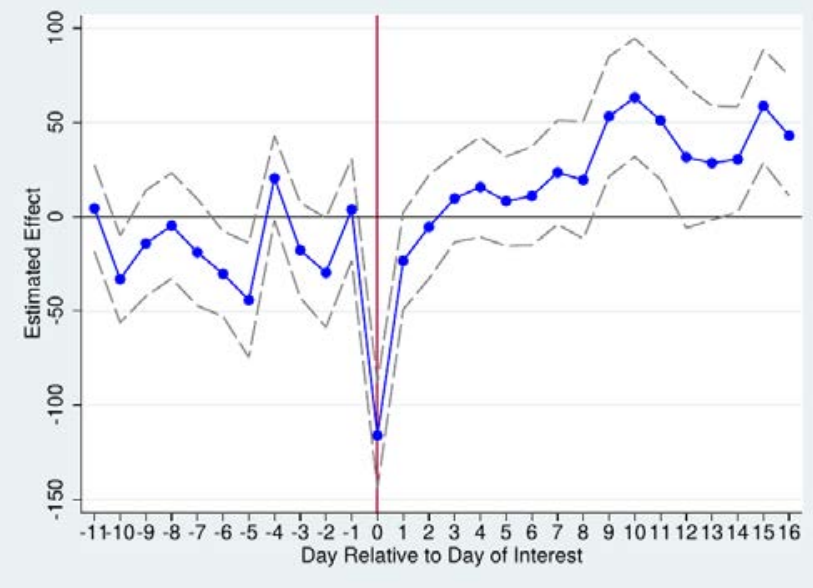

C. Spontaneous Vaginal Deliveries

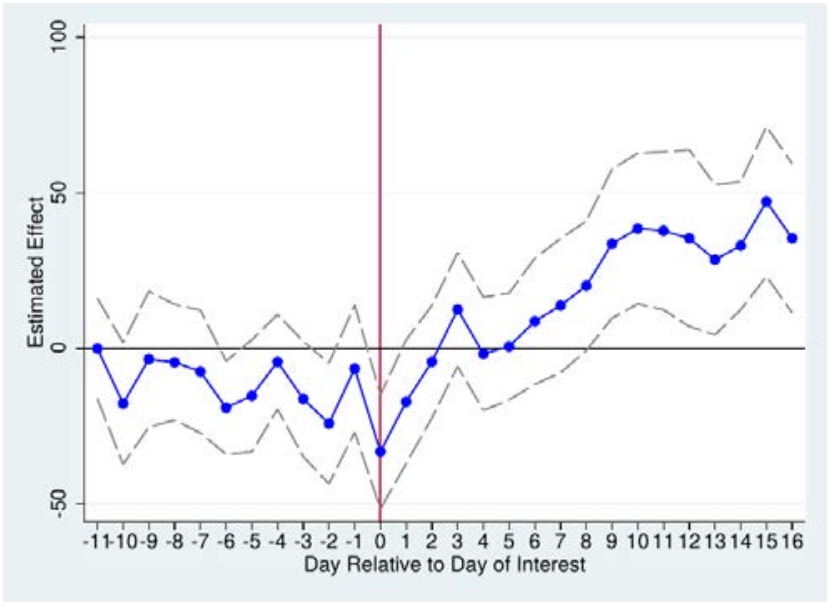

B. Cesarean Section Deliveries

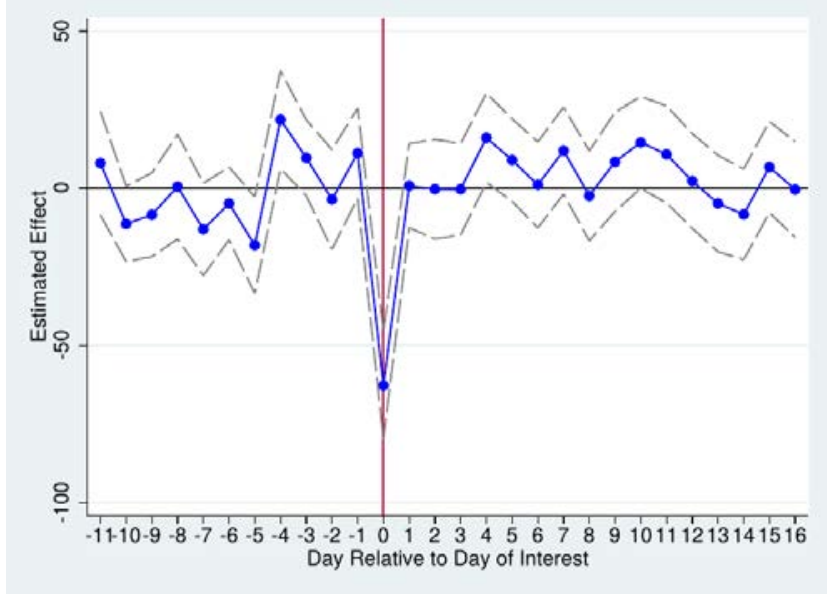

D. Induced/Stimulated Vaginal Deliveries

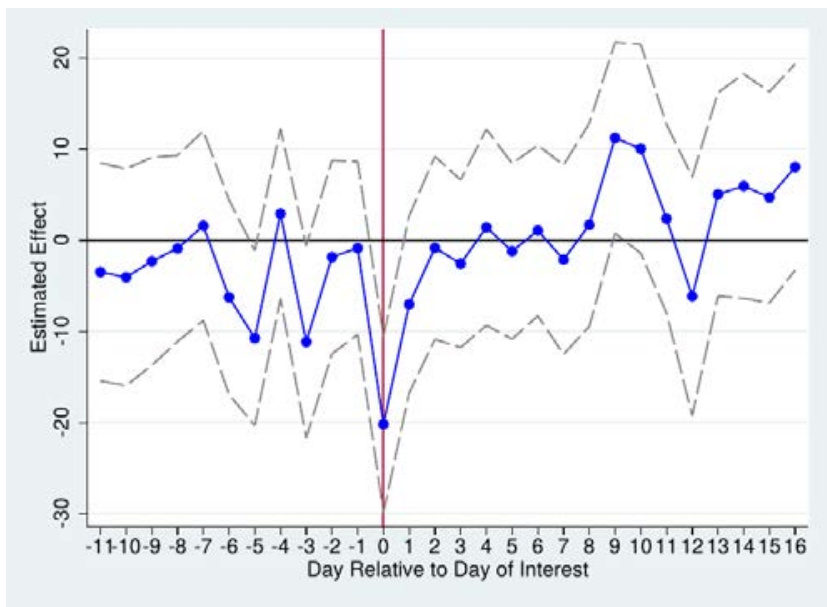

Notes: This figure shows the effect of September 11 (after 2001) and Friday the 13 on the number of births (Panel A), the number of births delivered via cesarean section (Panel B), spontaneous vaginal deliveries (Panel C), and induced/stimulated deliveries (Panel D). Plotted are regression estimates from equation (2). On the $\mathrm{x}$-axis is the day relative to the day of interest, i.e. September 11 or Friday the 13, (-1=day before day of interest, 1=day after day of interest, etc.). On the y-axis are estimates of the day relative to day-of-interest-dummy coefficients from equation (2) along with the $95 \%$ confidence interval. 
Table 1. Mean Daily Births Overall and by Delivery Mode in California: 2000-2016

\begin{tabular}{|c|c|c|c|c|c|}
\hline Type of Days & $\begin{array}{c}\text { Obs } \\
\text { (Number of } \\
\text { Days) }\end{array}$ & Total Births & $\begin{array}{c}\text { Cesarean } \\
\text { Section }\end{array}$ & $\begin{array}{c}\text { Spontaneous } \\
\text { Vaginal }\end{array}$ & $\begin{array}{l}\text { Induced/ } \\
\text { Stimulated } \\
\text { Vaginal }\end{array}$ \\
\hline All & 6210 & $\begin{array}{l}1442 \\
(229)\end{array}$ & $\begin{array}{c}442 \\
(130)\end{array}$ & $\begin{array}{c}666 \\
(109)\end{array}$ & $\begin{array}{l}293 \\
(63)\end{array}$ \\
\hline Holiday & 119 & $\begin{array}{l}1118 \\
(126)\end{array}$ & $\begin{array}{l}272 \\
(62)\end{array}$ & $\begin{array}{l}582 \\
(87)\end{array}$ & $\begin{array}{l}229 \\
(53)\end{array}$ \\
\hline Weekend & 1761 & $\begin{array}{l}1150 \\
(106)\end{array}$ & $\begin{array}{l}267 \\
(39)\end{array}$ & $\begin{array}{l}606 \\
(83)\end{array}$ & $\begin{array}{l}241 \\
(49)\end{array}$ \\
\hline Other & 4330 & $\begin{array}{l}1570 \\
(128)\end{array}$ & $\begin{array}{l}518 \\
(67)\end{array}$ & $\begin{array}{c}693 \\
(108)\end{array}$ & $\begin{array}{l}316 \\
(54)\end{array}$ \\
\hline 7-Holiday Analytic Sample & 4599 & $\begin{array}{l}1444 \\
(233)\end{array}$ & $\begin{array}{c}442 \\
(132)\end{array}$ & $\begin{array}{c}668 \\
(110)\end{array}$ & $\begin{array}{l}293 \\
(64)\end{array}$ \\
\hline Holiday & 119 & $\begin{array}{l}1118 \\
(126)\end{array}$ & $\begin{array}{l}272 \\
(62)\end{array}$ & $\begin{array}{l}582 \\
(87)\end{array}$ & $\begin{array}{l}229 \\
(53)\end{array}$ \\
\hline Weekend & 1300 & $\begin{array}{l}1153 \\
(106)\end{array}$ & $\begin{array}{l}267 \\
(40)\end{array}$ & $\begin{array}{l}608 \\
(82)\end{array}$ & $\begin{array}{l}241 \\
(49)\end{array}$ \\
\hline Other & 3180 & $\begin{array}{l}1575 \\
(131)\end{array}$ & $\begin{array}{l}520 \\
(68)\end{array}$ & $\begin{array}{c}696 \\
(109)\end{array}$ & $\begin{array}{l}316 \\
(55)\end{array}$ \\
\hline 5-Holiday Analytic Sample & 4256 & $\begin{array}{l}1447 \\
(233)\end{array}$ & $\begin{array}{c}443 \\
(132)\end{array}$ & $\begin{array}{c}669 \\
(110)\end{array}$ & $\begin{array}{l}294 \\
(64)\end{array}$ \\
\hline Holiday & 85 & $\begin{array}{l}1164 \\
(112)\end{array}$ & $\begin{array}{l}291 \\
(59)\end{array}$ & $\begin{array}{l}598 \\
(88)\end{array}$ & $\begin{array}{l}240 \\
(51)\end{array}$ \\
\hline Weekend & 1220 & $\begin{array}{l}1155 \\
(107)\end{array}$ & $\begin{array}{l}268 \\
(40)\end{array}$ & $\begin{array}{l}608 \\
(82)\end{array}$ & $\begin{array}{l}242 \\
(49)\end{array}$ \\
\hline Other & 2951 & $\begin{array}{l}1576 \\
(139)\end{array}$ & $\begin{array}{l}520 \\
(72)\end{array}$ & $\begin{array}{c}696 \\
(110)\end{array}$ & $\begin{array}{l}317 \\
(55)\end{array}$ \\
\hline
\end{tabular}

Notes: Standard deviations are in parentheses. All days uses the full set of births in California from 2000-2016. The analytic samples include the holiday interval (11 days before until 16 days after a holiday) as well as the control group (14-25 days before a holiday, and 22-37 days after a holiday). The 7-Holiday Analytic Sample considers New Year's, President's Day, Memorial Day, Independence Day, Labor Day, Thanksgiving, and Christmas Day as holidays. The 5-Holiday Analytic Sample considers President's Day, Memorial Day, Independence Day, Labor Day, and Thanksgiving as holidays. Other days are non-holiday, non-weekend days. Means for births classified as deivery type unknown are not shown here. The number of observations are the number of days by day type, multiplied by years in the sample (e.g., 7 holidays times 17 years yields 119 observations). 
Table 2. Aggregate Effect of the Holiday Period on Births and Delivery Types

\begin{tabular}{|c|c|c|c|c|}
\hline & Total Births & $\begin{array}{c}\text { Cesarean } \\
\text { Section Births } \\
\end{array}$ & $\begin{array}{l}\text { Spontaneous } \\
\text { Vaginal Births }\end{array}$ & $\begin{array}{c}\text { Induced/ } \\
\text { Stimulated Vaginal } \\
\text { Births }\end{array}$ \\
\hline \multicolumn{5}{|c|}{ Panel A: Without Christmas and New Year's } \\
\hline Holiday Interval & $\begin{array}{l}-4.07 \\
(2.99)\end{array}$ & $\begin{array}{l}-2.42 \\
(1.72)\end{array}$ & $\begin{array}{c}1.05 \\
(1.84)\end{array}$ & $\begin{array}{c}-2.71 * * * \\
(0.98)\end{array}$ \\
\hline Daily Mean Births & 1447 & 443 & 709 & 294 \\
\hline Number of Observations & 4256 & 4256 & 4256 & 4256 \\
\hline \multicolumn{5}{|c|}{ Panel B: Including Christmas and New Year's } \\
\hline Holiday interval & $\begin{array}{c}1.23 \\
(2.86)\end{array}$ & $\begin{array}{l}-1.55 \\
(1.63)\end{array}$ & $\begin{array}{c}4.36 * * * \\
(1.63)\end{array}$ & $\begin{array}{l}-1.60^{*} \\
(0.90)\end{array}$ \\
\hline Daily Mean Births & 1444 & 442 & 709 & 293 \\
\hline Number of Observations & 4599 & 4599 & 4599 & 4599 \\
\hline
\end{tabular}

Notes: Robust standard errors are in parentheses. ${ }^{* *} \mathrm{p}<0.01,{ }^{*} \mathrm{p}<0.05,{ }^{*} \mathrm{p}<0.1$. The holiday interval is the period 11 days prior to a major holiday and 16 days after a major holiday. Panel A considers the following as major holidays: Presidents' Day, Memorial Day, Independence Day, Labor Day and Thanksgiving. The 4256 observations correspond to approximately 250.3 days over 17 years, Panel B adds Christmas and New Year's Day to the holiday list. The 4599 observations correspond to approximately 270.5 days over 17 years. 


\begin{tabular}{|c|c|c|c|c|c|c|}
\hline & $\begin{array}{c}\text { Mean } \\
\text { Gestational } \\
\text { Age } \\
\end{array}$ & $\begin{array}{c}\text { Pre-Term: } \\
\text { before } 37 \\
\text { weeks } \\
\end{array}$ & $\begin{array}{r}\text { Early Term: } \\
370 / 7 \text { - } 38 \\
6 / 7 \text { weeks } \\
\end{array}$ & $\begin{array}{l}\text { Full Term: } \\
390 / 7-40 \\
6 / 7 \text { weeks } \\
\end{array}$ & $\begin{array}{c}\text { Late Term: } \\
410 / 7-41 \\
6 / 7 \text { weeks } \\
\end{array}$ & $\begin{array}{c}\text { Post-Term: } \\
42 \text { weeks or } \\
\text { later } \\
\end{array}$ \\
\hline \multicolumn{7}{|c|}{ Panel A: Without Christmas and New Year's } \\
\hline Holiday Interval & $\begin{array}{c}0.03 \\
(0.03)\end{array}$ & $\begin{array}{l}1.52^{* *} \\
(0.68)\end{array}$ & $\begin{array}{c}-5.62^{* * *} \\
(1.82)\end{array}$ & $\begin{array}{c}0.38 \\
(2.76)\end{array}$ & $\begin{array}{c}3.58^{* * *} \\
(1.32)\end{array}$ & $\begin{array}{c}-3.32^{* * *} \\
(0.74)\end{array}$ \\
\hline Daily Mean of Outcome & 275 & 141 & 360 & 679 & 138 & 80 \\
\hline Number of Observations & 4256 & 4256 & 4256 & 4256 & 4256 & 4256 \\
\hline \multicolumn{7}{|c|}{ Panel B: Including Christmas and New Year's } \\
\hline Holiday Interval & $\begin{array}{c}0.02 \\
(0.02)\end{array}$ & $\begin{array}{l}0.36 \\
(0.62)\end{array}$ & $\begin{array}{c}1.92 \\
(1.75)\end{array}$ & $\begin{array}{l}-1.54 \\
(2.50)\end{array}$ & $\begin{array}{c}1.60 \\
(1.23)\end{array}$ & $\begin{array}{l}-0.37 \\
(0.68)\end{array}$ \\
\hline Daily Mean of Outcome & 275 & 141 & 360 & 677 & 137 & 81 \\
\hline Number of Observations & 4599 & 4599 & 4599 & 4599 & 4599 & 4599 \\
\hline
\end{tabular}

Notes: Robust standard errors are in parentheses. ${ }^{* *} \mathrm{p}<0.01,{ }^{* *} \mathrm{p}<0.05,{ }^{*} \mathrm{p}<0.1$. The holiday interval is the period of time covering the period 11 days prior to a major holiday through 16 days after a major holiday. Panel A considers the following as major holidays: Presidents' Day, Memorial Day, Independence Day, Labor Day and Thanksgiving. The 4256 observations correspond to approximately 250.3 days over 17 years, Panel B adds Christmas and New Year's Day to the holiday list. The 4599 observations correspond to approximately 270.5 days over 17 years. 
Table 4. Effects on Number of Births Classified by the Characteristics of Moms over the Holiday Interval

\begin{tabular}{|c|c|c|c|c|c|c|c|c|}
\hline & $\begin{array}{c}\text { Low-Risk } \\
\text { Births }\end{array}$ & $\begin{array}{l}\text { Low-Risk } \\
\text { First Births }\end{array}$ & $\begin{array}{c}\text { Moms over } \\
\text { Age } 35\end{array}$ & $\begin{array}{c}\text { Teenage } \\
\text { Moms }\end{array}$ & $\begin{array}{l}\text { White } \\
\text { Moms }\end{array}$ & $\begin{array}{c}\text { Moms with } \\
\text { High School } \\
\text { Degree or Less }\end{array}$ & $\begin{array}{c}\text { Deliveries with } \\
\text { Private } \\
\text { Insurance } \\
\text { Payment }\end{array}$ & $\begin{array}{c}\text { Deliveries with } \\
\text { Public } \\
\text { Insurance } \\
\text { Payment }\end{array}$ \\
\hline \multicolumn{9}{|c|}{ Panel A: Without Christmas and New Year's } \\
\hline Holiday Interval & $\begin{array}{l}-0.76 \\
(0.65)\end{array}$ & $\begin{array}{l}-0.48 \\
(0.54)\end{array}$ & $\begin{array}{c}-2.10^{* * * *} \\
(0.75)\end{array}$ & $\begin{array}{c}0.23 \\
(0.28)\end{array}$ & $\begin{array}{l}-3.99 \\
(2.57)\end{array}$ & $\begin{array}{c}1.52 \\
(2.30)\end{array}$ & $\begin{array}{c}-8.49 * * * \\
(1.81)\end{array}$ & $\begin{array}{c}5.22 * * * \\
(1.67)\end{array}$ \\
\hline Daily Mean of Outcome & 121 & 93 & 205 & 39 & 1113 & 699 & 701 & 689 \\
\hline Number of Observations & 2756 & 2756 & 4256 & 4256 & 4256 & 3502 & 4256 & 4256 \\
\hline \multicolumn{9}{|c|}{ Panel B: Including Christmas and New Year's } \\
\hline Holiday Interval & $\begin{array}{l}-0.61 \\
(0.60)\end{array}$ & $\begin{array}{l}-0.47 \\
(0.50)\end{array}$ & $\begin{array}{c}-1.44 * * \\
(0.70)\end{array}$ & $\begin{array}{c}0.00 \\
(0.25)\end{array}$ & $\begin{array}{c}0.85 \\
(2.43)\end{array}$ & $\begin{array}{c}1.47 \\
(2.08)\end{array}$ & $\begin{array}{l}-2.13 \\
(1.69)\end{array}$ & $\begin{array}{c}4.30 * * * \\
(1.58)\end{array}$ \\
\hline Daily Mean of Outcome & 120 & 93 & 204 & 39 & 1111 & 700 & 699 & 688 \\
\hline Number of Observations & 2974 & 2974 & 4599 & 4599 & 4599 & 3790 & 4599 & 4599 \\
\hline
\end{tabular}

Notes: Robust standard errors are in parentheses. ${ }^{* *} \mathrm{p}<0.01,{ }^{* *} \mathrm{p}<0.05,{ }^{*} \mathrm{p}<0.1$. The holiday interval is the period of time covering the period 11 days prior to a major holiday through 16 days after a major holiday. Panel A considers the following as major holidays: Presidents' Day, Memorial Day, Independence Day, Labor Day and Thanksgiving. The 4256 observations correspond to approximately 250.3 days over 17 years, Panel B adds Christmas and New Year's Day to the holiday list. The 4599 observations correspond to approximately 270.5 days over 17 years. Other payment categories (self-paid and other) are excluded for brevity. This category comprises less than 3 percent of deliveries and is unchanged over the holiday period. The sample size for low-risk births, overall or of first births, is lower because these variables cannot be constructed prior to 2006, when characteristics such as intrauterine growth restrictions were not captured in the California birth data. Similarly, the sample size for moms with a high school degree or less is smaller as the education variable is not available 2003-2005. 


\begin{tabular}{|c|c|c|c|c|c|}
\hline & $\begin{array}{l}\text { Mean Birth } \\
\text { Weight }\end{array}$ & $\begin{array}{l}\text { Low Birth } \\
\text { Weight }\end{array}$ & $\begin{array}{c}\text { Any } \\
\text { Newborn } \\
\text { Conditions }\end{array}$ & $\begin{array}{l}\text { Any Labor } \\
\text { Complications }\end{array}$ & $\begin{array}{c}\text { Low Apgar } \\
\text { Score }\end{array}$ \\
\hline \multicolumn{6}{|c|}{ Panel A: Without Christmas and New Year's } \\
\hline \multirow[t]{2}{*}{ Holiday Interval } & $-2.00 * * *$ & 0.40 & $-0.88^{* *}$ & -1.56 & -0.49 \\
\hline & $(0.70)$ & $(0.29)$ & $(0.40)$ & $(1.02)$ & $(0.35)$ \\
\hline Daily Mean of Outcome & 3309 & 0.07 & 0.09 & 0.46 & 0.06 \\
\hline Fraction of Births Manipulated & 0.013 & 0.013 & 0.013 & 0.013 & 0.013 \\
\hline Implied IV Estimate & -159 & 0.032 & -0.070 & -0.124 & -0.039 \\
\hline Number of Observations & 4256 & 4256 & 4256 & 4256 & 2506 \\
\hline \multicolumn{6}{|c|}{ Panel B: Including Christmas and New Year's } \\
\hline \multirow[t]{2}{*}{ Holiday Interval } & -0.66 & 0.17 & $-1.03^{* * *}$ & $-2.95^{* * *}$ & -0.44 \\
\hline & $(0.63)$ & $(0.27)$ & $(0.36)$ & $(0.88)$ & $(0.31)$ \\
\hline Daily Mean of Outcome & 3309 & 0.07 & 0.09 & 0.46 & 0.06 \\
\hline Fraction of Births Manipulated & 0.014 & 0.014 & 0.014 & 0.014 & 0.014 \\
\hline Implied IV Estimate & -48 & 0.012 & -0.075 & -0.215 & -0.032 \\
\hline Number of Observations & 4599 & 4599 & 4599 & 4599 & 2700 \\
\hline
\end{tabular}

Notes: Robust standard errors are in parentheses. ${ }^{* * *} \mathrm{p}<0.01,{ }^{* *} \mathrm{p}<0.05,{ }^{*} \mathrm{p}<0.1$. The holiday interval is the period of time covering the period 11 days prior to a major holiday through 16 days after a major holiday. Panel A considers the following as major holidays: Presidents' Day, Memorial Day, Independence Day, Labor Day and Thanksgiving.. The 4256 observations correspond to approximately 250.3 days over 17 years, Panel B adds Christmas and New Year's Day to the holiday list. The 4599 observations correspond to

approximately 270.5 days over 17 years. The fraction of births manipulated is calculated as the effect of the holiday on births on the day of the holiday and the day after the holiday divided by the total number of births in the 28-day manipulation window period. The implied IV estimate is the ratio of the holiday interval effect in the table divided by the fraction of births manipulated, 0.0126. The sample size for the share of babies with a low Apgar score is lower, as this variable is not available prior to 2007. Estimates and standard errors are multiplied by 1000, except for the mean birth weight outcome. 
Table 6. Aggregate Effect of the Holiday Period on Births and Delivery Type among High-Risk Pregnancies

\begin{tabular}{lcccc} 
& Total Births & $\begin{array}{c}\text { Cesarean Section } \\
\text { Births }\end{array}$ & $\begin{array}{c}\text { Induced/ } \\
\text { Spontaneous } \\
\text { Vaginal Births }\end{array}$ & $\begin{array}{c}\text { Stimulated } \\
\text { Vaginal Births }\end{array}$ \\
\hline \hline Holiday Interval & -1.55 & -1.28 & -0.17 & -0.10 \\
& $(1.27)$ & $(1.25)$ & $(0.11)$ & $(0.07)$ \\
Daily Mean of Outcome & 259 & 248 & & 3 \\
Number of Observations & 4256 & 4256 & 4256 & 4256 \\
\hline Notes: Robust standard errors are in parentheses. ${ }^{* * *} \mathrm{p}<0.01,{ }^{* *} \mathrm{p}<0.05,{ }^{*} \mathrm{p}<0.1$. The holiday interval is the period 11 days prior
\end{tabular}

Notes: Robust standard errors are in parentheses. ${ }^{* * *} \mathrm{p}<0.01,{ }^{* *} \mathrm{p}<0.05,{ }^{*} \mathrm{p}<0.1$. The holiday interval is the period 11 days prior to a major holiday and 16 days after a major holiday. 
Table 7. Aggregate Effect of the Holiday Period on Term Length among High-Risk Pregnancies

\begin{tabular}{|c|c|c|c|c|c|c|}
\hline & \multirow[b]{2}{*}{$\begin{array}{c}\text { Mean } \\
\text { Gestational } \\
\text { Age } \\
\end{array}$} & \multicolumn{5}{|c|}{ Number of Births by Term Length } \\
\hline & & $\begin{array}{c}\text { Pre-Term: } \\
\text { before } 37 \\
\text { weeks }\end{array}$ & $\begin{array}{c}\text { Early Term: } \\
370 / 7 \text { - } 38 \\
6 / 7 \text { weeks }\end{array}$ & $\begin{array}{l}\text { Full Term: } \\
390 / 7-40 \\
6 / 7 \text { weeks }\end{array}$ & $\begin{array}{c}\text { Late Term: } \\
410 / 7-41 \\
\text { 6/7 weeks }\end{array}$ & $\begin{array}{c}\text { Post-Term: } \\
42 \text { weeks or } \\
\text { later }\end{array}$ \\
\hline Holiday Interval & $\begin{array}{c}0.06 \\
(0.08)\end{array}$ & $\begin{array}{l}-0.33 \\
(0.34)\end{array}$ & $\begin{array}{l}-1.09 \\
(0.59)\end{array}$ & $\begin{array}{l}-0.27 \\
(0.90)\end{array}$ & $\begin{array}{c}0.69^{* *} \\
(0.22)\end{array}$ & $\begin{array}{c}-0.46^{* * *} \\
(0.16)\end{array}$ \\
\hline Daily Mean of Outcome & 269 & 42 & 81 & 106 & 13 & 10 \\
\hline Number of Observations & 4256 & 4256 & 4256 & 4256 & 4256 & 4256 \\
\hline
\end{tabular}


Table 8. Characteristics of Moms over the Holiday Interval among Women with High-Risk Pregnancies

\begin{tabular}{|c|c|c|c|c|c|c|}
\hline & $\begin{array}{c}\text { Moms over } \\
\text { Age } 35\end{array}$ & $\begin{array}{c}\text { Teenage } \\
\text { Moms }\end{array}$ & $\begin{array}{l}\text { White } \\
\text { Moms }\end{array}$ & $\begin{array}{l}\text { Moms with } \\
\text { High School } \\
\text { Degree or } \\
\text { Less } \\
\end{array}$ & $\begin{array}{c}\text { Deliveries with } \\
\text { Private Insurance } \\
\text { Payment }\end{array}$ & $\begin{array}{c}\text { Deliveries with } \\
\text { Public } \\
\text { Insurance } \\
\text { Payment } \\
\end{array}$ \\
\hline Holiday Interval & $\begin{array}{l}-0.56 \\
(0.42)\end{array}$ & $\begin{array}{c}0.01 \\
(0.05)\end{array}$ & $\begin{array}{l}-1.26 \\
(1.016)\end{array}$ & $\begin{array}{c}0.58 \\
(0.76)\end{array}$ & $\begin{array}{c}-1.96 * * * \\
(0.71)\end{array}$ & $\begin{array}{c}0.62 \\
(0.73)\end{array}$ \\
\hline Daily Mean of Outcome & 57 & 2 & 199 & 124 & 127 & 122 \\
\hline Number of Observations & 4256 & 4256 & 4256 & 3502 & 4256 & 4256 \\
\hline
\end{tabular}


Table 9. Aggregate Effect of the Holiday Period on Birth Outcomes among High-Risk Pregnancies

\begin{tabular}{|c|c|c|c|c|c|}
\hline & $\begin{array}{l}\text { Mean } \\
\text { Birth } \\
\text { Weight }\end{array}$ & $\begin{array}{l}\text { Low Birth } \\
\text { Weight }\end{array}$ & $\begin{array}{c}\text { Any } \\
\text { Newborn } \\
\text { Conditions }\end{array}$ & $\begin{array}{l}\text { Any Labor } \\
\text { Complications }\end{array}$ & $\begin{array}{c}\text { Low Apgar } \\
\text { Score }\end{array}$ \\
\hline Holiday Interval & $\begin{array}{l}-1.32 \\
(2.34)\end{array}$ & $\begin{array}{c}-0.05 \\
(1.20)\end{array}$ & $\begin{array}{l}-1.38 \\
(1.21)\end{array}$ & $\begin{array}{c}1.63 \\
(1.71)\end{array}$ & $\begin{array}{c}0.12 \\
(1.02)\end{array}$ \\
\hline Daily Mean of Outcome & 3187 & 0.14 & 0.15 & 0.45 & 0.07 \\
\hline Fraction of Births Manipulated & 0.022 & 0.022 & 0.022 & 0.022 & 0.022 \\
\hline Implied IV Estimate & -60.03 & -0.002 & -0.063 & 0.074 & 0.005 \\
\hline Number of Observations & 4256 & 4256 & 4256 & 4256 & 2506 \\
\hline \multicolumn{6}{|c|}{$\begin{array}{l}\text { Notes: Robust standard errors are in parentheses. The holiday interval is the period of time covering the period } 11 \text { days prior to a } \\
\text { major holiday through } 16 \text { days after a major holiday. The } 4256 \text { observations correspond to approximately } 250.3 \text { days over } 17 \text { years. } \\
\text { The sample size for the share of babies with a low Apgar score is lower, as this variable is not available prior to } 2007 \text {. The fraction of } \\
\text { births manipulated is calculated as the effect of the holiday on births on the day of the holiday, divided by the total number of births } \\
\text { in the } 28 \text {-day manipulation window period. The implied IV estimate is the ratio of the holiday interval effect in the table divided by } \\
\text { the fraction of births manipulated. Estimates and standard errors are multiplied by } 1000 \text {, except for the mean birth weight outcome. }\end{array}$} \\
\hline
\end{tabular}


Appendix Table 1. Aggregate Effect of the Holiday Period on Birth Outcomes, Controlling for Moms over Age 35, Private and Public Delivery Payment

\begin{tabular}{|c|c|c|c|c|c|}
\hline & $\begin{array}{c}\text { Mean Birth } \\
\text { Weight }\end{array}$ & $\begin{array}{c}\text { Low Birth } \\
\text { Weight }\end{array}$ & $\begin{array}{c}\text { Any Newborn } \\
\text { Conditions }\end{array}$ & $\begin{array}{c}\text { Any Labor } \\
\text { Complications }\end{array}$ & $\begin{array}{c}\text { Low Apgar } \\
\text { Score }\end{array}$ \\
\hline \multirow[t]{2}{*}{ Holiday Interval } & $-1.32^{*}$ & 0.31 & $-1.06 * * *$ & $-2.33^{* * *}$ & -0.52 \\
\hline & $(0.69)$ & $(0.29)$ & $(0.39)$ & $(0.95)$ & $(0.35)$ \\
\hline Mean Dependent Variable & 3309 & 0.07 & 0.09 & 0.46 & 0.06 \\
\hline Fraction of Births Manipulated & 0.013 & 0.013 & 0.013 & 0.013 & 0.013 \\
\hline Implied IV Estimate & -105 & 0.025 & -0.084 & -0.185 & -0.041 \\
\hline Observations & 4256 & 4256 & 4256 & 4256 & 2506 \\
\hline
\end{tabular}

Notes: Robust standard errors are in parentheses. ${ }^{* * *} \mathrm{p}<0.01,{ }^{* *} \mathrm{p}<0.05,{ }^{*} \mathrm{p}<0.1$. The holiday interval is the period of time covering the period 11 days prior to a major holiday through 16 days after a major holiday. The 4256 observations correspond to approximately 250.3 days over 17 years. The sample size for the share of babies with a low Apgar score is lower, as this variable is not available prior to 2007 . The share of moms over age 35, the share of private insurance delivery payments, as well as the share of public insurance delivery payments are included as additional controls. Estimates and standard errors are multiplied by 1000, except for the mean birth weight outcome. 


\begin{tabular}{ccccc} 
Newborn was in & Neo-natal \\
Very Low & Intensive Care & Newborn had & Assisted & Mean Number \\
of Newborn & $\begin{array}{c}\text { Mean Number } \\
\text { of Labor } \\
\text { Complications }\end{array}$ \\
\hline \hline
\end{tabular}

Panel A: Without Christmas and New Year's

Holiday Interval

0.08

$-0.10$

$-0.14$

$-1.55^{* *}$

$-2.20$

$(0.30)$

(0.14)

(0.68)

(2.01)

Daily Mean of Outcome

$\begin{array}{lcccc}0.01 & 0.05 & 0.01 & 0.14 & 0.72 \\ 0.013 & 0.013 & 0.013 & 0.013 & 0.013 \\ 0.006 & -0.008 & -0.011 & -0.123 & -0.175 \\ 4256 & 4256 & 4256 & 4256 & 4256\end{array}$

Fraction of Births Manipulated

Implied IV Estimate

4256

4256

Number of Observations

(1.07.

Holiday Interval

$0.07 \quad-0.41$

$-0.41$

$-0.18$

$-1.73 * * *$

$-5.14 * * *$

$(0.12)$

$(0.27)$

Daily Mean of Outcome

$\begin{array}{lcccc}0.01 & 0.05 & 0.01 & 0.14 & 0.72 \\ 0.014 & 0.014 & 0.014 & 0.014 & 0.014 \\ 0.005 & -0.030 & -0.013 & -0.126 & -0.375 \\ 4599 & 4599 & 4599 & 4599 & 4599\end{array}$

Fraction of Births Manipulated

Implied IV Estimate

4599

4599

4599

Number of Observations

11 days prior to a major holiday through 16 days after a major holiday. The set of holidays in Panel A includes Presidents' Day, Memorial Day, Independence Day, Labor Day and Thanksgiving. The 4256 observations correspond to approximately 250.3 days over 17 years, Panel B adds Christmas and New Year's Day to the holiday list. The 4599 observations correspond to approximately 270.5 days over 17 years. The fraction of births manipulated is calculated as the effect of the holiday on births on the day of the holiday and the day after the holiday after divided by the total number of births in the 28-day manipulation window period. The implied IV estimate is the ratio of the holiday interval effect in the table divided by the fraction of births manipulated. Estimates and standard errors are multiplied by 1000 . 


\section{Appendix Table 3. Aggregate Effect of the Holiday Period on Birth Outcomes for High-Risk Pregnancies, Controlling for Private Delivery Payment}

\begin{tabular}{lccccc} 
& $\begin{array}{c}\text { Mean Birth } \\
\text { Weight }\end{array}$ & $\begin{array}{c}\text { Low Birth } \\
\text { Weight }\end{array}$ & $\begin{array}{c}\text { Any } \\
\text { Newborn } \\
\text { Conditions }\end{array}$ & $\begin{array}{c}\text { Any Labor } \\
\text { Complications }\end{array}$ & $\begin{array}{c}\text { Low Apgar } \\
\text { Score }\end{array}$ \\
\hline \hline Holiday Interval & -1.40 & 0.13 & -1.42 & 1.44 & 0.09 \\
& $(2.34)$ & $(1.20)$ & $(1.23)$ & $(1.71)$ & $(1.02)$ \\
Mean Dependent Variable & 3309 & 0.14 & 0.15 & 0.45 & 0.07 \\
Fraction of Births Manipulated & 0.022 & 0.022 & 0.022 & 0.022 & 0.022 \\
Implied IV Estimate & -63.78 & 0.006 & -0.065 & 0.066 & 0.004 \\
Observations & 4256 & 4256 & 4256 & 4256 & 2506 \\
\hline
\end{tabular}

Notes: Robust standard errors are in parentheses. ${ }^{* * *} \mathrm{p}<0.01,{ }^{* *} \mathrm{p}<0.05,{ }^{*} \mathrm{p}<0.1$. The holiday interval is the period of time covering the period 11 days prior to a major holiday through 16 days after a major holiday. The 4256 observations correspond to approximately 250.3 days over 17 years. The sample size for the share of babies with a low Apgar score is lower, as this variable is not available prior to 2007. The share of private insurance delivery payments, as well as the share of public insurance delivery payments, are included as additional controls. Estimates and standard errors are multiplied by 1000, except for the mean birth weight outcome. 
Appendix Table 4. Poisson Model Estimates of Aggregate Effect of the Holiday Period on Births and Delivery Types

\begin{tabular}{lcccc}
\hline & & & & Induced/ \\
& Total Births & $\begin{array}{c}\text { Cesarean Section } \\
\text { Births }\end{array}$ & $\begin{array}{c}\text { Spontaneous } \\
\text { Vaginal Births }\end{array}$ & $\begin{array}{c}\text { Stimulated } \\
\text { Vaginal Births }\end{array}$ \\
\hline \hline Holiday Interval & -0.02 & -0.04 & 0.01 & $-0.09 * * *$ \\
& $(0.02)$ & $(0.04)$ & $(0.02)$ & $(0.03)$ \\
Daily Mean Births & 1447 & 443 & 709 & 294 \\
Number of Observations & 4256 & 4256 & 4256 & 4256 \\
\hline
\end{tabular}

Notes: Robust standard errors are in parentheses. ${ }^{* *} \mathrm{p}<0.01,{ }^{*} \mathrm{p}<0.05,{ }^{*} \mathrm{p}<0.1$. The holiday interval is the period of time covering the period 11 days prior to a major holiday through 16 days after a major holiday. 
Appendix Table 5. Aggregate Effect of the Holiday Period on Births and Delivery Types using Only Holidays that Vary Day of the Week

\begin{tabular}{lcccc}
\hline & & & & Induced/ \\
& Total Births & $\begin{array}{c}\text { Cesarean Section } \\
\text { Births }\end{array}$ & $\begin{array}{c}\text { Spontaneous } \\
\text { Vaginal Births }\end{array}$ & $\begin{array}{c}\text { Stimulated } \\
\text { Vaginal Births }\end{array}$ \\
\hline \hline Holiday Interval & $-12.78^{* * *}$ & -2.33 & $-4.43^{* *}$ & $-6.02^{* * *}$ \\
& $(4.00)$ & $(2.24)$ & $(2.02)$ & $(1.18)$ \\
& & & & \\
Daily Mean Births & 1447 & 443 & 710 & 294 \\
Number of Observations & 4256 & 4256 & 4256 & 4256 \\
\hline
\end{tabular}

Notes: Robust standard errors are in parentheses. ${ }^{* *} \mathrm{p}<0.01,{ }^{* *} \mathrm{p}<0.05,{ }^{*} \mathrm{p}<0.1$. The holiday interval is the period of time covering the period 11 days prior to a major holiday through 16 days after a major holiday. The holidays considered are Independence Day, Christmas, and New Year's Day. The 4256 observations correspond to approximately 250.3 days over 17 years. 


\section{Appendix Table 6. Aggregate Effect of the Holiday Period on Births and Delivery Types with Varying Window Size}

\begin{tabular}{|c|c|c|c|c|}
\hline & Total Births & $\begin{array}{c}\text { Cesarean } \\
\text { Section Births } \\
\end{array}$ & $\begin{array}{l}\text { Spontaneous } \\
\text { Vaginal Births } \\
\end{array}$ & $\begin{array}{l}\text { Induced/ } \\
\text { Stimulated Vaginal } \\
\text { Births } \\
\end{array}$ \\
\hline \multicolumn{5}{|c|}{ Panel A: Optimal Window of $[-11,+16]$} \\
\hline \multirow[t]{2}{*}{ Holiday Interval } & -4.07 & -2.42 & 1.05 & $-2.71 * * *$ \\
\hline & $(2.99)$ & $(1.72)$ & $(1.84)$ & $(0.98)$ \\
\hline Daily Mean Births & 1447 & 443 & 709 & 294 \\
\hline Number of Observations & 4256 & 4256 & 4256 & 4256 \\
\hline \multicolumn{5}{|c|}{ Panel B: Holiday Window $[-8,+13]$} \\
\hline \multirow[t]{2}{*}{ Holiday Interval } & $-9.74 * * *$ & -2.02 & $-3.72^{*}$ & $-4.00 * * *$ \\
\hline & $(3.11)$ & $(1.75)$ & $(2.01)$ & $(1.03)$ \\
\hline Daily Mean Births & 1445 & 442 & 711 & 293 \\
\hline Number of Observations & 3519 & 3519 & 3519 & 3519 \\
\hline \multicolumn{5}{|c|}{ Panel C: Holiday Window $[-14,+19]$} \\
\hline \multirow[t]{2}{*}{ Holiday Interval } & $8.54 * * *$ & $3.83^{* * *}$ & $3.47 * * *$ & $1.24 * *$ \\
\hline & $(2.26)$ & $(1.24)$ & $(1.08)$ & $(0.63)$ \\
\hline Daily Mean Births & 1450 & 446 & 710 & 295 \\
\hline Number of Observations & 4943 & 4943 & 4943 & 4943 \\
\hline \multicolumn{5}{|c|}{ Panel D: Holiday Window $[-10,+18]$} \\
\hline \multirow[t]{2}{*}{ Holiday Interval } & -4.26 & -2.76 & 1.60 & $-3.11 * * *$ \\
\hline & $(3.07)$ & $(1.74)$ & $(1.88)$ & $(0.99)$ \\
\hline Daily Mean Births & 1449 & 445 & 709 & 293 \\
\hline Number of Observations & 4368 & 4368 & 4368 & 4368 \\
\hline \multicolumn{5}{|c|}{ Panel E: Holiday Window $[-14,+10]$} \\
\hline \multirow[t]{2}{*}{ Holiday Interval } & -4.74 & -0.92 & -1.21 & $-2.60 * * *$ \\
\hline & $(2.78)$ & $(1.72)$ & $(1.99)$ & $(1.00)$ \\
\hline Daily Mean Births & 1445 & 448 & 711 & 296 \\
\hline Number of Observations & 3816 & 3816 & 3816 & 3816 \\
\hline \multicolumn{5}{|c|}{$\begin{array}{l}\text { Notes: Robust standard errors are in parentheses. }{ }^{* *} \mathrm{p}<0.01,{ }^{*} \mathrm{p}<0.05,{ }^{*} \mathrm{p}<0.1 \text {. Panel A provides our main birth } \\
\text { displacement results from Table } 2 \text {. Panel B shows results using a window that is reduced by } 3 \text { days on each side. Panel C } \\
\text { shows results using a window that is increased by } 3 \text { days on either side. Panels D and E consider the "second-best" } \\
\text { optimal windows, according to our grid search. }\end{array}$} \\
\hline
\end{tabular}




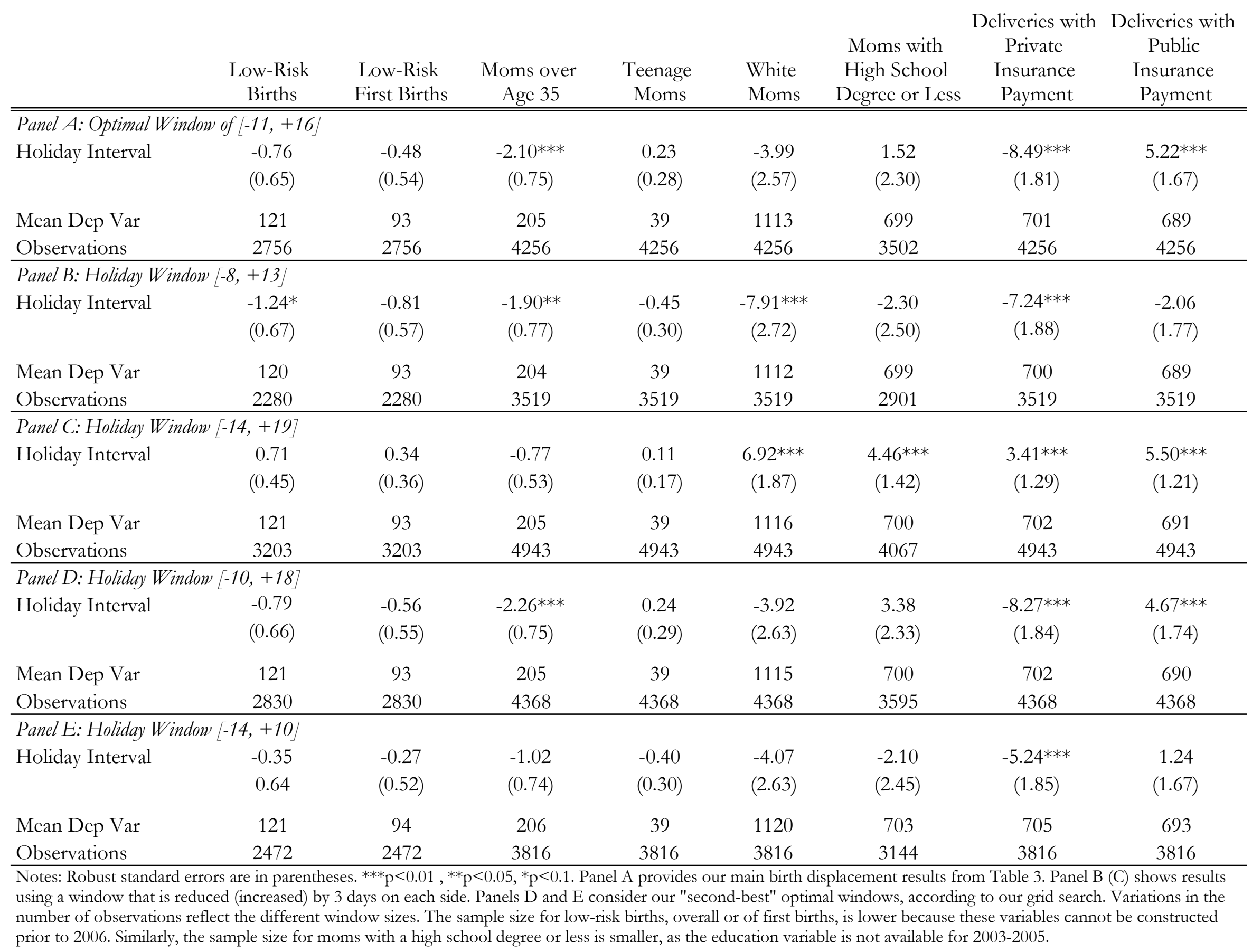




\begin{tabular}{|c|c|c|c|c|c|}
\hline & $\begin{array}{c}\text { Mean Birth } \\
\text { Weight } \\
\end{array}$ & $\begin{array}{c}\text { Low Birth } \\
\text { Weight }\end{array}$ & $\begin{array}{c}\text { Any Newborn } \\
\text { Conditions }\end{array}$ & $\begin{array}{c}\text { Any Labor } \\
\text { Complications } \\
\end{array}$ & $\begin{array}{c}\text { Low Apgar } \\
\text { Score } \\
\end{array}$ \\
\hline \multicolumn{6}{|c|}{ Panel A: Optimal Window of $[-11,+16]$} \\
\hline Holiday Interval & $\begin{array}{c}-2.00 * * * \\
(0.70)\end{array}$ & $\begin{array}{c}0.40 \\
(0.29)\end{array}$ & $\begin{array}{c}-0.88^{* *} \\
(0.40)\end{array}$ & $\begin{array}{l}-1.56 \\
(1.02)\end{array}$ & $\begin{array}{l}-0.49 \\
(0.35)\end{array}$ \\
\hline Mean Dependent Variable & 3309 & 0.07 & 0.09 & 0.46 & 0.06 \\
\hline Fraction of Births Manipulated & 0.013 & 0.013 & 0.013 & 0.013 & 0.013 \\
\hline Implied IV Estimate & -159 & 0.032 & -0.070 & -0.124 & -0.039 \\
\hline Observations & 4256 & 4256 & 4256 & 4256 & 2506 \\
\hline \multicolumn{6}{|l|}{ Panel B: Holiday Window $[-8,+13]$} \\
\hline Holiday Interval & $\begin{array}{l}-1.17 \\
(0.75)\end{array}$ & $\begin{array}{l}0.59 * \\
(0.32)\end{array}$ & $\begin{array}{l}-0.40 \\
(0.43)\end{array}$ & $\begin{array}{l}-0.74 \\
(1.11)\end{array}$ & $\begin{array}{l}-0.02 \\
(0.36)\end{array}$ \\
\hline Mean Dependent Variable & 3309 & 0.07 & 0.09 & 0.46 & 0.06 \\
\hline Fraction of Births Manipulated & 0.016 & 0.016 & 0.016 & 0.016 & 0.016 \\
\hline Implied IV Estimate & -71.07 & 0.036 & -0.024 & -0.045 & -0.001 \\
\hline Observations & 3519 & 3519 & 3519 & 3519 & 2074 \\
\hline \multicolumn{6}{|l|}{ Panel C: Holiday Window [-14, +19] } \\
\hline Holiday Interval & $\begin{array}{c}1.64 * * * \\
(0.45)\end{array}$ & $\begin{array}{c}-0.41 * * \\
(0.20)\end{array}$ & $\begin{array}{l}-0.11 \\
(0.23)\end{array}$ & $\begin{array}{c}0.20 \\
(0.41)\end{array}$ & $\begin{array}{l}-0.11 \\
(0.23)\end{array}$ \\
\hline Mean Dependent Variable & 3309 & 0.07 & 0.09 & 0.46 & 0.06 \\
\hline Fraction of Births Manipulated & 0.010 & 0.010 & 0.010 & 0.010 & 0.010 \\
\hline Implied IV Estimate & 168.02 & -0.042 & -0.011 & 0.020 & -0.011 \\
\hline Observations & 4943 & 4943 & 4943 & 4943 & 2911 \\
\hline \multicolumn{6}{|l|}{ Panel D: Holiday Window $[-10,+18]$} \\
\hline Holiday Interval & $\begin{array}{c}-1.97 * * * \\
(0.71)\end{array}$ & $\begin{array}{c}0.37 \\
(0.30)\end{array}$ & $\begin{array}{c}-1.07^{* *} \\
(0.42)\end{array}$ & $\begin{array}{l}-1.85^{*} \\
(1.04)\end{array}$ & $\begin{array}{l}-0.50 \\
(0.35)\end{array}$ \\
\hline Mean Dependent Variable & 3309 & 0.07 & 0.09 & 0.46 & 0.06 \\
\hline Fraction of Births Manipulated & 0.013 & 0.013 & 0.013 & 0.013 & 0.013 \\
\hline Implied IV Estimate & -155 & 0.029 & -0.084 & -0.145 & -0.039 \\
\hline Observations & 4368 & 4368 & 4368 & 4368 & 2572 \\
\hline \multicolumn{6}{|l|}{ Panel E: Holiday Window $[-14,+10]$} \\
\hline Holiday Interval & $\begin{array}{c}-1.38^{*} \\
(0.72)\end{array}$ & $\begin{array}{c}0.42 \\
(0.29)\end{array}$ & $\begin{array}{l}-0.38 \\
(0.43)\end{array}$ & $\begin{array}{l}-0.43 \\
(1.14)\end{array}$ & $\begin{array}{l}0.078 \\
(0.36)\end{array}$ \\
\hline Mean Dependent Variable & 3310 & 0.07 & 0.09 & 0.46 & 0.06 \\
\hline Fraction of Births Manipulated & 0.013 & 0.013 & 0.013 & 0.013 & 0.013 \\
\hline Implied IV Estimate & -104.72 & 0.031 & -0.029 & -0.033 & 0.006 \\
\hline Observations & 3816 & 3816 & 3816 & 3816 & 2248 \\
\hline
\end{tabular}

Notes: Robust standard errors are in parentheses. ${ }^{* * *} \mathrm{p}<0.01,{ }^{*} \mathrm{p}<0.05,{ }^{*} \mathrm{p}<0.1$. Panel A provides our main birth displacement results from Table 5. Panel B (C) shows results using a window that is reduced (increased) by 3 days on each side. Panels D and E consider our "second-best" optimal windows, according to our grid search. The fraction of births manipulated is calculated as the effect of the holiday on births on the day of the holiday and the day after, divided by the total number of births in the 28 -day manipulation window period. The implied IV estimate is the ratio of the holiday interval effect in the table divided by the fraction of births manipulated. Variations in the number of observations reflect the different window sizes. The sample size for the low Apgar score outcome is lower, as this variable is not available prior to 2007. Estimates and standard errors are multiplied by 1000 , except for the mean birth weight outcome. 
Appendix Table 9. Sub-group Analysis of Manipulated Births as a Percent of Total Births in the Window

Lower Bound \# Percent of

\begin{tabular}{lccccc}
\multicolumn{1}{c}{ Subgroup } & N & $\begin{array}{c}\text { Mean \# Daily } \\
\text { Births }\end{array}$ & $\begin{array}{c}\text { \# Births in } \\
\text { Window }\end{array}$ & $\begin{array}{c}\text { of Manipulated } \\
\text { Births }\end{array}$ & $\begin{array}{c}\text { Total Births in } \\
\text { the Window }\end{array}$ \\
\hline \hline Total Sample & 4256 & 1447.0 & 40516 & 511.9 & 1.26 \\
\hline \hline Teenage Mom & 4256 & 39.0 & 1093 & 7.6 & 0.70 \\
Older Mom & 4256 & 204.5 & 5726 & 88.8 & 1.55 \\
\hline High-Risk Birth & 4256 & 258.8 & 7246 & 159.2 & 2.20 \\
Low-Risk First Birth & 2756 & 93.0 & 2603 & 38.7 & 1.49 \\
Low-Risk Birth & 2756 & 120.5 & 3374 & 54.6 & 1.62 \\
\hline White Non-Hispanic Mom & 4256 & 419.8 & 11754 & 179.1 & 1.52 \\
Black Non-Hispanic Mom & 4256 & 83.1 & 2327 & 26.1 & 1.12 \\
Asian Non-Hispanic Mom & 4256 & 114.7 & 3212 & 33.3 & 1.04 \\
Hispanic Mom & 4256 & 722.5 & 20230 & 239.3 & 1.18 \\
\hline Mom has Some College or More Education & 3502 & 687.8 & 19258 & 253.5 & 1.32 \\
Mom has High School or Less Education & 3502 & 698.8 & 19566 & 237.3 & 1.21 \\
\hline Public Insurance Delivery & 4256 & 688.9 & 19289 & 236.6 & 1.23 \\
Private Insurance Delivery & 4256 & 700.8 & 19622 & 262.1 & 1.34 \\
Self-pay Delivery & 4256 & 39.3 & 1101 & 8.1 & 0.73 \\
\hline Kaiser & 4256 & 187.7 & 5256 & 34.0 & 0.65
\end{tabular}

Notes: Each row represents the analysis from a separate sub-group. The 4256 observations correspond to approximately 250.3 days over 17 years. The sample size for low-risk births, overall or of first births, is lower because these variables cannot be constructed prior to 2006, when characteristics such as intrauterine growth restrictions were not captured in the California birth data. Similarly, the sample size is smaller for education outcomes, as the education variable is not available in the data between 2003-2005. 